(W)

Check for

Cite as

Nano-Micro Lett.

(2021) 13:142

Received: 27 November 2020

Accepted: 23 January 2021

Published online: 12 June 2021

(c) The Author(s) 2021

\title{
Bio-Nanocarriers for Lung Cancer Management: Befriending the Barriers
}

\author{
Shruti Rawal ${ }^{1}$, Mayur Patel ${ }^{1} \bowtie$
}

\section{HIGHLIGHTS}

- Due to their multifaceted oncological applications and immense translational potential, the bio-nanocarriers and nano-biodevices are being conceived as a futuristic panacea for cancer.

- Aspects impeding promising prognosis of lung cancer, various nano-biotools, and their plausible benefits over the conventional nanocarriers for lung cancer management have been briefed upon in this review.

- Research findings from relevant investigations, perspectives, and stipulations for the overall management of lung cancer have also been deliberated.

ABSTRACT Lung cancer is a complex thoracic malignancy developing consequential to aberrations in a myriad of molecular and biomolecular signaling pathways. It is one of the most lethal forms of cancers accounting to almost 1.8 million new annual incidences, bearing overall mortality to incidence ratio of 0.87 . The dismal prognostic scenario at advanced stages of the disease and metastatic/resistant tumor cell populations stresses the requisite of advanced translational interdisciplinary interventions such as bionanotechnology. This review article deliberates insights and apprehensions on the recent prologue of nanobioengineering and bionanotechnology as an approach for the clinical management of lung cancer. The role of nanobioengineered (bio-nano) tools like bio-nanocarriers and nanobiodevices in secondary prophylaxis, diagnosis, therapeutics, and theranostics for lung cancer management has been discussed. Bioengineered, bioinspired, and biomimetic bio-nanotools of considerate translational value have been reviewed. Perspectives on existent oncostrategies, their critical comparison with bio-nanocarriers, and issues hampering their clinical bench side to bed transformation have also been summarized.

KEYWORDS Biomimetic nanoparticles; Exosomes; Circulating tumor cells; Mesenchymal stem cells; Theranostics

Mayur Patel, drmayurmpatel@gmail.com

1 Department of Pharmaceutics, Institute of Pharmacy, Nirma University, SG Highway, Chharodi, Ahmedabad, Gujarat 382 481, India

\section{Multifaceted role of nanobioengineering in the clinical management of lung cancer}

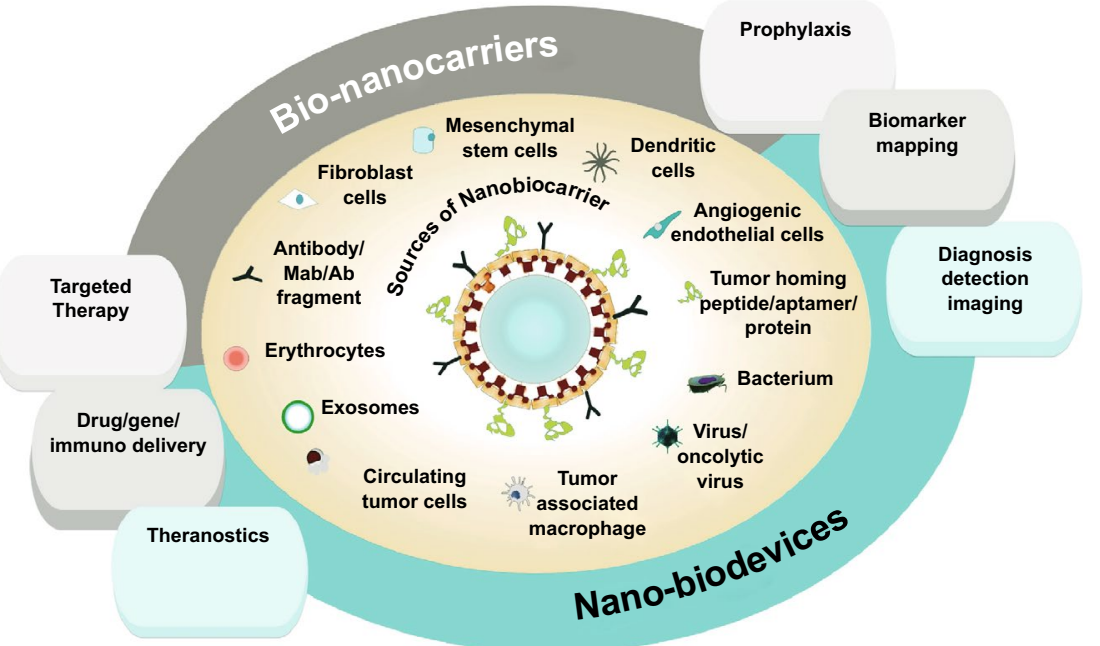




\section{Introduction}

The global burden of cancer is rising insidiously. With disquietingly high mortality rates ( 1 in 5 cancer deaths worldwide), lung cancer has been entitled as one of the most lethal forms of cancer [1]. As per cancer statistics provided by the American Cancer Society, $11.6 \%$ of all new cancer incidences and $18.4 \%$ of cancer mortalities (1.8 million in 2018) are ascribed to lung cancer [2]. Lung cancer is a highly heterogenic disease with complex clinical repercussions and a poor prognosis. The major reproachful factors that worsen the prognosis of lung cancer are lack of prophylactic modality, diagnosis at an advanced stage, extremely mutable tumor milieu, diverse genetic and epigenetic aberrations, multidrug resistance, and metastatic dissemination [3].

Nanotechnology has provided a platform to design nanocarriers and nanodevices that manifest their activity through various magnetic, thermal, electrical, and optical properties by the virtue of their tunable composition, shapes, structure, and sizes (1-100 $\mathrm{nm}$ at least in one dimension) [4]. Nanotechnology has leveraged the precincts of biomedical and oncology science beyond many physiological barriers for the effective management of complex diseases like cancer. However, the sluggish approval pace and poor clinical performance of the nano-medicines implore the scientific community to foster breakthrough innovation in clinical and translational oncology for achieving better prognosis in lung cancer patients.

On the other hand, concurrent efforts in the fields of molecular biology, omics, genetic engineering, and cancer biology have revolutionized biotechnology and bioengineering to a significant extent. Sophisticated biotechnology tools have extensively contributed to oncology over recent years toward gathering information about complex cancer biological milieu and biomolecular signaling thereof. However, despite tremendous advances in both of these individual scientific disciplines, the gap between bio-sciences and nanotechnology has undermined their actual potential. The realization of the need to unify these individual disciplines to gain miraculous biomedical outcomes has surfaced up with nanobioengineering. Nanobioengineering is amongst the most challenging domain of bionanotechnology that is advancing rapidly. Nanobioengineering is an applied science that integrates the fundamentals of basic sciences like physics, chemistry, and biology to engineer material properties in nano-dimensions for manifold bio-medical and medical applications. It has assisted contrive novel nanobiotools and strategies for comprehending, managing, and revolutionizing clinical aspects of lung cancer management.

Despite the advances in oncological sciences, clinical management of lung cancer is still a perplexing task. The present article scrutinizes abstruseness in the current scenario of lung cancer management and discusses nanobioengineering strategies to overcome the same. A comprehensive overview of the bio-nanotools (bio-nanocarriers and nano-biodevices) for multifaceted applications in lung cancer along with a comparative assessment of the principal advantages and shortcomings has been briefed upon. In the clinical context, disease management comprises four (quadripartite) different aspects: prophylaxis/prevention, diagnosis, treatment/therapeutics, and therapeutic drug monitoring (facilitated through theranostics). A critical appraisal of the research works relating to the application of bio-nanotools for each of these aspects of lung cancer management has been elaborated.

Nanobioengineering has assisted the development of nano-based cancer vaccines and chemopreventive nanomedicine that can be employed for secondary prophylaxis in lung cancer. Novel bio-nanotools like nano-bio-based contrast and imaging agents, nanoprobes, nanobiosensors, biomarker detection devices, and high-throughput nanodevices have been researched to reinforce early-stage diagnostic techniques for detection, imaging, and molecular imaging at high detection speeds with high specificity and sensitivity. Additionally, the advances in the 'nano-bioera' in oncotherapy have resulted in a paradigm shift from conventionally non-targeted therapies to tumor-targeted therapies. Nano-bioengineering has extended its application to radiotherapy, immunotherapy, phototherapy, gene therapy, and combination therapy as well as novel therapies to facilitate multimodal oncotargeting of lung cancer. Nanobioengineering had a late advent in the therapeutic segment of oncotargeting due to delayed evidence of translational and clinical incompetency of a multitude of nanocarrier-based therapeutics reported in the literature. The search for competent targeting strategies has led to the development of novel third-generation nanocarriers termed 'nano-biocarriers'. Nano-biocarriers are bioengineered, bioinspired, biogenic, bio-mimicking, and bio-hybrid nanocarriers, cells, or vesicles that employ biological moiety/biomimetic moiety/bioinspired/bioderived moiety as a bioactive or as active targeting 
vector/ligand. Unlike the other nanocarriers, the nano-biocarriers have distinct advantages like being multi-targeted, highly bio-interactive, biocompatible, intrinsically camouflaged, and scaleable. Additional attributes like tropism and host integration may also aid in personalized therapy, or in enhancing the efficiency and safety of bio-nanocarriers.

The multi-functional bio-nanotools have extended their application in theranostics as well. Some researchers have also proposed multi-functional nanoparticles to merge all the facets like diagnosis, therapy as well as prevention with the use of a single nano-modality. Therapeutic drug monitoring, real-time monitoring, and image-guided therapy are some major applications that may be facilitated with the help of theranostics. The contemporary erudition and prospects pertinent to the subject have been summarized as an endnote.

\section{Challenges Associated with Current Lung Cancer Management}

Despite the advances in lung cancer diagnostics and therapeutics, lung cancer is still an incurable disease. As stated earlier, metastatic, malignant, resistant, or advanced stage lung cancers are difficult to treat within the precincts of currently available knowledge of lung cancer biology. Chemoprevention and cancer vaccine development have been subject to oncological research for decades, but have not been substantiated through clinical appraisal. While there has been considerable advancement in imaging and screening techniques, the current detection techniques fail to diagnose the early stage of the disease due to a lack of biomarker detection at low concentrations. The other limitation of the prevalent diagnostic option is the lack of identification of the molecular/genetic variant of the tumor sub-type due to high inter-patient diversity. Techniques to preclude the aforementioned disadvantages while facilitating the identification of novel biomarkers and molecular targets are being sought. While considering the therapeutic aspects, combination chemotherapy, nanocarrier-based therapy, biological therapy, and immunotherapy have clinically materialized as adjuvant and neoadjuvant therapy to surgery and radiotherapy. With the advent of novel targeted biological agents and immunotherapeutic agents for the treatment of non-small cell lung cancer (NSCLC), there has been a considerable improvement in therapeutic outcomes \& patient survival rates [5]. However, the treatment scenario of other subtypes of lung cancer such as small cell lung cancer (SCLC) and malignant pleural mesothelioma is disquieting and contradictory. Striking difference in the treatment protocols for each sub-type of lung cancer can be attributed to the underlying cytological, histological, genetic, epigenetic and molecular target diversity. A comprehensive understanding of underlying molecular signaling and targets is obligatory for enhancing the therapeutic and prognostic efficiency in all clinical cases of lung cancer. Diverse receptor upregulation indicates involvement of different molecular signaling pathways and molecular targets in the pathogenesis of different lung cancer sub-types. A brief summary of receptors identified in different sub-types of lung cancer is presented in Table 1 [6].

As demonstrated in Table 2, there are very few targeted therapeutic options approved by the FDA for the treatment of SCLCStill worse, there is only one therapy (the combination of the NovoTTF-100L system with platinum-based chemotherapy and pemetrexed) that has been approved by the FDA for the treatment of malignant pleural mesothelioma [7]. Lack of knowledge about molecular targets in lung cancer variants except for the non-small cell lung carcinoma (NSCLC), lack of bio-stability of therapeutic and targeting moieties, failure of enhanced permeation retention (EPR) phenomenon, and active targeting in complex biological milieu may be the liable factors. A closer understanding of cellular, genetic, and molecular alterations in the emergence, progression, and metastasis of lung carcinoma are imperative for promoting the identification of novel targets. The concept of therapeutic drug monitoring and theranostics is still at a preliminary stage of their development and demands extensive research. In this context, seeking a resort of bionanotechnology for prophylaxis, diagnosis, therapeutic, and theranostics of lung cancer may prove to be a boon to mankind.

\section{Nanobioengineering and Bio-nanotools: Types and Sub-types}

Various bio-nanotechnology-derived tools like nano-biocarriers and nano-bio-devices have recently gained tremendous scientific interest in addressing issues of lung cancer management. The most widely explored bio-nanocarriers for oncological applications can be summarized as: (1) microbiotic nanosystems and bio-nanocarriers, (2) cells and cell 


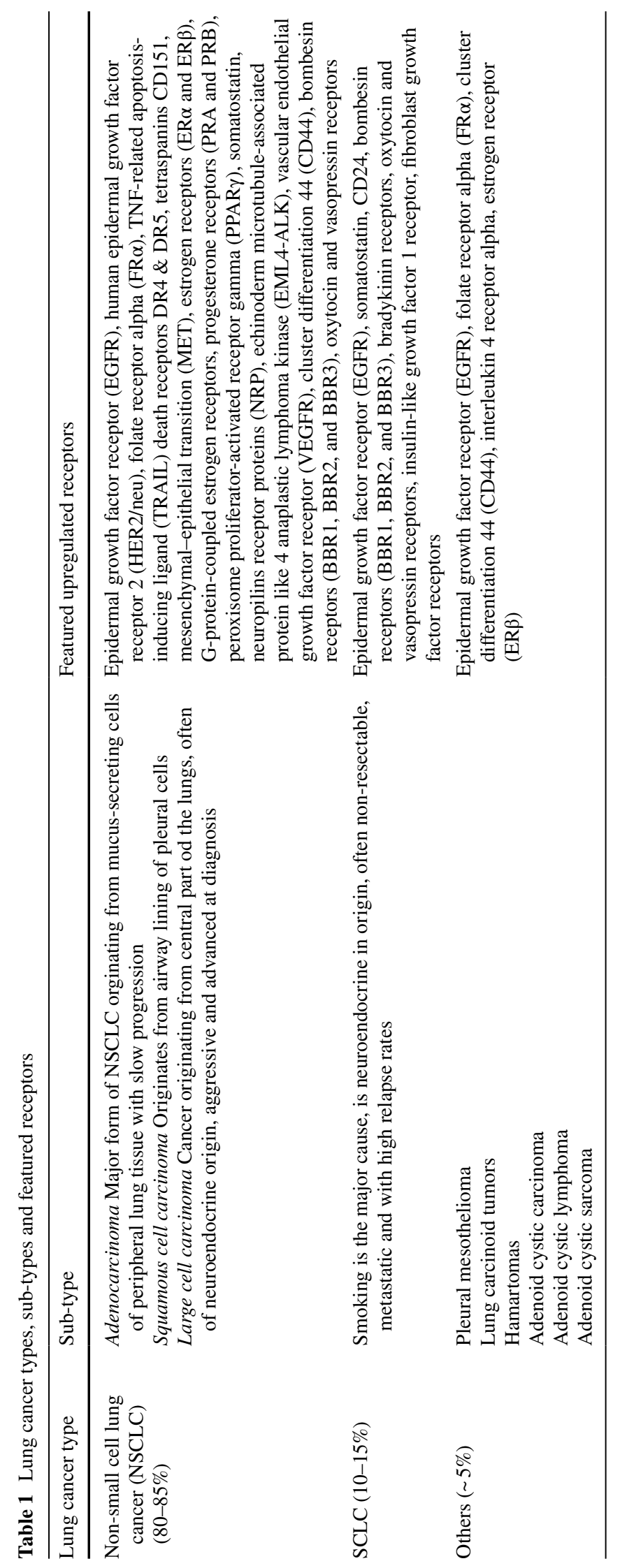


Table 2 Drugs approved for the treatment of lung cancer

Chemotherapeutic agents

Biologically targeted therapeu- Immunotherapeutic agents tic agents

Drugs approved for the treatment of small-cell lung carcinoma

Doxorubicin

Everolimus

Atezolizumab

Etoposide phosphate

Pembrolizumab

Methotrexate

Nivolumab

Mechlorethamine

Topotecan

Drugs approved for the treatment of non-small cell lung carcinoma

Albumin-stabilized nanoparticle formulation of paclitaxel (Abraxane $\left.{ }^{\circledR}\right)$

Carboplatin

Carboplatin + paclitaxel

Docetaxel

Doxorubicin

Gemcitabine

Mechlorethamine

Methotrexate

Paclitaxel

Pemetrexed disodium

$\begin{array}{ll}\text { Afatinib dimaleate } & \text { Atezolizumab } \\ \text { Alectinib } & \text { Bevacizumab } \\ \text { Brigatinib } & \text { Durvalumab } \\ \text { Ceritinib } & \text { Necitumumab } \\ \text { Crizotinib } & \text { Nivolumab } \\ \text { Dacomitinib } & \text { Pembrolizumab } \\ \text { Entrectinib } & \text { Ramucirumab } \\ \text { Erlotinib.HCl } & \\ \text { Everolimus } & \\ \text { Gefitinib } & \\ \text { Osimertinib Mesylate } & \\ \text { Trametinib } & \end{array}$

membrane-derived nanosystems, (3) ligand-conjugated nanosystems, and (4) nano-bio-devices (Fig. 1).

\subsection{Microbiotic Nanosystems and Bio-nanocarriers}

Amidst significant controversies, microbiotic-based nanosystems are progressively gathering compelling preclinical and clinical evidences in their favor for being applicable in oncology [8-14]. Because the micro-organisms like bacteria, viruses, and fungi have a strong innate tropism toward specific cells/organs, their vectorization potential seems promising. Also, they bear an immense potential for cell-specific delivery to the tumors due to higher intracellular penetration and cell uptake. Advances in biomics and bioengineering techniques have significantly reduced the pathogenicity and biotoxicity of the microbiome tools while enhancing their vectorization potential. There have been several ongoing efforts in the utilization of these microbiome-derived tools like oncolytic viruses (virotherapy) or oncolytic bacteria for addressing various issues pertaining to tumor targeting [15]. Various microbiotic bio-nanocarriers that have been researched for the management of various malignancies including lung cancer have been discussed in the following sections:

\subsubsection{Bacterial Bio-nanocarriers}

Bacterial properties like high motility, immune evasion ability, chemotaxis, invasion capability, cytotoxicity, tumor vasculature accumulation, and abundance and composition of pathogen-associated molecular patterns (PAMP) are the major factors that have upraised the interest of researches worldwide for tumor targeting [16]. With the help of several bioengineering tools, novel bacterial systems with attenuated pathogenicity, high tumor-targeting ability, strategic drug expression, and versatile payload deliverability are being researched and developed [16, 17]. Some of the most investigated bacteria for oncological applications are Streptococcus, Salmonella, Proteus, Listeria, Clostridium, Bifidobacterium, Escherichia, Caulobacter [18].

A promising scenario can be predicted from the number of ongoing clinical trials for the bacterial treatment of cancer [16]. Bionanotechnology advances have come up with several bacterial-based nanoplatforms for oncological applications. Various types of bacterial bio-nanocarriers 


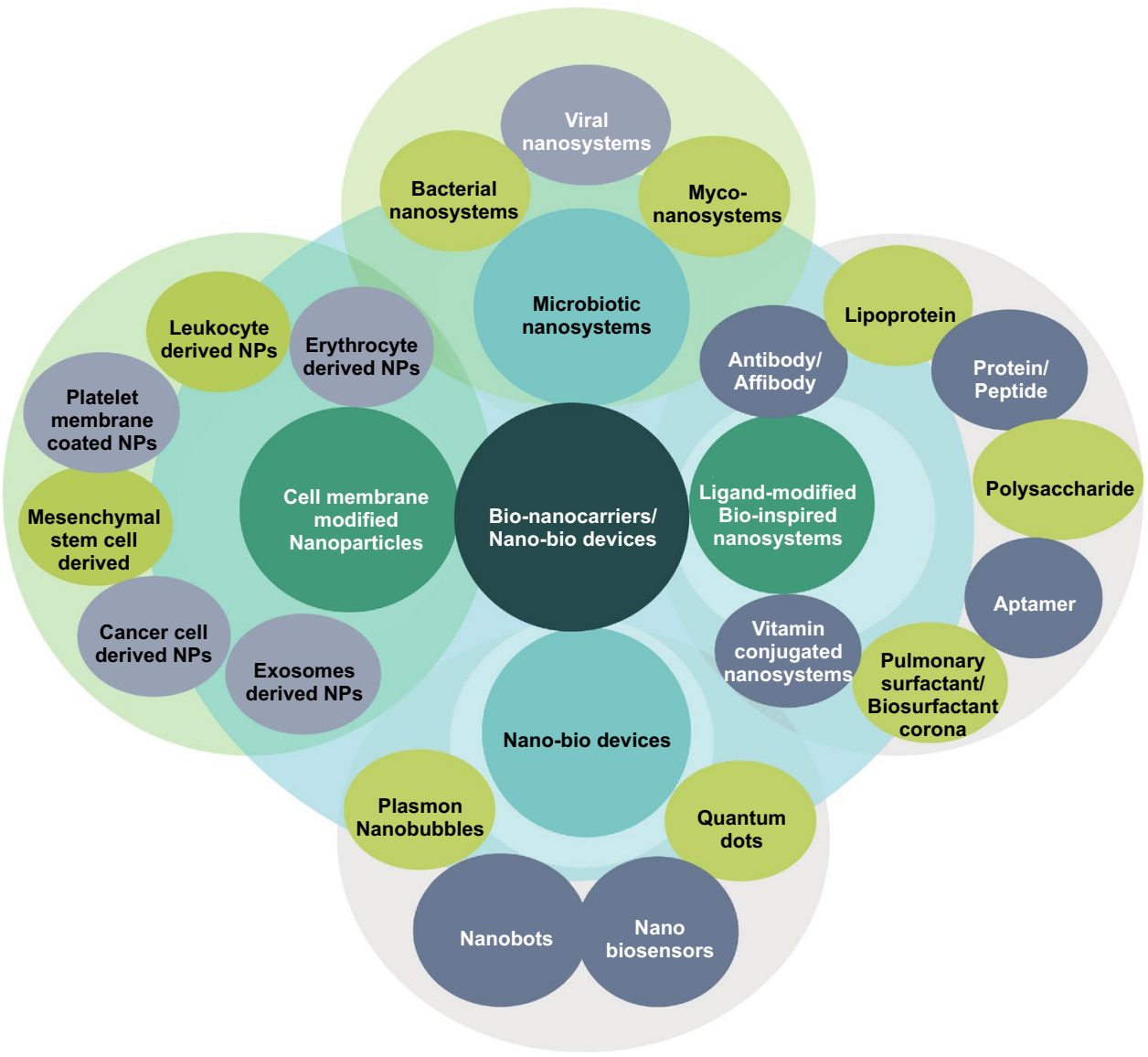

Fig. 1 Bio-nanocarriers and nano-bio-devices for oncological applications

like bioengineered bacteria, bacterial minicells, bacterial membrane-derived nanovesicles (proteoliposomes), bacterial ghosts, bacterial components like the "S-layer", bacterial cell membrane, bacterial derivatives like the endospores (spore vaccine), magnetosomes, and bacterially derived polymers (e.g., alginate, hyaluronic acid, cellulose, poly1-lactic acid, and $\varepsilon$-poly-1-lysine) have been reported to be employed in oncology [19]. Nanobio-hybrids are fabricated by employing physical attachments, chemical propagation, and biological reconstruction/engineering methods.

3.1.1.1 Bioengineered Bacteria Bioengineered bacteria are bacteria that are genetically modified for specialized oncological applications. Various tumor-targeted strategies like the release of anticancer agents (cytotoxic agents, cytokines, antigens, and antibodies), genetic transfer (cytotoxic and anti-angiogenic agents, cytokines and growth factors, tumor antigens, gene silencing (shRNA), gene triggering strategies (signal promoters), combinations with other treatments (anti-vascular agents, chemotherapeutic drugs, heat shock proteins, heavy metals), radiation and imaging strategies like bioluminescence, fluorescence, magnetic resonance (MRI), positron emission (PET), etc., have been reported [18].

3.1.1.2 Bacterial Minicells These are enucleated spherical derivatives of $\sim 400 \mathrm{~nm}$ diameter formed as a result of polar division from the bioengineered bacteria [20]. Bacterial minicells are known to target tumors due to the interaction of bispecific antibodies with O-polysaccharide moiety of the minicell and tumor cell-specific receptors. Erbitux ${ }^{\circledR} \mathrm{EDV}_{\mathrm{PAC}}$, developed by EnGeneIc, is a prototype of such targeted minicells, undergoing clinical trials for the treatment of various solid tumors. The minicells were reported to be loaded with chemotherapeutic agents like doxorubicin (DOX), cisplatin, and paclitaxel (PTX) and gene-based therapeutics like siRNA, plasmid DNA encoding the short hairpin RNA (shRNA) [9, 10]. Different minicell formulations like the ${ }^{\mathrm{HER} 2}$ minicells $\mathrm{DOX}_{\text {, }}$, ${ }_{\text {EGFR }}$ minicells $s_{\text {PAC, }}$ and ${ }^{\text {EGFR }}$ minicells $s_{\text {DOX }}$ were reported to have high antitumor efficacy in several tumor xenograft 
models including lung cancer [8]. Besides this, the bacterial minicells have been reported to be bio-stable for a long duration $(\sim 6 \mathrm{~h})$ and prevent opsonization by macrophages [21].

\subsubsection{S-Membrane-Derived Nanovesicles The surface} layer or S-layer of bacteria is the outermost membrane of the bacteria, constituting its envelope. These simple protein/glycoprotein structures offer an enormous possibility of manipulations to formulate various bio-nanocarriers through bioengineering. Some of the most attractive features of the S-layer that have been exploited to meet various oncological applications are highly porous structural scaffold ( 30-70\% porosity), regularly repeating sub-units with different shapes and geometry, highly modifiable protein/ glycoprotein structure, and self-assembling ability. Details about the use of S-layer for various oncological aspects such as diagnostics, sensors, cancer vaccine, bio-marker, and nano-targeted drug delivery have been elaborately explained elsewhere [19]. The S-layer has been reported to serve as a targeting ligand for the targeting of various nanocarrier systems like liposomes and emulsomes [22, 23]. Additionally, the S-layer can serve as a carrier for antigen, and vaccine delivery is being researched upon for its use as a cancer vaccine and in immunotherapy of various forms of cancers [24]. Application of such S-layer-coated bio-nanocarrierbased biosensors and detection techniques have also been well reported [22, 25].

3.1.1.4 Magnetosomes 'Magnetosensitive'/magnetotactic bacteria or the bacteria that respond to the external magnetic field were first observed by Salvatore Bellini in 1963 [26]. It has been reported that the subcellular organelles of bacterial species like Magnetospirillumm bavaricum and Magneticum contain magnetic-iron-containing minerals such as greigite $\left(\mathrm{Fe}_{3} \mathrm{~S}_{4}\right)$ and magnetite $\left(\mathrm{Fe}_{3} \mathrm{O}_{4}\right)$, referred to as magnetosomes. The biomedical application of magnetic principles was commenced in 1960 by Freeman et al., following which there was a significant rise in this direction. While magnetic nanoparticles like superparamagnetic iron oxide (SPIONs) have gained significant attention from researchers worldwide due to their magnetic targetability, surface mouldability, low toxicity, and biocompatibility, the magnetosomes also present a promising alternative for similar applications [27]. The magnetosomes can be applied for targeted drug delivery of various oncological modalities like gene or theranostics [28-30]. Biomagnetites have also been employed for the development of biosensors to detect mutations [31, 32]. Several research works that have been utilized in the context of lung cancer management have been discussed later [31, 33-35].
3.1.1.5 Bacterial Ghosts The envelope of gram-negative bacteria emptied of its cytoplasmic contents through cloned lysis/tunnel formation is termed as bacterial ghosts. Despite the removal of cytoplasmic contents, the bacterial ghosts conserve the cell morphology and cell surface structure. Their intrinsic adjuvant properties make them ideal for the formulation of vaccines or aid as immunotherapeutic. Besides this, the surface of these bionanocarriers can be modified to present native antigens or DNA and other recombinant antigens simultaneously to elicit specific humoral/cellular responses to target the cancer cells. The bacterial ghosts may contain several types of payloads like drugs, imaging agents, etc., to facilitate its applicability for diverse functions. Batch fermentation, product recovery, and tangential flow filtration can yield high loads of bacterial ghosts. To ensure the pathogenicity of the bacterium, they are subsequently purified with staphylococcal nuclease $\mathrm{A}$ and $\beta$-propiolactone. These bacterial bio-nanocarriers may be lyophilized to meet large-scale production needs for various biotechnological applications including lung cancer oncotheranostics [36-38].

\subsubsection{Bacteria-Derived Outer Membrane Vesicles (Pro-} teoliposomes) (OMVs) OMVs of the bacteria are components of gram-negative bacteria, composed of latent membrane protein (LMP), phospholipids, lipoproteins, exogenous protein epitopes, flagellin, nucleic acids, and peptidoglycan, through which the bacteria communicate. The OMVs are derived from the bacteria during normal bacterial growth or under stressful growth conditions [19]. The OMVs elicit an immune response by interacting with Toll-like receptor 4 (TLR4) [39]. The OMVs are advantageous in terms of biostability of the cargo as it provides protection from the DNase, RNase, protease, and extreme $\mathrm{pH}$ [40]. The OMVs derived very small proteoliposomes have been reported to facilitate the targeted delivery of various therapeutic, imaging, and theranostic agents to lung cancer cells [11, 39, 41-43]. In addition to drug delivery applications, the OMVs are also applied for the development of cancer vaccines, immunotherapy, and very recently for photoacoustic imaging of tumors [44].

3.1.1.7 Bacterial Polymer-Based Nanocarriers The first bacterial bio-polymer discovery was made by Louis Pasteur in 1861, which later became known as dextran. Various bacteria like Leuconostoc mesenteroides, Acetobacter xylinumin, and Ralstonia eutropha, Streptomycetaceae actinobacteria, B. subtilis, Salmonella, Sarcina, Achromobacter, Gluconacetobacter, Agrobacterium, Aerobacter, Rhizobium, Agrobacterium, and Azotobacter are known to synthesize and accumulate various biopolymers. Such bio- 
polymers include polysaccharides (hyaluronic acid, dextran, alginate, starch, K30 antigen, xanthan, and glycogen), polyamides (poly ( $\gamma$-glutamic acid), polypeptides and proteins), polyesters (polythioesters and polyhydroxyalkanoates), polyphosphates and polyphenols such as lignin. Nanoparticles composed of or nanocarriers that are surface-modified using any of these bio-polymers have been employed in diverse applications like drug delivery, biosensor fabrication, etc. [45-52]. Applications of bacterial nano-biohybrids from preventive, detection, imaging, therapeutic, and theranostics in lung cancer are discussed in the forthcoming section.

\subsubsection{Bioengineered Viruses, Bacteriophage, and Viral Bio-nanocarriers}

Immense transgene expression capacity, tropism, and cellspecificity make the oncological application of viral vectors an attractive approach. However, due to the high pathogenicity and virulence of viruses, this strategy was highly discouraged [53]. However, advances in bioengineering and biotechnology have facilitated viral modifications to reduce their virulence and enhance the targeting ability. Bioengineered viruses like oncolytic viruses, bacteriophage, and viral bio-nanocarriers are recently being employed for the management of various cancers including lung cancer [53-55]. Viral bio-nanocarriers are specially fabricated by employing physical methods, chemical methods, and biotemplation methods. Due to the presence of surface functional groups like the amide, aniline, thiol, carboxyl and phenol moieties, chemical modifications in the viral groups can be easily done [14].

Viral bio-nanocarriers can be formulated by chemical methods like direct conjugation, wherein the nanomaterial and viral capsid are conjugated directly [56, 57]. Viral components can be bioconjugated over the surface of various nanocarriers like quantum dots, gold nanoparticles, bacteriophage, etc., by employing this method. The bioconjugation potential of viruses with chemotherapeutic agents, imaging agents, proteins, chromophores, and nanomaterials has also been reported to confer specificity and biostability to such cargoes [14]. Owing to the features like structural symmetry and chemical self-assembly of the viral capsids, the viral bio-nanocarriers, consisting of nanoparticles deposited over the viruses, may be constructed using the biotemplation method [58-60].

\subsubsection{Fungal and Yeast Bio-nanocarriers}

Oncological research toward the development of fungal and yeast-based bio-nanocarriers has recently gained interest amongst scientists worldwide [61, 62]. Fungus and yeast cells have been reported to serve as a targeting vector for various nanoparticle systems for diverse oncological applications [62]. Fungal bio-derived polymers like $\beta$-glucan, chitin, and chitosan have also been reported to facilitate the encapsulation of various oncological modalities $[63,64]$. It has been reported that the Glucan biopolymer has potential therapeutic efficacy in lung cancer [65]. Bio-synthesized/biogenic silver nanoparticles and zinc oxide nanoparticles from various fungi and yeasts are also gaining significant attention for their anticancer applications [66-68]. Furthermore, bioengineered yeast-derived vacuoles have also been explored for oncological applications [69]. Fungal bio-nanocarriers that utilize the electrostatic method/chemical modification method for conjugation of nanoparticles to yeast cells or vice versa are other sub-types of bio-nanocarriers that have been formulated for oncological applications in lung cancer [70-72]. The fungal bio-nanocarriers and nano-biocarriers provide an excellent platform for reasons of being an easily modifiable, cost-effective, and safer alternative to the other microbiome-derived counterparts [61, 62].

\subsection{Cells and Cell Membrane-derived Bio-nanocarriers}

Novel archetypes of drug delivery carriers and devices are being developed extensively to meet oncological challenges. The bioinspired and biomimetic nanoparticles are gaining significant attention amongst researchers worldwide owing to their distinct attributes like non-iatrogenicity, biocompatibility, biodegradability, and tailoring ability. Mammalian cell and cell-membrane-derived bionanocarriers are progressively being sought for devising novel targeting strategies for the treatment of various malignancies including lung cancer. Cell-based targeting oncovectors that have been researched include the whole cell-based carriers, cell membrane-derived nanocarriers, membrane-cloaked bio-nanocarriers, microvesiclebased nanocarriers, and exosome-based bio-nanocarriers. 
Some of the sources from which such bio-nanocarriers are formed include erythrocytes, leukocytes, platelets, mesenchymal stem cells, cancer cells, and exosomes. In addition to biomimetic camouflaging, the cell-based nano-biocarriers exhibit excellent biocompatibility, multi-molecular and intrinsic targeting ability, self-stealthing ability, and favorable host bio-integration for multiple oncological applications.

\subsubsection{Erythrocyte-Derived Bio-nanocarriers}

Amongst the nano-biocarriers, erythrocytes have gained significant attention from the scientific community due to additional advantages like large quantities of the cell membrane, high internal capacity volume $\left(185-191 \mu \mathrm{m}^{3}\right)$, high biostability and biodurability, high in vitro storage ability, simplistic isolation methods, long systemic circulation ( 120 days), high loading capacity and low aggregation. Erythrocytes, erythrocyte membrane-based bio-nanocarriers, and nanoerythrosomes are some of the most explored cell-based nano-biocarriers [73, 74].

Erythrocyte/red blood cell (RBC)-based drug delivery was pioneered by Gardos in 1953, who first attempted the loading of ATP inside the erythrocyte ghosts. Led by the premise of the work by Gardos, Marsden and Ostling reported the use of erythrocytes for carrying dextran in 1959. Thereafter, the term "carrier red blood cells" was coined in 1979 after a breakthrough was brought about by an erythrocyte-based delivery for delivery of $\beta$-glucosidase and $\beta$-galactosidase to treat Gaucher's disease. Subsequently, the RBC-based drug delivery was attempted for drugs like gentamicin, leukemia, and L-asparagine-dependent leukemia [75].

The first nano-biohybrid of its kind was developed and reported by Lejeune et al. in 1994. The developed erythrocyte-derived liposomes termed "nanoerythrosomes" were formed by the physical squeezing of the RBC ghosts through the membranes of definite pore sizes. However, due to issues such as vesicle aggregation, lack of structural integrity, and rapid systemic clearance, such a system was not found to be applicable. Later on, in 2013, Zhang's group developed novel toxin nanosponges that were composed of a polymeric core and erythrocyte shell, which revitalized the field with breakthrough opportunities that underlie the formulation approach. Erythrocyte membranes have several immune evading mechanisms mediated by CD47 receptor activation, CD59, homologous restriction protein (HRP), C8 binding protein $(\mathrm{C} 8 \mathrm{bp})$, membrane cofactor protein (MCP), decayaccelerating factor (DAF), and complement receptor 1 (CR1) due to such a 'self-recognizing' [76, 77].

The circulation half-life of RBC membrane-coated nanoparticles was reported to be 2 times greater than the halflife of PEGylated nanoparticles [74, 78]. There are several methods employed for the preparation of the RBC-coated bio-nanocarriers. Physical methods like hypotonic dialysis, hypotonic dilution, hypotonic hemolysis, hypotonic pre-swelling, electrical breakdown, and osmotic pulse have been widely employed in the preparation of RBC-coated bio-nanocarriers. Some other methods that are employed are the chemical perturbation method and chemical perturbation method in combination with an electrical breakdown, lipid fusion, intrinsic cell uptake, and endocytosis [78-83]. Formulating erythrocyte-based nanocarriers have a distinct advantage over the natural erythrocytes due to a reduction in direct physicochemical interaction of payload with the membrane components, their consecutive leakage, and toxicity. Some interesting studies have exquisitely described how RBC hitchhiking [84] and other nano-biointeractions of RBCs (radiotherapy assistance, etc.) have been employed in context with lung cancer therapy (Fig. 2) [85-87].

\subsubsection{Leukocyte (WBC)-Derived Bio-nanocarriers}

Leukocytes or WBCs are major saviors of the immune system that participate in the majority of the morbidities in addition to cancer. The special attributes that attract the scientists to employ them as drug carriers are: (1) specialized transmigration capability to the cancer site, (2) tumor endothelial adhesion, and (3) chemotaxis-driven targeting ability [76]. However, due to low systemic circulation halflife ( 20 days), their application in drug delivery is limited. To overcome the limitations of the natural leukocyte-based drug delivery, the leukocyte-based bio-nanocarriers are being researched. The leukocyte-derived bio-nanocarriers can be classified into the following sub-types:

3.2.2.1 Monocyte/Macrophage Bio-nanocarriers Macrophages are modified monocytes that are major constituents of tumoral mass ( $50 \%$ of tumor mass) and are vital regulators of the immune response. Tumoral chemotaxis of 


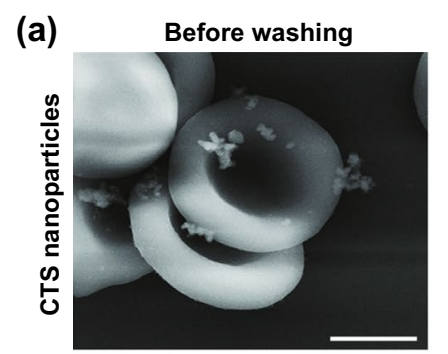

(c)

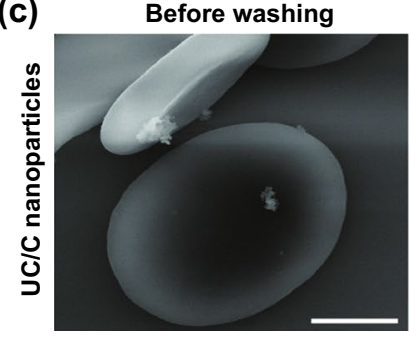

(e)
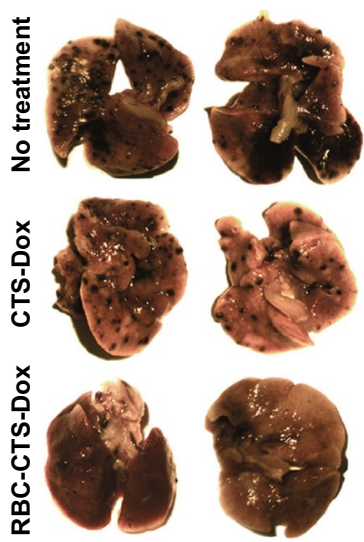

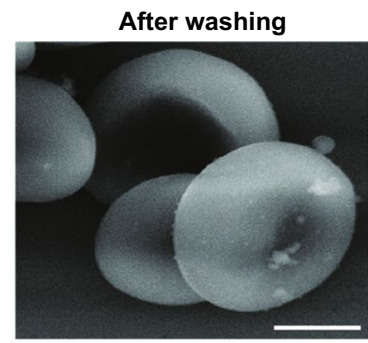

After washing
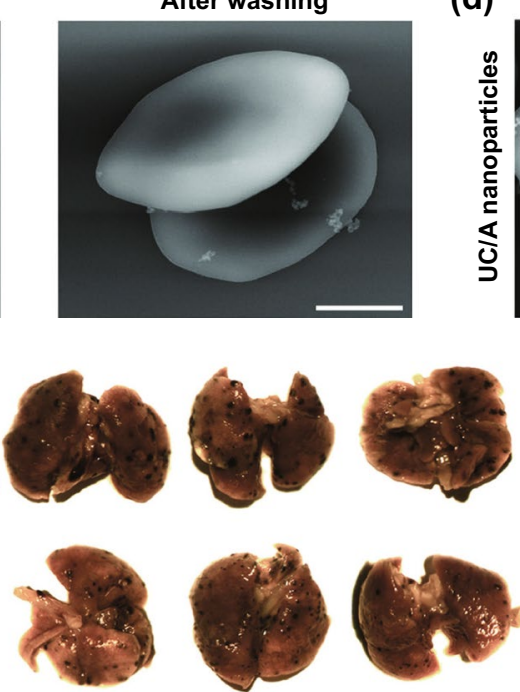

(d)

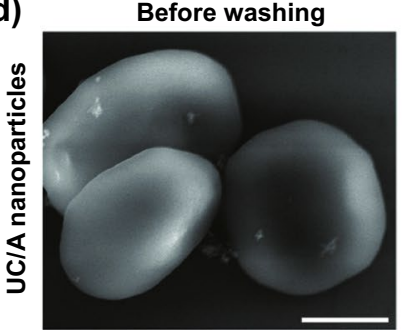

After washing
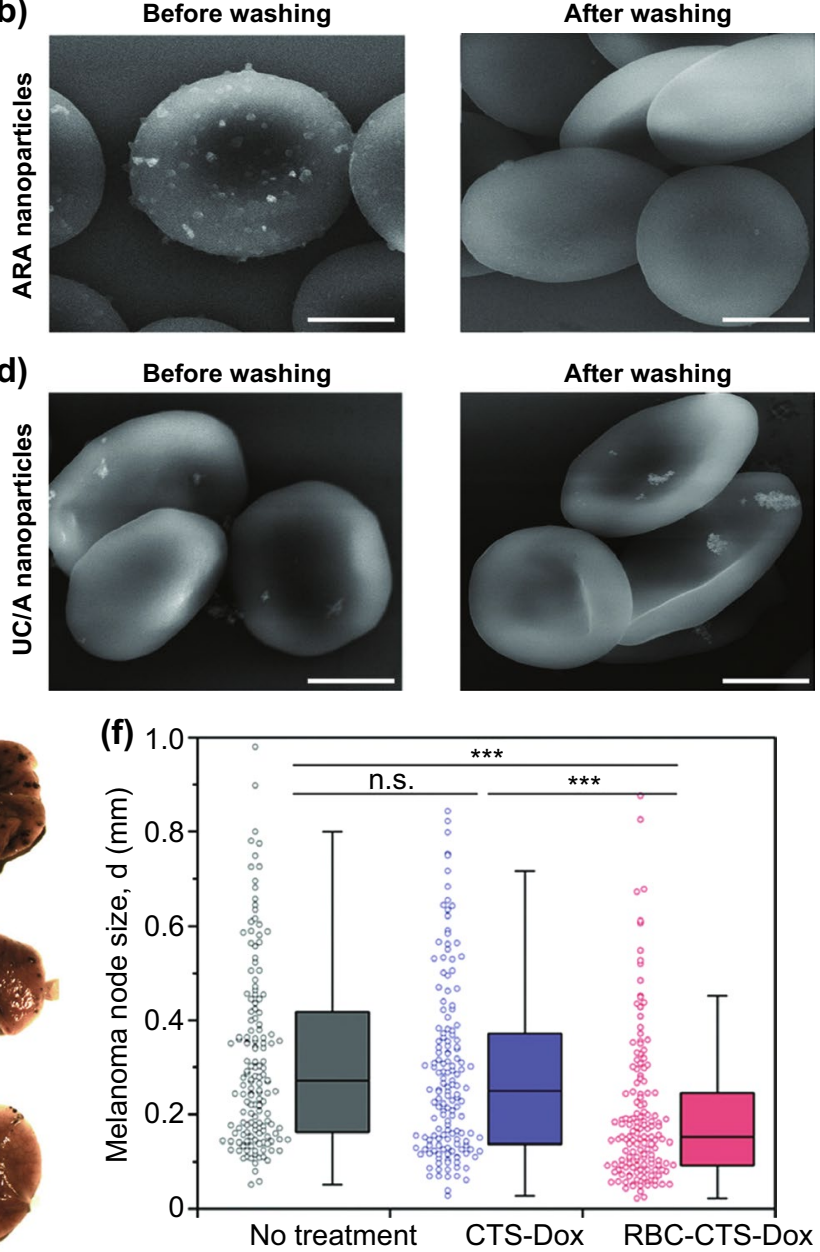

Fig. 2 Electron microphotographs of erythrocyte complexes with a chitosan (CT), b glucuronic acid, $\mathbf{c}$ cationic non-coated, and $\mathbf{d}$ anionic noncoated $100 \mathrm{~nm}$ nanoparticles (scale $=2 \mu \mathrm{m}$ ) before and after washing. e Images of metastatic foci on lung tissues excised from untreated animals, animals treated with CT-doxorubicin nanoparticles and RBC bound-CT-doxorubicin nanoparticles in metastatic melanoma murine model $\mathbf{f}$ melanoma node size $\left(\mathrm{mm}^{3}\right)$ (data representing 100 metastasis in each group, distinct values represented by Tukey-type box plots. Statistical implications determined using Welch's t test (n.s, ${ }^{* * *} P<0.001 *, * P<0.01$, and $P>0.05$ ). Adapted from Ref. [86] with permission from Royal Society of Chemistry RSC

these immune cells is mediated by chemoattractants such as chemokine ligand 2 (CCL 2, 5, 7, 8, 22), CXCL 8 and 12, PDGF, VEGF, endothelial monocyte-activating polypeptide (EMAPII), and colony-stimulating factor-1 (CSF-1). Moreover, localization of the macrophages to the tumor stroma is driven by hypoxia, which results in the formation of tumorassociated macrophages (TAMs) [88]. Due to tumor tropism of such kind, macrophages and monocytes are attractive tumor-targeting vectors $[88,89]$. Factors that impede the enhanced permeation of nanoparticles and therefore their intratumoral penetration, such as high tumor interstitial pressure, discontinuous tumor vasculature and dense tumor stroma, lead to decreased intratumoral bioavailability. However, bare loading of payload into macrophages/monocytes may result in drug inactivation and randomized drug release [90]. Formulating the bio-nanocarriers using macrophage/ monocyte membrane may offer potential benefits over the conventionally used nanoparticles and drugs by facilitating intratumoral penetration and localization of diverse payloads such as polysaccharides, endotoxins, complement, lipoproteins, affibodies, and antibodies. Bio-nanocarriers based on macrophages have been reported with the drug crystals, liposomes, emulsions, bacteria, and gold particles [90].

\subsubsection{Dendritic Cell-Derived Bio-nanocarriers Den-} dritic cells (DC) are one of the most important immune system mediators that unify the innate and adaptive responses through the formation of major histocompatibil- 
ity complexes to expose foreign antigens by the formation of antigen-presenting cells (APCs) [91]. The plasmacytoid DCs (pDCs) and the myeloid DC-based bio-nanocarriers are highly favored for immunotherapy and devising cancer vaccines. The approach of employing DCs as the vaccine is approved by the FDA for the treatment of metastatic hormone-refractory malignancies. In a clinical phase III trial of one such DC-based formulation, i.e., Provenge ${ }^{\circledR}$ (Sipuleucel-T), it was observed to increase the median survival rate of patients by four months. Due to the requirement of a low cell dose, a single DC formulation was claimed to deliver five doses. Due to the presence of mannose receptor, $\mathrm{Fc}$ receptor, complement receptor, C-type lectin receptor, and the DEC-2005 receptor, the Dcs have an immense immune-evoking capacity and cell interaction ability. These attributes of DCs present an opportunity to fabricate immunomodulatory nanoparticles. These DC-based bio-nanocarriers can facilitate cell uptake, intracellular activation, and APC presentation, mediated by MHC-I and MHC-II [88].

\subsubsection{Neutrophil-Derived Bio-nanocarriers Neutro-} phils are perceived as excellent bio-carriers due to the advantages like being the most populous sub-types of the leukocytes, excellent transmigration capacity across blood vessel endothelium toward cancer cells, and aggressive response to inflammation [92, 93]. The neutrophils can be localized to the tumor sites and form tumor-associated neutrophils (TANs), which offer an immense potential of forming the bio-nanocarriers.

3.2.2.4 Lymphocyte-Derived Bio-nanocarriers Amongst the two main subtypes of lymphocytes, i.e., the T cells and the $\mathrm{B}$ cells, the $\mathrm{T}$ cells are the most explored for drug delivery applications. With the use of gene-editing techniques, the autologous $\mathrm{T}$ cells are bioengineered using chimeric antigen receptors (CAR) and employed as CAR-T therapy in cancer patients [94]. However, due to the loss in the cell viability of the $\mathrm{T}$ cells post-injection, bio-nanocarriers composed of the T-cell membrane were developed for the first time by Stephen et al., who proposed a novel means of attaching the nanoparticles with $\mathrm{T}$ cells, loaded with IL-5 and IL-21. It was observed to release the interleukins in an autocrine fashion from these carrier cells, leading to $\mathrm{T}$ cellmediated immune response and tumor elimination.

\subsubsection{Platelet-Derived Bio-nanocarriers}

The interplay of platelet localization and tumor metastasis has long been exploited in the field of oncology. Altered
RNA and ultrastructure of platelets have been associated with the diagnosis of some malignancies including lung cancer $[95,96]$. Recently, bio-nanocarriers composed of platelet membrane-conjugated nanoparticulate systems (PNP) are being researched for their oncological applications. The PNP has been reported to exhibit enhanced collagen binding, enhanced endothelial adherence, and significantly greater antigen binding as compared to their conventional counterparts [97]. Some of the platelet-derived bio-nanocarriers employed in lung cancer therapy are discussed in reference $[95,97,98]$.

\subsubsection{Mesenchymal Cell (MSC)-Derived Bio-nanocarriers}

Due to their explicit anti-inflammatory and immunomodulatory modes of action, more than 550 clinical trials are being executed employing the mesenchymal cells [99]. The MSCs have been reported to possess inflammation-driven tumor tropism mediated by the adhesion ligands like Sialyl Lewis $\mathrm{X}$ (SLeX) and P-selectin glycoprotein ligand (PSGL-1) as well as CXCL12, CXXR4, and CCR2. The presence of surface antigenic moieties and innate targeting ligands largely favor their use as a vector for oncotargeting. MSCs have been employed for the delivery of protein and peptide oncotherapeutics such as CX3CL1, interferon, and interleukins [100]. The bio-nanocarriers like MSC nanoghosts and MSCderived nanovesicles are highly favored over the MSCs due to their safety in terms of non-tumorigenicity. The molecular mechanisms of tumor-targeting, the modes of genetic and non-genetic bioengineering of MSC-based bio-nanocarriers have been described elsewhere in detail [101].

\subsubsection{Cancer Cell-Derived Bio-nanocarriers}

Cancer cell membrane-modified bio-nanocarriers (CCMNs) are widely researched for oncological targeting of various payloads [102, 103]. CCMNs confer unique attributes to the nanoparticles like homotypic targetability, unique binding ability, and selective cell uptake to primary and metastatic tumor nodules [102, 104-107]. Their biomimetic camouflaging properties prevent their premature immune system clearance and prolong their systemic circulation. Additionally, due to the ease of culture of the cancer cells and their robustness, they serve as an extremely vital source for the mass 
production of the cancer cell membrane [108]. The CCMNs have been employed for phototherapy, targeted chemotherapy, enhanced tumor imaging, and molecular diagnosis in addition to their immunomodulatory effect [108].

\subsubsection{Extracellular Vesicles and Exosome-Derived Nanosystems and Bio-nanocarriers}

Diverse subtypes of membrane-coated particles that are formed by the mammalian cells for mediation of paracrine signaling are termed as 'extracellular vesicles (EVs)' [109]. EVs are classified into the following subtypes: microvesicles, nanovesicles, exomeres, exosomes, oncosomes, apoptotic bodies, and arrestin domain-containing protein 1-mediated microvesicles (ARMMs) [110]. These naturally existing biocarriers carry payloads such as lipids, proteins, nucleic acids, and other bioactive cargoes. The EVs have been postulated to have a major role in the bio-signaling interplay between the tumor cells to cause immunosuppression, tumor progression, and tumor metastasis. Due to their natural payload-carrying capacity, they have been explored for diverse oncological applications $[111,112]$.

Amongst EVs, exosomes are one of the most explored nanocarriers. The EVs of $30-150 \mathrm{~nm}$ diameter that are secreted by most of the body cells into the body fluids are termed exosomes [113]. Exosomes derived from the cancer cells and salivary exosomes have been reported to have plausible oncological applications $[111,114]$. The exosomes originate from the inward endosomal budding and subsequent fusion of the cell membrane with multivesicular bodies (MVBs) containing the intraluminal vesicles (ILVs) [110]. The structural composition of exosomes depends upon the chemical composition of the parent cells from which they emerge. The exosomal surface overexpresses characteristic proteins, namely tetraspanins (TSPAN6, TSPAN 8, CD9, CD63, and CD81), cell adhesion proteins (lactadherin, integrin), cell-type-specific proteins (FasL, MHC-I, MHC-II, and WNT), and heat shock proteins (Hsc70), that directs the function, cell interaction, cell uptake, and the fate of exosomes $[110,115]$.

\subsection{Bioinspired/Bioderived Ligand Conjugated Nanosystems}

Bio-nanocarriers in which the conventional nanosystems/ nanoparticles are modified for facilitating tumor targeting by the means of natural, bioengineered, bioinspired, or bioderived biomolecules are discussed under this category of bio-nanocarriers. To serve the purpose of tumor-targeting efficiently, such bio-nanocarriers may be either of the following sub-types: conjugate (drug-biopolymer), nanoreservoir (biomolecule used as a corona/surface coating), or nanomatrix (nanosystem is entirely fabricated from the biomolecule). In many of the cases, the bio-molecules themselves possess some anticancer properties. Considering the limitations of the review, only some of the studies employing novel biological ligands have been prioritized and briefed upon. Some novel biomolecules that are intensively researched upon for serving the purpose of active targeting through the bionanotechnology approach include the antibody/affibody [116, 117], lipoproteins [118], proteins and peptides [119-121], pulmonary surfactant, and biosurfactant [122-126], vitamins and other small molecules [127]. The basic nanocarriers that can be modified using any of the aforementioned biomolecules for diverse oncological applications can be summarized as lipid-based nanoparticles (liposomes, SLNs, NLCs) [128-130], polymeric nanoparticles (dendrimers [131-134], polymeric [135-140], polymersomes [141-143], layer-by-layer nanoassembly (LBL) [144, 145], nanosponges [146-148], lipid-polymeric nanoparticles $[149,150]$, protein nanoparticles (casein, zein, etc.) [151], polysaccharide nanoparticles (mannosylated, chitosan, hyaluronan, fucoidan-based nanoparticles) [152, 153], carbon nanostructures (nanotubes, graphene, fullerene, nanodiamonds [154], inorganic nanoparticles (SPIONs, upconversion nanoparticles, silver nanoparticles, gold nanoparticles, mesoporous silica nanoparticles), and quantum dots [155-159]. Some other less explored nanostructured materials such as the biomolecular self-assemblies and nanofilaments have also been reported for the management of malignancies such as cancer [135, 160-164].

\subsubsection{Antibody, Antibody Fragments, and Affibody}

Antibodies or immunoglobulins (Ig) are specialized glycoproteins expressed over the surface of B cells to act as antigen receptors [165]. Amongst five major types of $\operatorname{Ig}(\mathrm{IgG}$, $\operatorname{IgE}$, IgM, $\operatorname{IgA}$, and $\operatorname{IgD})$, IgG is most abundantly found in the serum and has been extensively researched for immunotherapy, vaccine production, and nanoparticle functionalization. While bioengineered Ig has been employed for 
immunotherapy of cancer since long, their use as targeting agents has emerged lately [166, 167]. Antibody-functionalized nanoparticles have been reported for targeted therapy of various types of cancers including lung cancer [168-172]. However, despite improvement in pharmacokinetics and biodistribution, diffusion of full-length antibody largely limits the intratumoral penetration of the payload. Several monoclonal antibodies (MAbs) have been bioengineered for immunotherapy of cancer including lung cancer.

To combine the advantages of tumor-specificity and higher intratumoral penetration through improved tumoral diffusion and cellular uptake, small fragments of antibodies are now gaining greater attention [173, 174]. The use of $\mathrm{Ab}$ fragments also overcome the Fc-induced bystander activation, as observed in the case of the conventionally used antibodies [116]. The most commonly used Ab fragments that are employed for drug targeting are a single-chain viable fragment ( $\mathrm{scFv}$ ) and antigen-binding fragment ( $\mathrm{Fab})$, respectively. The Fab fragments are generated through enzymatic proteolysis at the hinge of the whole Ab, resulting in its fragmentation. However, the scFv fragment, consisting of peptide-linked $\mathrm{VL}$ and $\mathrm{VH}$, is produced employing $\mathrm{Ab}$ engineering techniques like ribosome display or phage display [175]. However, the Ab fragments lack immunogenicity and have low circulation half-lives due to their low molecular weight and lack of the Fc component. Strategies such as PEGylation and recombinant fragment fusion may be employed to overcome these limitations [176, 177]. Nanoparticles can also be conjugated with $\mathrm{Ab}$ or $\mathrm{Ab}$ fragments through functionalization methods that employ adapter molecules, covalent binding, or conjugate through adsorption to form bionanocarriers, thereby enhancing the targeting ability while minimizing their immunogenicity. Some of the factors to be considered while the formation of these bio-nanocarriers are: density of $\mathrm{Ab}$ per nanoparticle, steric orientation, and bond stability to ensure good in vivo performance and bioavailability [156]. Many research works utilizing antibody fragments for oncological applications have been reported in the literature [172, 178, 179].

Yet another bioapproach of a similar kind is the use of affibodies for targeted therapy of cancers. Affibodies represent a distinct class of bioengineered affinity proteins of low molecular weights $(6.5 \mathrm{kDa})$ with diverse diagnostic, therapeutic and biotechnological applications [117]. Affibodies have high specificity and affinity toward definite protein targets and can be engineered to target different types of proteins. Affibodies are actually, mutated derivatives of the B-domain of the Ig-binding region of staphylococcal protein A (also referred to as Z-domain) [180]. This bioengineered $\mathrm{Z}$ domain displayed a high affinity for the Fc part of the Ab, but the affinity toward the Fab region was almost entirely deactivated. Affibodies targeted toward proteins like fibrinogen, insulin, transferrin, tumor necrosis factor-a, CD28, gp120, IL-8, EGFR, IgM, IgE, IgA, serum albumin, HER2, etc., have been studied extensively [117]. Affibodies have been extensively employed for imaging and optical imaging purposes, for affinity chromatography-based diagnostics, and for targeting payloads through bio-nanocarriers to tumors. Bio-nanocarriers employing the virus-derived affibodies, liposome-conjugated with affibodies "affisomes", etc., for oncological applications have been discussed elsewhere in detail $[117,181]$. Some examples relevant to lung cancer management have been discussed in the forthcoming section.

\subsubsection{Lipoproteins}

Lipoproteins are a group of endogenous nanoparticles composed of phospholipids, amphiphilic apoproteins, and neutral lipids. The use of lipoproteins as a carrier for diverse payloads can be attributed to its role as an endogenous bio-carrier for the delivery of hydrophobic cargoes like triglyceride and cholesterol. Their specialized bio-synthetic, bio-transport, and biodegradation pathway make them an attractive carrier system for specialized applications. Oncotargeting via lipoproteins is an attractive strategy because of (1) increased demand of lipids for cancer cell membrane synthesis causing overexpression of their receptors, (2) pharmacological substantiation of vascular drug-lipoprotein interaction, (3) epidemiologic association of cancer and lipoproteins, (4) bi-directional signaling and signal transduction mediated by lipoproteins and lipid rafts. This was evidenced by the involvement of the lipid rafts in H-RAS, Insulin-like growth factor (IGFR), EGFR, and the Hedgehog-mediated signaling pathways, which are majorly involved in malignancies [182]. However, it has been reported that only the HDL and LDL are suitable for oncological applications and delivery through bio-nanocarriers due to their unique alpha-helical protein-intercalation. This is because the other lipoproteins have larger lipid curvature and large diameter, which exposes them to water and renders them unstable [118]. Novel types of bio-nanocarriers that employ lipoprotein 
as targeting ligand through conjugation are being explored more recently for the treatment of cancer. The modification methods that are employed for the fabrication of such bionanocarriers include covalent alteration of proteins or the phospholipids, non-covalent surface loading, and reconstitution-mediated core loading [118, 182-185]. The application of such bio-nanocarriers in the context of lung cancer management has been briefed upon in the upcoming section.

\subsubsection{Protein/Peptides}

Protein and peptide bio-nanocarriers are one of the most common forms of bio-hybrids. Being one of the most ubiquitous biomolecules, the proteins and peptides have multimodal roles in the management of various diseases including lung cancer. Besides being employed as biomarkers [186-189], the proteins and peptides also have therapeutic [190-194] and drug delivery applications in lung cancer $[119,120,151,195,196]$. Due to significantly greater biocompatibility and biodegradability, as compared to the synthetic nanoparticles, protein-based nanocarriers, composed of albumin, gelatin, gliadin, elastin, zein, casein, $\beta$-lactoglobulin, soy protein, and whey proteins, have been employed since long for drug delivery applications in oncology [151]. Besides being employed as a nanocarrier and nanocages, the glycoproteins like transferrin- and apoferritin-based carriers are also employed as targeting vector and theranostic agents/nanoprobes [157, 197-199]. However, due to high molecular weights, poor in vivo bioavailability, and difficulty in conjugation to nanoparticles, peptides are being preferred over proteins for drug targeting. Recently used peptides for lung cancer targeting include the cellpenetrating peptides, iRGD peptide sequence, bombesin peptide, somatostatin peptide sequence, FSH-33 (Folliclestimulating hormone analog), fibroblast growth factor peptide (tbFGF), peptides targeting epidermal growth factor receptor (EGFR), peptide GFE, peptide F3 [200]. A novel 7-mer peptide termed as "I-peptide" that mimicked carbohydrates and inhibits carbohydrate-mediated cell localization was devised by Hatakeyama et al. for the treatment of various types of cancers including lung cancer [201]. Bionanocarriers employing nanoparticles modified with such targeting moieties for lung cancer management have been elaborated in the forthcoming section.

\subsubsection{Carbohydrates and Polysaccharides}

Various carbohydrate- and polysaccharide-based nanodelivery systems have recently emerged as an important platform for oncotargeting. Due to high biostability, safety, biocompatibility, and low toxicity, it has gained considerable interest amongst scientists. Just as in the case of the protein-based delivery platforms, this platform is being shared for the fabrication of nanoparticles as well as for targeting purposes. Nanoparticles composed of or modified by chitosan, fucoidan, glycosaminoglycan, cellulose, galactomannans, pectins, starch, dextran, alginate have been reported for cancer targeting [153, 202, 203]. Several novel polysaccharide-based nanosystems are recently being developed for devising active targeting to the solid tumors. The lungs being macrophage-rich organs have numerous mannose receptors (MRs) and GLUT1 receptors on their cell surface, which favor the translocation and endocytosis of polysaccharide-modified/carbohydrate-modified nanoparticles into the tumor tissues [202].

\subsubsection{Aptamers and Aptasensors}

Bio-functional class of oligonucleotides with distinctive 3D conformations that have been engineered using a combination of in vitro selection and systematic ligand evolution methods to confer high specificity and affinity toward specific targets are termed as 'aptamers' [204]. With gaining pace in bionics and bioengineering, the aptamers are being explored for their oncological applications. The process of bioengineering and aptamer designing is largely facilitated by an in vitro selection method known as the "systematic evolution of ligands by exponential enrichment' (SELEX). Due to significant molecular recognition capability, aptamers are being employed for functionalizing nanomaterials, nanoparticles, and fabricating devices like aptasensors. Aptasensors are biosensors fabricated using specific aptamers. Based upon mechanistic recognition, aptasensors are of the following subtypes: (a) sandwich-type, (b) split-type assay-based, aptasensors based on (c) cell membrane-aptamer interactions, (d) conformational switch, and (e) competitive binding of the aptamer to the target [205]. Several aptamer-based nanosystems that have been developed by researchers are discussed elsewhere in detail [206-213]. 


\subsubsection{Pulmonary Surfactant and Biomimetic-surfactants}

Pulmonary surfactant is an endogenous surfactant that is composed of phospholipids such as phosphatidylcholines and phosphatidylglycerols (90\%) and a mixture of fatty acids, cholesterol, and surfactant proteins (10\%) [214, 215]. The pulmonary surfactant is a complex lipoprotein, with unique interfacial properties that may serve to confer greater biostability and safety while predicting the inadvertent interactions of the pulmonary linings with the delivered nanoparticles. Some of the most commonly used pulmonary-derived surfactants, employed for formulating such bio-nanocarriers, are Alveofact ${ }^{\circledR}$, Curosurf $®$, and Surfactin ${ }^{\circledR}$. Bio-nanocarriers, composed of pulmonary surfactant, is an attractive strategy that has been attempted by several researchers for the delivery of various types of anticancer payloads to lung tumors [123-125, 216]. However, due to limitations associated with the mass production of the natural pulmonary surfactants, biomimetic pulmonary surfactants, and other biosurfactants have been developed and employed for similar purposes. The details of such bio-nanocarriers are referred to in the upcoming section [126, 217].

\subsubsection{Vitamin and Other Small Molecules}

Nano-biocarriers employing biomolecules like vitamins may be considered as the foundational-bioinspired nanocarriers. Led by the fact that receptors for some vitamins are overexpressed over the cancer cells, research interest grew in an entirely novel direction of active targeting to intracellular levels. Vitamins like folate, biotin, riboflavin, and tocopherol have been employed and extensively researched for their drug delivery applications due to their ease of conjugation over the nanoparticle surface, economic feasibility, their innocuous nature \& high biocompatibility contributing a major share in the fabrication of the bio-nanocarriers [127, 155, 218-228]. Biotinylation is also an immensely useful tool for hybridization, bioengineering, and biomanufacturing of nanovesicles and bioderived cell/cell surface molecule or cell membranes. However, the success of vitamin-conjugated nanoparticles for active-targeted delivery is controversial due to their non-specific overexpression over many normal cells. This reason is likely to favor the use of other bio-molecules and bio-moieties over vitamins for more specific and targeted active-targeting. Other small molecules like anisamide and phenylboronic acid have also been extensively reported for designing cancer-targeted drug delivery in the literature [229-232]. But the constraints such as higher costs and biological instability of the small molecules greatly limit their further nanobiotechnological applicability.

\subsection{Novel Nano-biodevices}

Nano-biodevices are the gadgets, equipment, contrivance, or their component (s) fabricated through multidisciplinary research in bionanotechnology for various clinical and biomedical applications [233]. Based upon the material of construction, there are four types of nano-bio-devices: microbial-based, immunosensors, DNA-based, and tissue-based nano-biodevices [234]. The biosensors, devised utilizing aptamers, have been discussed previously. Other nanodevices utilizing the function of membrane proteins have also been developed for diverse oncological applications [235]. With advances in bionanotechnology, several nanomaterials such as nanopillars, nanowalls, nanoballs, nanotubes, plasmon nanobubbles, and nanodots/quantum dots are being employed for the development of nano-biodevices such as nanowire arrays, nanobiosensors, nanochips, and nanobots, that have immense oncological applicability [233, 234, 236-240].

Considering the vastness of the topic and limitations of the article, only the nano-biocarriers and nano-biodevices that have been exploited for lung cancer management have been considered and discussed further.

\section{Bio-nanocarriers for Clinical Management of Lung Cancer}

With several unaddressed oncological issues, the present oncological scenario demands an immediate pragmatist approach. Bionanotechnology emerged as a consequence of the convergent evolution of nanotechnology and biotechnology in oncological sciences to offer several advantages while overcoming their individual pitfalls. Bionanotechnology has assisted drug discovery and development in addition to 
quadripartite management of various types of malignancies including lung cancer.

\subsection{Bionanotechnology in Drug Discovery and Development}

For understanding the complexity of cancer and underlying cellular and bio-molecular pathways involved therein, advanced nanobioengineered interventions are highly anticipated. Employing nanobioengineering-based tools have aided the process of drug discovery and drug development at several stages. Identification of molecular and genetic abberations in lung cancer has led to the development of several targeted therapeutics, also termed as "precision or targeted therapy", which is highly specific for cancer cells. For example, the identification of EGFR led to the development of tyrosine kinase inhibitors, cetuximab (KRAS-interfering monoclonal antibody), VEGFRtargeted monoclonal antibodies such as bevacizumab and ramucirumab [6]. Several nanobioengineering-based tools like nanoproteomics, nanogenomics, nanosensors, nanoprobes, and cantilevers have contributed immensely to tracing biomolecular interactions and facilitated the identification and validation of novel targets. Discovery and identification of novel cellular, bio-molecular and molecular targets may help overcome the limitations of existent therapeutics like resistance and non-selective cytotoxicity. The next step of lead identification is facilitated with the use of bio-nanotools like nanobiosensors, nanoscale endocytosis assays, nanowire devices, nanoflow liquid chromatography, nanofluidics, nanobiochips, nanoarrays, and surface plasmon resonance. Furthermore, the process of lead optimization is facilitated with the use of quantum dots, inorganic nanoparticles, bio-nanocarriers employing small biomolecules attached to the nanoparticles, and fluorescence planar waveguide technique [241].

\subsection{Bio-nanocarriers for Secondary Prophylaxis of Lung Cancer}

Secondary prevention/prophylaxis refers to the application of clinical and pharmaceutical interventions for prevention, suppression, or reversal of oncogenic progression from a premalignant condition to invasive malignancy [242]. Secondary prevention mode is meant for switch maintenance, continuation, or post-front-line therapy for prevention of relapse and achievement of better prognosis. Despite several attempts, cancer chemoprevention prevails in an inconclusive state [242, 243]. However, nano-biocarriers have also been employed extensively in designing cancer vaccines and immunotherapeutics that have therapeutic as well as a prophylactic role in high-risk patients (malignant oncological conditions) [244].

Tecemotide (L-BLP25, StimuVax) is an ideal example of one such nano-biohybrid. Tecemotide is a lyophilized liposomal formulation ( 150-180 nm diameter) composed of lipids (dimyristoyl phosphatidylglycerol, cholesterol, and dipalmitoylphosphatidylcholine), monophosphoryl lipid A, and BLP25 lipopeptide (mucin 1(MUC1 specific antigen)). The glycoprotein MUC1 was evidenced to be overexpressed and aberrantly glycosylated in the patients of non-small cell lung cancer. MUC1 is identified as one of the most prevalent cancer-associated antigens that are involved in the biosignaling tumor cell survival, proliferation, and progression in many forms of cancers including lung cancer. This can be attributed to MUC1-mediated interplay with many cell surface receptors like tyrosine kinase. BLP25, being MUC1targeted immunogen, and monophosphoryl lipid A, being a TLR4 agonist were observed to trigger Th1 polarization and CD8c T cell-mediated immune response. Clinical evidence of the safety, immunogenicity, and efficacy of Tecemotide in patients with stage III B locoregional NSCLC was found to be promising in terms of improved survival rates and for secondary prophylaxis in the clinical phase III trial. Tecemotide is currently undergoing phase III clinical trial for maintenance immunotherapy in the patients of colorectal cancer following surgical resection or hepatic metastases and as a maintenance therapy or adjuvant therapy post-chemoradiotherapy in the patients of stage III NSCLC [245-249].

Cancer vaccine development and cancer immunotherapy have gained a significant boost with an oncolytic virus-based bio-nanocarriers. ExtraCRAd is a unique multivaccination platform designed by Fusciello et al. for the prevention as well as treatment of melanoma and lung cancer. The ExtraCRAd nanoparticles are composed of bioengineered oncolytic virus Ad5-D24-CpG, encapsulated in cancer cell membranes. For the preparation of the ExtraCRAd vaccine, the polymeric membrane extrusion method was employed. 
This strategy synergizes the immunogenicity of the tumorassociated proteins present in the cancer cell membrane with oncolytic and adjuvant properties of the oncolytic viruses. The ExtraCRAd displayed a significant increase in the infectivity and was observed to elicit $\mathrm{CD}^{+}{ }^{+}$and $\mathrm{CD}^{+}$mediated by an antitumor response in a solid tumor model. Moreover, ExtraCRAd may be personalized for immunotherapy of different patients through the biopsy-derived tumor cell membrane. Excellent tumor regression was observed in vivo, both, in preventive and therapeutic preclinical settings. The scientists foresee such nano-biocarrier to be a promising platform for personalized vaccination and prevention [250].

Yet another nano-biohybrid platform that facilitates intranasal administration of the recombinant CCL21 gene for prophylactic immunotherapy has been proposed by Kar et al. The researchers have developed EGF-appended CCL21 vault nanocapsules from Chalmydial membrane protein that can target the tumor cells overexpressing EGFR receptor and elicit an immune response through the phosphorylation of Tyr1173. The CCL21 nanovaults were observed to partake in chemotaxis and promote leukocyte infiltrates such as $\mathrm{DEC} 205+\mathrm{DC}, \mathrm{CCR}^{+} \mathrm{T}, \mathrm{CXCR}^{+} \mathrm{T}$, and $\mathrm{IFNc}^{+} \mathrm{T}$ lymphocytes. A significant tumor growth suppression was also observed with the CCL21 nanovaults in the preclinical trials. This result was justified by the observation of augmented splenic $\mathrm{T}$ cell activity that results in a systemic antitumor response, accompanied by a reduction in the immunosuppressive cells like the IL-10 T cells, regulatory T cells, and the myeloid-derived suppressor cells (MDSC). The preclinical results in a murine model demonstrated the efficacy of this approach for secondary prophylaxis and immunotherapy of several malignancies including lung cancer [245].

The clinical establishment of the anticancer activity of CpG-oligodeoxynucleotides (ODNs) in lung cancer has led to the development of several novel formulations for increasing its selective tumor targetability and cell uptake through the optimization of its pharmacokinetics and biodistribution. Several studies that utilize lipid-based delivery systems and virus-like particles have been employed by researchers to achieve the aforementioned goals while increasing their immunostimulatory action [251-253]. A review of the lipidbased bio-nanocarriers of CpG ODNs (LCpGODNs) has presented the immense potential associated with their use as an immunostimulant anticancer immunotherapeutic and vaccine. The review also reports studies that have observed strong elicitation of immune response mediated by $\mathrm{CD} 8^{+}$
T cells after the administration of LCpGODNs, suggesting the role of lipids as an adjuvant. The strategy was reported to defend against the xenogeneic antigens while sensitizing the immune cells to attack the self-antigens like glycoprotein 100 and TRP2 in a pulmonary metastatic B16 model. This presents an immense potential to target aggressive tumors expressing even very low MHC class I levels [252].

A similar research work that reports the use of mannosylated lipid-calcium-phosphate nanoparticles (LCP) for facilitating intracellular co-delivery of CpG ODN and Trp2 peptide (Trp2-P) to lung cancer cells has been reported by $\mathrm{Xu}$ et al. This novel nano-biohybrid was observed to augment the Trp2-P-specific immune response, mediated by MHC-I restricted T lymphocyte and IFN- $\gamma$ in B16F10 lung metastatic model. Such mannosylated nanoparticle-based vaccines may facilitate dendritic cell delivery and can stimulate immune response directed to cancer cells (Fig. 3) [254].

Research by Chen et al. has demonstrated the use of bacterial (Salmonella) outer membrane vesicle (BOMVs) for secondary prophylaxis to metastasis and chemo-immunotherapy of lung cancer. This novel nano-biohybrid consists of tegafur-loaded polymeric micelle core, coated over with BOMVs. The BOMVs were designed to induce an immune response by sensitizing the cytotoxic T lymphocytes-mediated immune response to target the tumor cells directly. The antitumor efficacy and antimetastatic activity of BOMVs were apparent from the results of the preclinical in vivo data in a murine model of melanoma. A remarkable increase in the survival rates, tumor inhibition, and antimetastatic potential were observed with the BOMVs, suggesting their use as a versatile nano-biocarrier [255].

An entirely novel bioinspired approach was adapted by Chen et al. for the prevention of pulmonary metastasis of melanoma. The researchers developed a TRAIL-decorated nanovector composed of high-density lipoprotein (HDL) for targeting mesenchymal stem cells (MSCs) that overexpress scavenger receptor B type I (SR-BI). The pDNA that encodes the genetic expression of tumor necrosis factor (TNF)-related apoptosis-inducing ligand (TRAIL) was used as a vector for targeting the pulmonary MSCs. For the construction of this bioinspired nanovector, pDNA was electrostatically conjugated to cationic copolymer, composed of polyethyleneimine and lauric acid. The developed nanoparticles had uniform particle size and high in vitro stability in plasma. The nanovectors had high transfection ability and cell uptake by the MSCs targeting B16F10 (melanoma) 

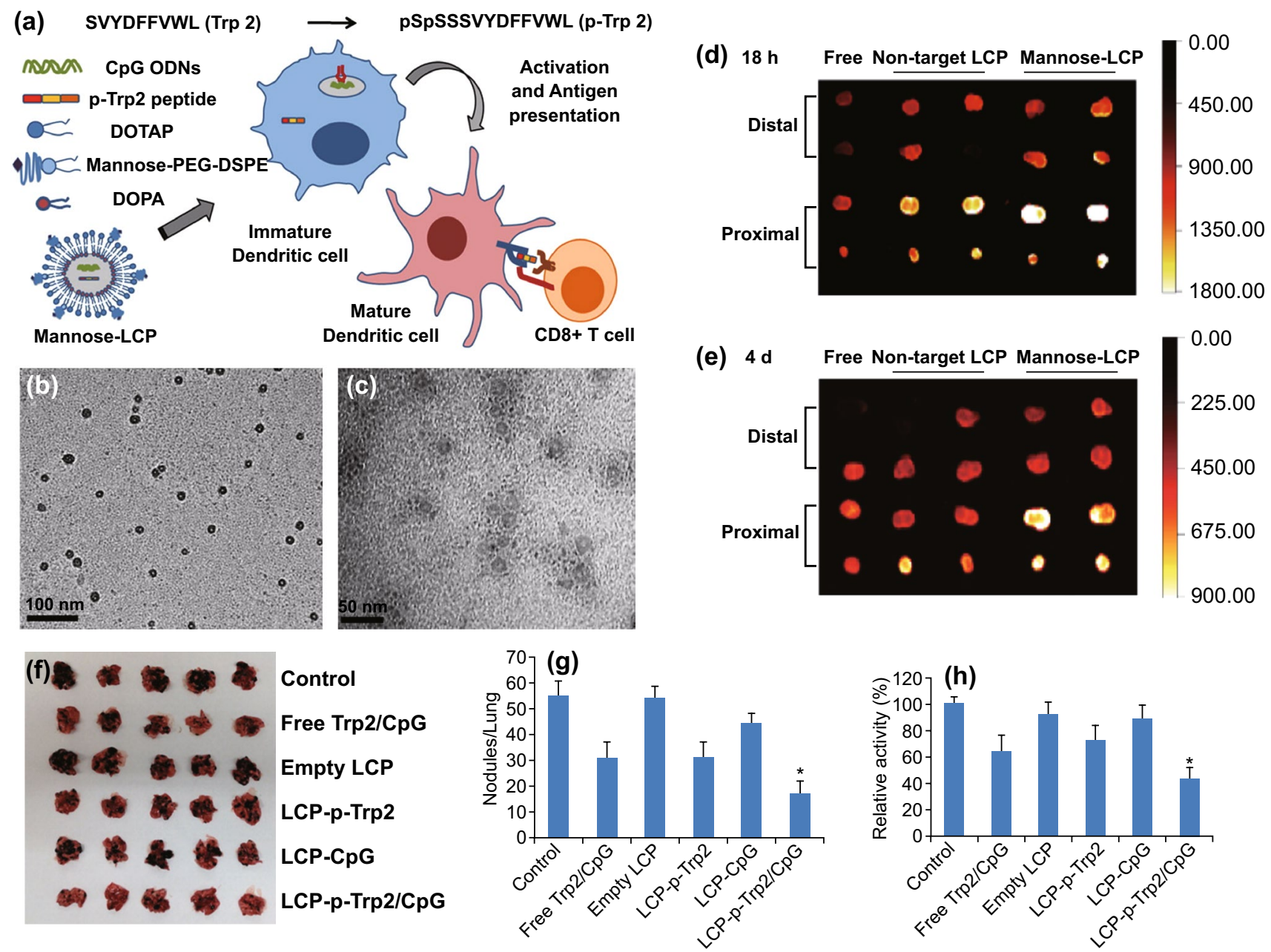

Fig. 3 a Mannosylated LCP-nanoparticle (MN-LCP-NP)-based vaccine for dendritic cell (DCC) activation. DC activation results in inducing cytotoxic T-cell-mediated immune response. TEM microphotographs of $\mathbf{b}$ mannosylated nanoparticles and $\mathbf{c}$ p-Trp2 peptide and CpG ODNloaded MN-LCP-NP. Scaling = $100 \mathrm{~nm}$ and $50 \mathrm{~nm}$ respectively. d Biodistribution in lymph nodes of the vaccine formulation upon s.c administration in C57BL/6 mice containing ${ }^{125}$ I-labeled p-Trp2 peptide and Texas Red-labeled ODN. Free: in 5\% glucose; Non-target LCP-NPs, MNLCP-NP, LCP NPs without DSPE-PEG-Mannose; and with DSPE-PEG-Mannose. Readings noted after $18 \mathrm{~h}$ and $\mathbf{e}$ after 4 days. $\mathbf{f}$ Lungs isolated from C57BL/6 mice with B16F10-luc cells induced lung metastatic melanoma after being treated with different formulations. $\mathrm{g}$ Tumor nodules h luciferase activity in lungs $(\mathrm{n}=5, * P<0.05)$. Adapted from with permission from Ref. [254] Elsevier, Copyright 2013

cells through a highly targeted therapeutic approach. Such an approach not only prevents side effects but also prevents metastasis of the melanoma cells [256]. Another vaccination approach employing tumor cell lysate-encapsulated bacterial nanoghosts was reported for preventive immunotherapy against many forms of cancers including lung cancer [36, 257].

The research works discussed in this section are only a few of the researches that exemplify the emerging prophylactic role of bionanotechnology in pulmonary oncology.

\subsection{Nanobiodiagnostics in Lung Cancer}

Diagnostics in cancer involve two different aspects: (1) bioimaging and (2) identification of tumor-associated molecular markers. Conventional diagnosis of lung cancer is done employing diagnostic methods such as sputum cytology, imaging tests like CT scan, thoracic X-ray, PET and biopsy techniques such as bronchoscopy, thoracentesis, endoscopic ultrasound and open biopsy. The prevalent cancer diagnostic methods have limitations like poor image resolution, 
lack of specificity, low detection sensitivity, low signaling strength, and limited tumor-associated molecular marker identification techniques. In some cases, imaging methods have also been associated with toxicity issues [3]. Several genetic, epigenetic, proteomic, metabolic bio-molecules that are increasingly being recognized as biomarkers comprise mutated DNA/matrix RNA expression, altered/methylated DNA, altered protein levels, qualitative and quantitative alterations in low molecular mass metabolites [258-263]. Exosomal miRNAs and miRNAs, circulating tumor cells (CTCs), tumor stromal cells, endothelial cells, and immune cells are also gaining increased attention to be used as a biomarker for the detection of tumors. Tumor-associated bio-molecules like methylated sputum microRNAs/DNA, metabolome, microbiome, and airway epithelial cell biomarkers can be detected through several diagnostic methods upon screening of the respiratory tract. Peripheral tumorassociated bio-molecules like DNA methylation patterns of leucocytes, serum autoantibodies, microRNAs, CTCs proteomic signatures, and circulating cell-free DNA/circulating tumor DNA may also be screened upon for tumor detection [264-267]. These techniques provide a deeper understanding of the subtypes of lung cancer and aid in deciding therapeutic interventions thereof, wherefrom the concept of personalized therapeutics has emerged. This has even led to the development of tyrosine kinase inhibitors for targeting the patient populations with molecular aberrations in the EGFR and ALK genes. Novel bio-diagnostic methods like chromogenic/fluorescence in situ hybridization or PCR-based multiplexed techniques like SNap-Shot or mass spectroscopy-based genotyping-based methods like the Sequenom MassARRAY, Sanger sequencing, and restriction length fragment polymorphism have considerably revolutionized the diagnostic field [268-270]. Comprehension of sub-variants of lung cancer at genetic/molecular levels can help in devising novel personalized therapies. However, due to a large number of molecular aberrations involved in lung cancer, high-throughput screening methods capable of exome/genome/transcriptome sequencing are being developed [271]. The application of nano-bio-based detection and imaging techniques may facilitate high-throughput screening of biological samples, novel biomarker identification, biomarker detection with high specificity at low detection levels, and molecular mapping [114, 186, 187, 240, 265, 272-274]. Several attempts are being made for developing multifunctional molecular nanoprobes that may clarify the functionalization of biological systems at the nanometer scale, identify the process of their integration within the cells allowing recognition, thereby prompting spatiotemporal signals that are involved in cell-cell and cell-space interactions. Futuristic nano-biodevices attempt to develop tools that may dynamically track and observe cellular and biomolecular interactions, biodistribution, bio-kinetics, and bio-interaction of various therapeutic and diagnostic agents. Other unmet objectives such as bioengineering of encodable genetic markers and single-molecule analysis and bio-fate analysis are also being worked upon by the bionanotechnology researchers [4]. Quantitative analytical techniques and information integration techniques with bioengineered nanotools may be of great resort to the researchers in the development of multifunctional devices that not only sense the external and internal bio-signals but also regulate cellular responses like proliferation, differentiation, apoptosis, etc. Information integration from biotechnologically advanced "omics" techniques may be computed using predictive tools and may be employed as virtual models for extrapolating the spatio-mechanical, multimodal, and ordered assemblage of biomolecules and synchrony of several bioprocesses [4]. Some examples of bio-nanocarriers that have been researched upon with similar objectives have been discussed hereafter.

While metal-based nanoparticles have significantly contributed to the enhancement of conventional CT scanning techniques, most of them do not facilitate targeted imaging. To facilitate the targeted imaging of lung cancer, a novel nano-bio-hybrid platform was developed by Xu et al. The authors of this research have discussed the development of NJ0001-coated nanomagnetic beads targeted to the SP70 antigen that is overexpressed in the lung adenocarcinoma cells. NJ001 is a monoclonal antibody, directed to the SP70 antigen. Strong signaling intensities were observed in an orthotopic mice model upon a micro-CT scan. The NJ001 can also be labeled with a NIR-florescent dye CF750 to serve as a probe for molecular imaging using an anti-SP70 fluorescent imaging technique. With SP70-targeted bio-nanocarriers, it was possible to detect pulmonary lesions two weeks earlier than the detection in control. Such preclinical findings indicate the NJ0001-labelled probe to be an excellent tool for facilitating early detection of lung cancer through molecular imaging [275].

Due to the short biological half-life of the conventionally used PET tracers and their constrained diagnostic ability 
in various types of lung cancer, novel nano-approaches are being explored [3]. Cai et al. have reported the development of a nano-bio-hybrid system to facilitate imaging of tumors with a high spatial resolution with combined PET and CT imaging techniques. Such an imaging platform can combine the high spatial resolution of CT imaging with high sensitivity of the PET imaging techniques. To facilitate precise simultaneous PET/CT imaging, self-assembled lipidic nanocapsules encapsulated with iodixanol were tagged with self-chelated ${ }^{64} \mathrm{Cu}$ and targeted to the tumor cells using the GLT21T aptamer. GLT21T is an aptamer targeted to tyrosine kinase receptor AXL that is overexpressed in lung cancer. GLT21T-conjugated lipid nanocapsules were formulated using self-assembling of the Chlorin e 6 (Ce6)-conjugated lysophosphatidylcholine (LPC). The ${ }^{64} \mathrm{Cu}$ moiety was contained at the center of the $\mathrm{Ce} 6$ tetrapyrrole ring, by its selfchelating ability followed by loading of iodixanole into its cavity. The iodixanol loading can be modified to meet the imaging requirements. The bio-nanocarriers thus formed were assessed in the A549-orthotopic mice model and compared to the conventional PET and CT imaging results. It was reported that the microscopic tumors $(\sim 500 \mu \mathrm{m})$ that were undetectable using the conventional PET and CT imaging techniques were detectable at high resolution, contrast, and sensitivity by employing such a dual-mode imaging nano-bio-hybrid tool [276].

Magnetic resonance imaging (MRI) is not a favored diagnostic method for lung tumors due to biological factors like low intrapleural proton density, high mediastinal and thoracic movements, and heterogenic pleural magnetic distribution [277]. A novel nano-biohybrid was developed by $\mathrm{Xia}$ et al. to facilitate the multimodal (MRI imaging and micro PET) imaging of lung cancer. Bio-nanocarriers composed of octreotide-modified organic melanin nanoparticles (OC-MNPs) targeted to somatostatin receptors (SSTR2) were developed for photoacoustic imaging of
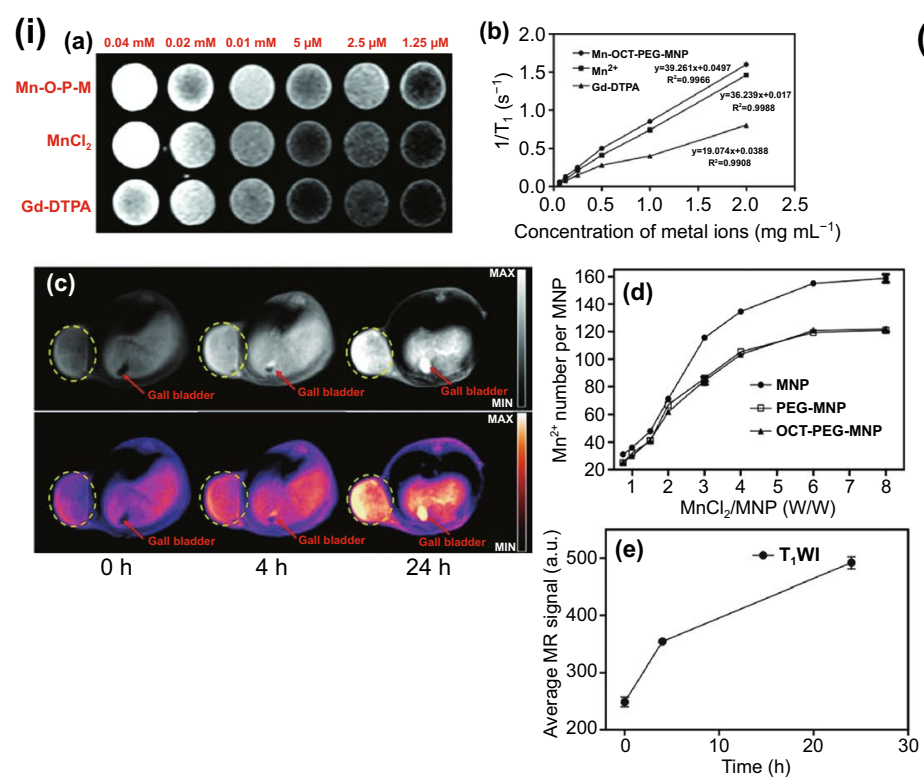

(ii)
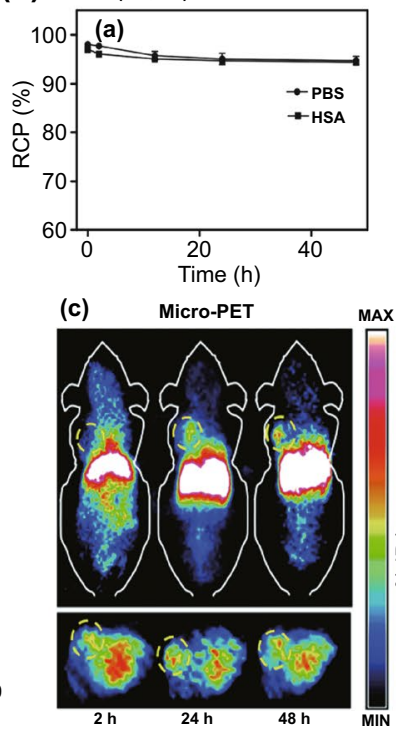

(b)
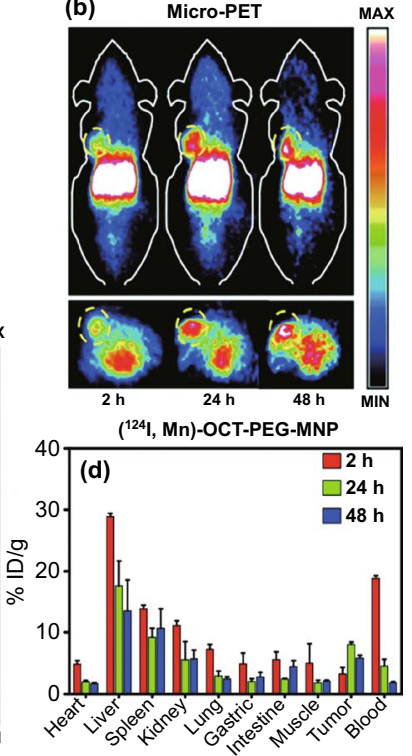

Fig. 4 (i) In vitro and in vivo MRI analysis of $\mathrm{Mn}^{2+}$-OCT-PEG-MNPs: a T1-weighted MRI images at $1.5 \mathrm{~T}, \mathrm{TR}: 531 \mathrm{~ms}, \mathrm{TE}: 9.1 \mathrm{~ms}$ of Mn ${ }^{2+}$ -OCT-PEG-MNPs (upper panel), $\mathrm{MnCl} 2$ (middle panel), Gd-DTPA (bottom panel) with various concentrations $(2.0,1.0,0.5,0.25,0.125$, and $0.0625 \mathrm{mg} \mathrm{mL}^{-1}$. b in vitro T1-linear relaxation rates $\left(1 / \mathrm{T} 1, \mathrm{~s}^{-1}\right)$ of Mn-OCT-PEG-MNPs, $\mathrm{Mn}^{2+}$ and Gd-DTPA measured. c Axially imaged T1-weighted MR images of NCI-H469 mice ((tumor site enveloped by a yellow dotted line, and gall bladder was indicated by a red line) before and after i.v, tail injection of Mn ${ }^{2+}-$ OCT-PEG-MNPs(TR: $531 \mathrm{~ms}$, TE: $9.1 \mathrm{~ms}$. d Relationship of $\mathrm{Mn}^{2+}$ attached on one MNP, PEG-MNP, and OCT-PEG-MNP and feed ratio (WMn/WMNPS). e Quantitative analysis of signaling intensity at the tumor site at various time intervals. (ii) 5

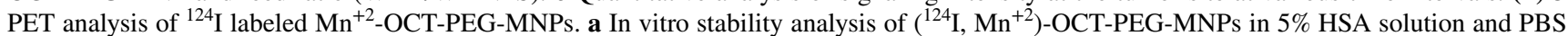
$(\mathrm{pH}=7.4)$. b The sagittal plane (upper panel) and transaxial (bottom panel). Micro-PET images of NCI-H69 tumor (tumor site enveloped by a yellow dotted line) scanned at 2, 24, and $48 \mathrm{~h}$ after tail vein injection of (124I, $\mathrm{Mn}^{+2}$ )-OCT-PEG-MNP. c Micro-PET imaging of A549 tumor mice at 2, 24, and $48 \mathrm{~h}$ after tail intravenous injection of (124I, $\left.\mathrm{Mn}^{+2}\right)$-OCT-PEG-MNPs. d Biodistribution of $\left(124 \mathrm{I}, \mathrm{Mn}^{+2}\right)$-OCT-PEG-MNPs in NCI-H69 tumor mice $(n=3)$ measured by gamma scintillator at 2, 24, and $48 \mathrm{~h}$ after tail vein injection (data expressed as $\%$ ID $\mathrm{g}^{-1} \pm$ SEM. Adapted from Ref. [278] with permission from The Royal Society of Chemistry, Copyright 2019 
pulmonary tumors. SSTR2 are highly overexpressed in many forms of lung cancers that are difficult to be diagnosed at early stages. The magnetic resonance contrast agents like $\mathrm{Mn}^{+2},{ }^{124} \mathrm{I}$, and N-Bromo succinimide can be chelated with MNPs directly to facilitate photoacoustic imaging (PI) also. The nanoprobe displayed assertive results when evaluated for imaging ability through PET, MRI, and PI in the xenograft model of NCI-H69 tumor overexpressing the SSTR2 receptors (Fig. 4). A remarkably higher T1-weighted signaling intensity was observed in the tumors on the PI imaging of tumors after $24 \mathrm{~h}$ on the administration of $\mathrm{Mn}^{+2}$ - modified OC-MNPs, as compared to the prescan control groups. The ${ }^{124} \mathrm{I}_{\mathrm{Mn}^{+2} \text {-modified }}$ OC-MNPs were observed to have significantly higher cell uptake in the NCI-H69 tumors as compared to the SSTR2negative A549 cells $\left(8.03 \pm 0.37 \% \mathrm{ID} \mathrm{g}^{-1}\right.$ as compared to $\left.3.35 \pm 0.54 \% \mathrm{ID} \mathrm{g}^{-1}\right)$. With favorable preclinical results, the OC-MNPs nanoprobe may be considered further for clinical trials [278].

Chen et al. developed a novel nano-biohybrid-based multivalent probe for the detection of metastatic lung cancer cells. Click chemistry-based reaction was employed to synthesize galactoside-capped gallamide with triantennary dendritic morphology, containing a thiolate focal group. While the core of the nano-biohybrid was composed of fluorescent $\mathrm{CdSe} / \mathrm{ZnS}$, the dendron formed its hydrophilic shell. The nano-biohybrid was evidenced to undergo high cell uptake via asialoprotein receptors that are overexpressed on lung cancer cells. The applicability of such a nano-biohybrid in photodynamic therapy has been evidenced by their uptake in an active mitotic state as well as non-mitotic lung cancer cells. The developed multivalent probe was reported to be a useful tool for studying the process of cell adhesion, cell identification, endocytic mechanisms, and multimeric carbohydrate interactions [279].

Despite having maximal permissible exposure and deeper laser penetration, most of the NIR-II-active nanomaterials face constraints about their tumor-targeting ability and imaging ability. A novel nano-biohybrid, comprising of macrophages loaded with bimetallic (FePd) nanoparticles, was developed by Yang et al. to facilitate targeted phototherapy in NIR-II biowindows and MRI imaging of various types of tumors. The developed nano-biohybrid was evaluated for their in vitro and in vivo photothermal activity and MRI imaging ability, wherein they showed excellent tumor targeting, good imaging ability, and photothermal conversion efficiency of $36.7 \%$. A tumor volume reduction of $\sim 90 \%$, with insignificant organ toxicity, was observed with the use of this nano-biohybrid as compared to the control group. The observed results present an excellent platform that can be explored further clinically for combining photodynamic therapy and MRI imaging [280].

With the advancing era of microfluidic-based nanomaterials, several nano-biodevices have emerged. Examples of such devices have been reported for the detection and diagnosis of serum biomarkers of lung cancer [281]. Gao et al. have devised CMOS-compatible silicon nanowire (SiN)-based multiplexed detection nanoarray for multiplexed detection of lung cancer biomarkers. The SiN nanosensors can be combined with a microfluidic device to enhance the performance of the nanodevice through rapid analysis of small sample volumes and allow multiplexed detection of the biomarkers of lung cancer such as miRNA-126 and CEA. Besides offering a sensitive real-time detection ability and offering single-molecule detection ability, these $\mathrm{SiN}$ nanosensors can be produced in bulk using the CMOS-compatible anisotropic self-stop etching method, thus providing an immensely useful method for clinical diagnosis of cancer as well as other diseases [240].

Some other examples of bio-nanotools that have been employed for diagnostics of lung cancer are summarized in Table 3.

\subsection{Nanobiotherapeutics in Lung Cancer}

Nanobioengineering may not only assist targeted drug development as mentioned earlier but also facilitate targeted drug delivery. Idealistic drug delivery is characterized by features like prolonged systemic circulation, controlled release pattern, high biostability, targeting ability across various biological barriers, immuno-stealthing property in addition to protecting the payload. Such idealistic criteria have led to the development of targeted nano-drug carriers that assemble these virtues by the means of their modifiable dimensional properties, fabrication, PEGylation, and surface modification.

Nanotechnology has come up with several nanocarriers that have brought a paradigm shift in the field of oncotherapy. Targeted drug delivery in oncology is of utmost 


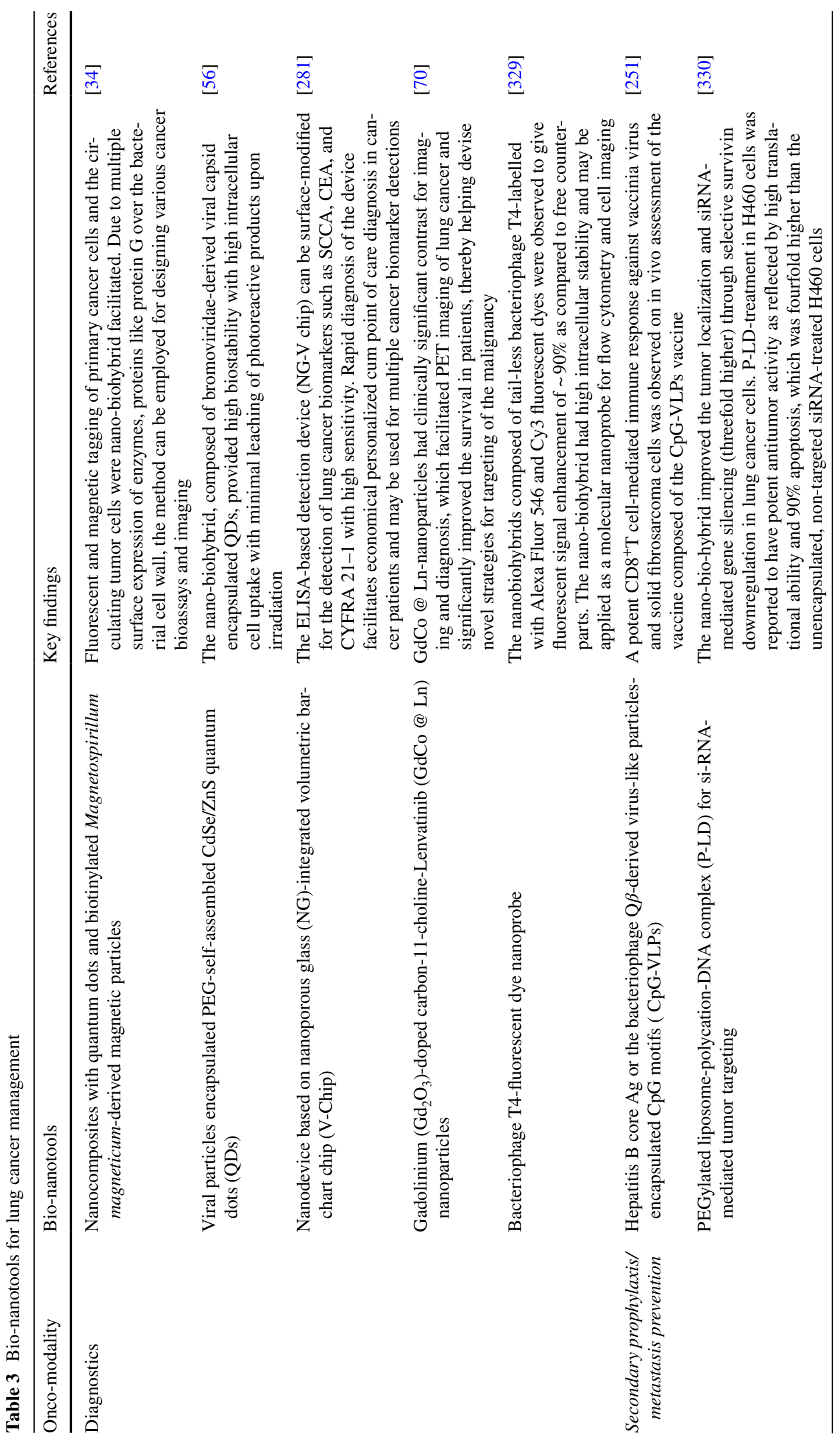




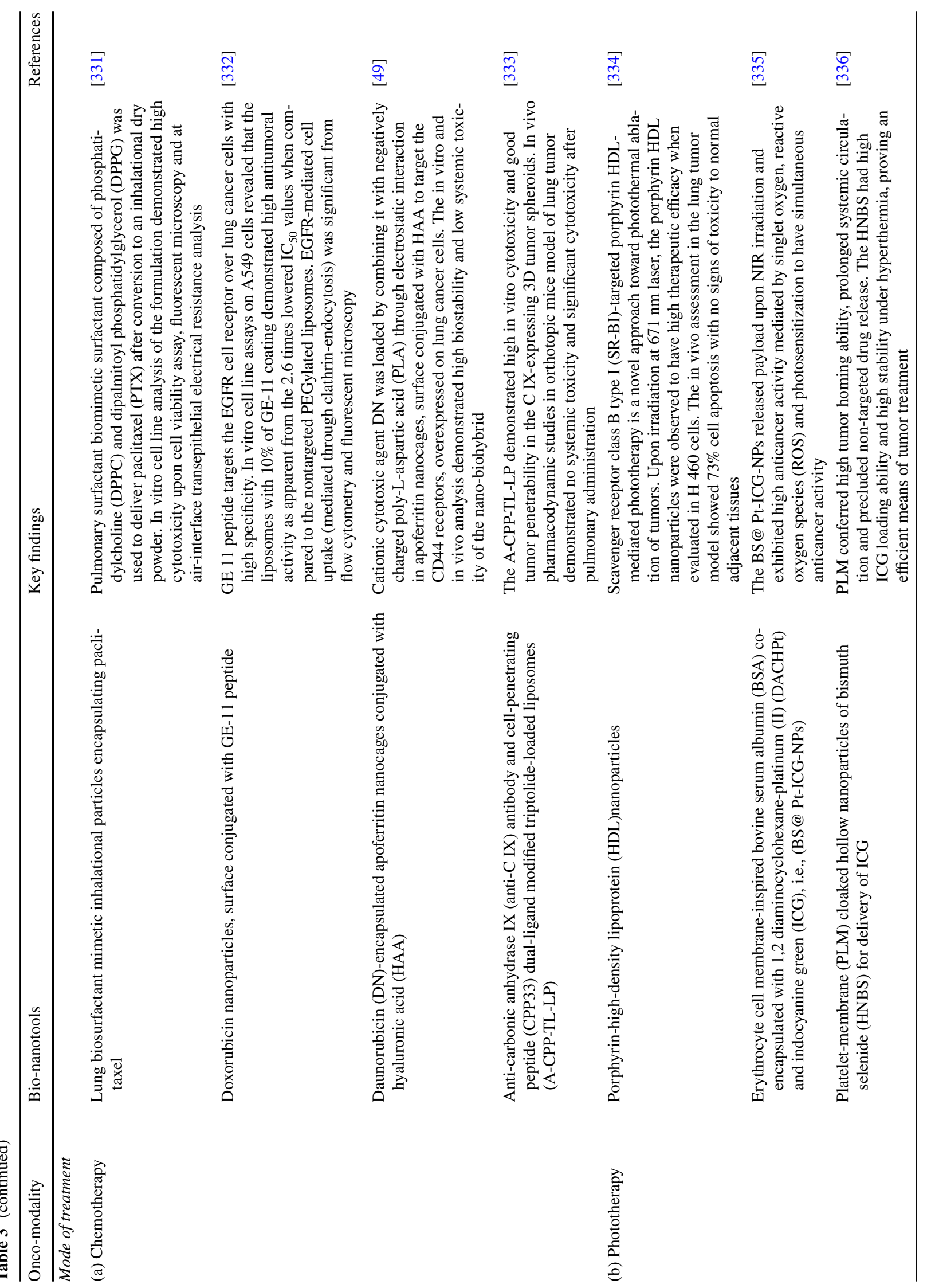




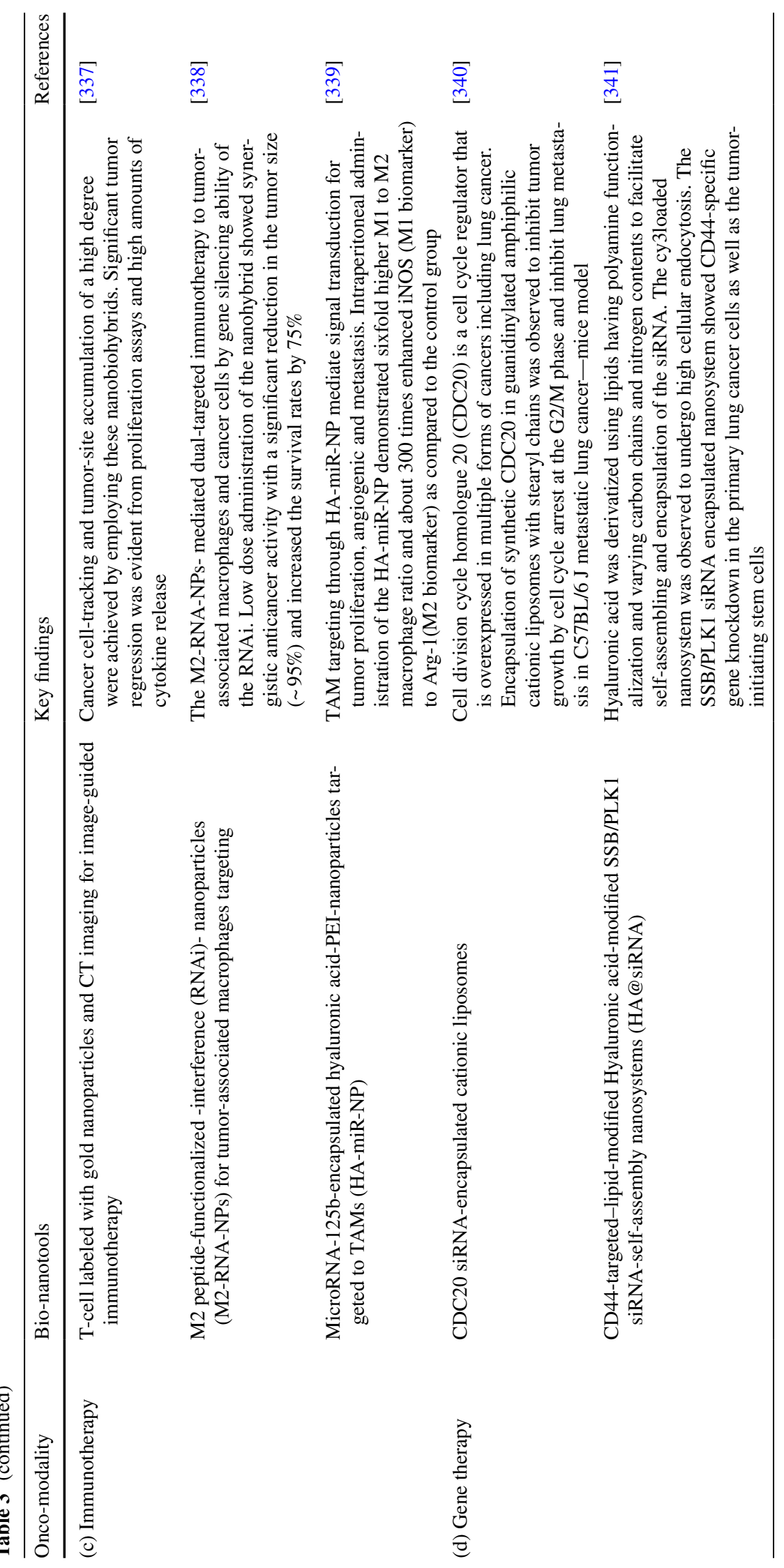




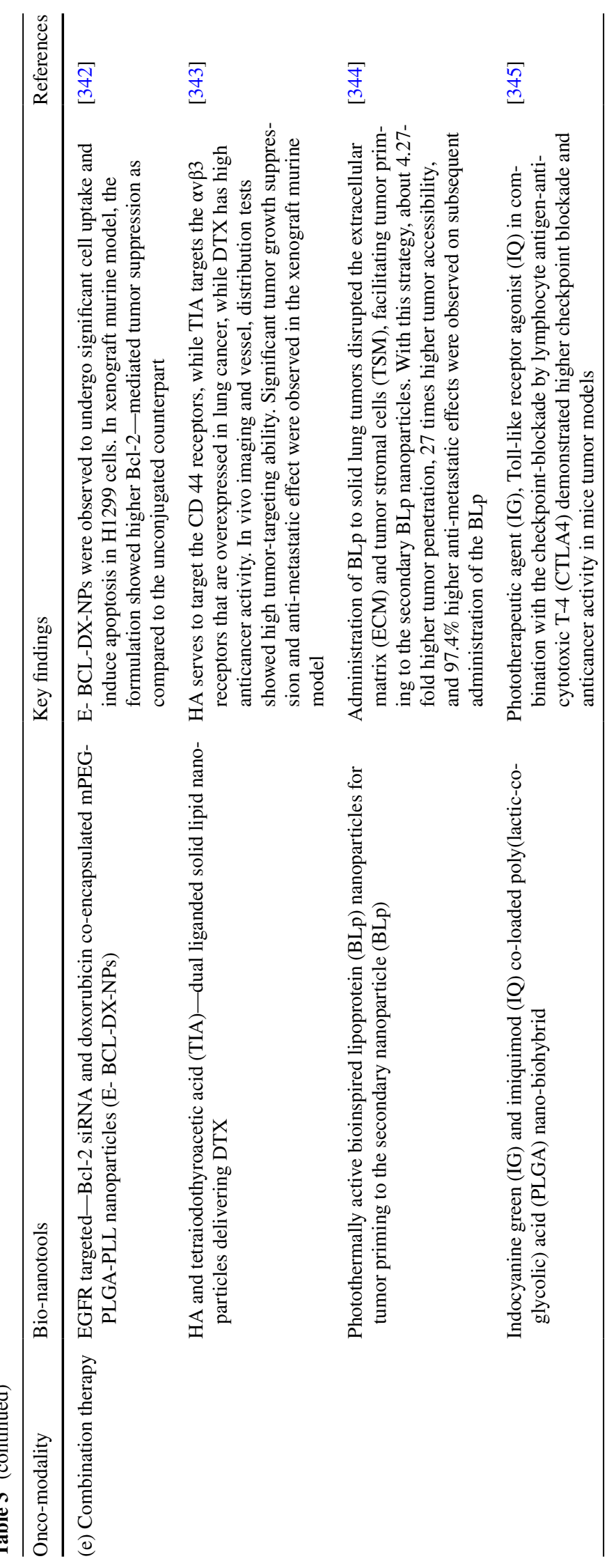




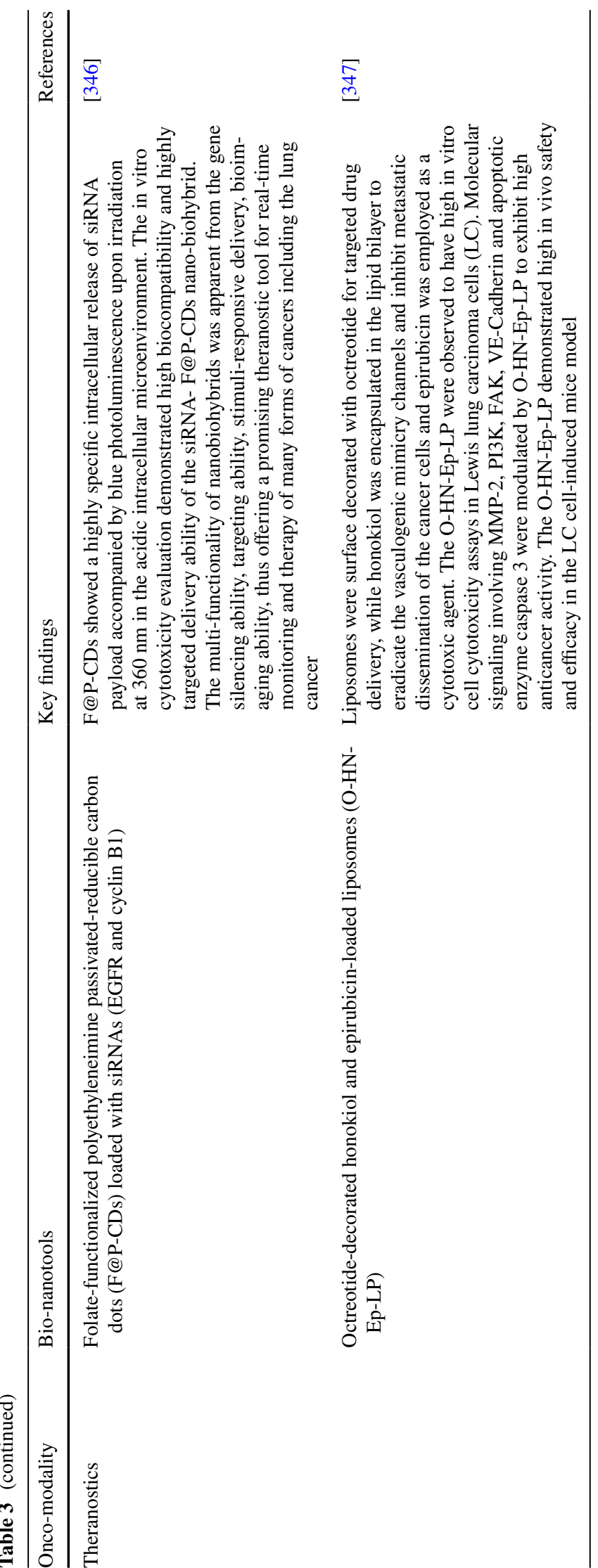

importance to overcome challenges associated with tumor targeting. Tumor-targeting may be achieved by the means of 'passive targeting' that operate through the EPR effect or by the means of 'active targeting' that operates via functionalization using targeting moiety/ligand. Given the complexity of tumor cytoarchitecture and barriers that prevent efficient antitumor activity, several shortcomings of the passive targeting strategies have been identified. These include a lack of selective cellular targeting and transitional hurdles across the tumor stroma. Such findings have led to the conceptualization of active targeting strategy as a futuristic mode of targeted drug delivery. The active targeting strategy can be employed for targeted delivery to extracellular tumor matrix, CTCs, lysosomes as well as mitochondria. Unlike passive drug targeting, active targeting operates via specific ligand-receptor interactions or biochemical mechanisms.

However, the real transformation of the active drug targeting approach is difficult due to challenges associated with oncotargeting. The factors such as proximity of the targeting moiety to the target, systemic clearance, unsolicited immune cell response, and immune cell uptake, nanoparticle characteristics, ligand density, non-specific biological/perivascular interactions, juxtaposing ligands at the target site, steric hindrance, unfavorable ligand orientation, etc., play a decisive role in active drug targeting of the nanoparticles [101].

Four generations of nanocarriers have evolved to date. The basic nanovescicular and nanoparticulate systems that aided solubility, conferred sustained/controlled release ability and bioprotection to the loaded cargo are considered as the first-generation nanocarriers. The second-generation nanocarriers are PEGylated nanocarriers that employ PEG as a 'stealth' molecule to prevent their immune recognition and RES uptake, thereby prolonging their systemic circulation and conferring passive targeting ability. Third-generation nanocarriers are complex nanocarriers that add to the virtues of the second-generation nanocarriers by offering 'active targeting ability', i.e., spatiotemporal delivery aided by the means of stimuli-sensitivity or through cell-targeted moieties. However, the in vivo performance of these activetargeted nanocarriers has been debated due to many factors [101]. The emerging concept of nanobioengineering has inspired researchers to design and develop novel fourthgeneration nanocarriers, the bio-nanocarriers through bioengineering of cells and cell membranes or other biological components. 
The majority of the active targeting strategies employed by researchers have been stratified as external stimuli-based, tumor microenvironment-based, and targeting ligand-based [282]. However, innovations in the nanobioengineering and nano-bioconjugation techniques have opened up several avenues in tumor targeting and have almost re-defined the terms of active drug targeting. Biocloaked, bioresponsive, bioinspired, biomimetic approaches of active drug targeting are recently gaining higher attention. The actively targeted nanobiocarriers have been reported to facilitate cancer cell targeting at the cellular/subcellular levels, to the tumor stroma, mitochondria, cancer stem cell, and tumorassociated cells [15, 74, 283-285]. Few other tumortargeting approaches offered by bio-nanocarriers are enlisted below:

- Nano-biocarriers that combine stimuli-sensitive and tumor micro-environment-sensitive intelligent drugdelivery systems may be employed to facilitate spatiotemporal drug release along with the most accurate biochemical means of active targeting [286].

- Approaches like multistage targeting that are difficult for conventional drug delivery systems have been employed using the nanocarriers [287] and may be combined with biotechnology to help devise the nano-biocarriers.

- Overcoming multidrug resistance with the possible use of P-gp inhibitors and nano-biocarriers [122, 288-291].

- Nano-biocarriers may facilitate ratiometric and synergistic drug delivery [292] or dosage form designing in a metronomic mode [293].

- Nano-biocarriers also address recently discovered 'on target but off the site' like advanced drug delivery issues, faced by several target-specific drug categories (e.g., nano-biocarrier-based delivery of anti-PD-1 inhibitors [294].

Nanobioengineering and bionanotechnology have proved their versatility and multimodal applicability in drug delivery for multiple types of payloads like chemotherapeutic agents, phototherapeutics, genes, antibodies, small molecules, phytochemicals, microbubbles, imaging, and theranostic agents. Nano-bioengineering is still at a primitive stage of research as far as the diagnosis and treatment of SCLC and pleural mesothelioma are concerned. Some bionanocarriers that have been explored for treatment of the lung cancer sub-types like the SCLC and pleural mesothelioma are elaborated below.
Pleural mesothelioma is one of the most lethal forms of lung cancer characterized by poor prognosis, aggressive growth pattern and high relapse rates. It has often been debated for the lack of efficient diagnostic and therapeutic strategies. Affordable and specific biomarker-based diagnostic method for pleural mesothelioma has recently gained significant scientific attention. Advanced biotechnological techniques have identified potential exosomal family of $\sim 570$ proteins termed as "mesothelioma exosomal signature" that can serve the diagnostic purpose quite well [295].

Sakura et al. researched antitumor activities of hemagglutinating virus of Japan envelope (HJ-E) isolated from inactivated non-replicating Sendai virus. The HJ-E were observed to evoke direct antitumor immune response upon activation of natural killer cells, dendritic cells, and regulatory T-cell suppression through the RIG-I/ MAVS pathway upon their intratumoral administration. Phase I dose escalation tolerability, safety and primary efficiency studies were performed on the patients with chemoresistant malignant pleural mesothelioma upon the intratumoral and s.c administration of HJ-E. The results were affirmative in terms of prevention of relapse at the injected tumor site as well as its safety. Though no serious adverse effects were observed, transient fever and mild site-specific symptoms were observed [296].

Sakurai et al. devised a novel bio-nanocarrier composed of cationic liposome and hyaluronic acid lipid conjugate for pleural mesothelioma therapy. The novel bionanocarrier was synthesized through reductive amination process that allowed HA-terminal attachment to the cationic lipids of liposomes containing Cisplatin, while sparing carboxylate group. Upon intrapleural administration of these bio-nanocarriers at a dose of $1.5 \mathrm{mg} \mathrm{kg}^{-1}$ Cisplatin in an orthotopic mice model of pleural mesothelioma, the bio-nanocarriers demonstrated significantly higher CD44 expression and subsequently synergistic cellular uptake of Cisplatin in the mesothelioma cells [297].

Singh et al. report the development of a novel injectable/ sprayable hydrogel composite with peptide-based microRNA nanoparticles to target pleural mesothelioma cells. The hydrogel serves as therapeutic depot for delivery of miRNA to the tumor cells. For the formation of stable nanoparticles, miRNA was firstly complexed with amphiphilic cationic peptide and these nanoparticles were incorporated into peptide hydrogel vai self-assembly of the amphiphilic cationic peptide to form a composite hydrogel. The formulation 
was optimized for properties like biopersistence, biostability, loading ability, specific targeting, bio adherenance and integrity. The miRNA nanoparticles were observed to be non-toxic and upon tracking of the Cy3-labelled miRNA, they demonstrated significantly higher clathrin receptormediated uptake. In vivo studies in orthotopic mice model demonstrated significantly enhanced anticancer activity, tumor regression, and higher overall survival [298].

Small cell lung cancer (SCLC) is second-most common type of lung cancer associated with very high mortality rates and poor prognosis (only $10 \%$ of the diagnosed patients survive for greater than five years).

Huang et al. developed a novel cytomembrane-mimicking bio-nanocarrier for targeted delivery of anticancer enzyme asparginase (ASP) to SCLC cells. The bio-nanocarriers are self-assembled structures composed of polyethylene glycol 2000 (HA-g-PEG) and $\alpha$-cyclodextrin conjugated to endogeneous CD44 targeting component. The supramolecular assembly and vesicular encapsulation served as a bioreactor that facilitated loading of ASP in its hollow interior, protected the enzyme and provided targeted delivery. The bio-nanocarrier had explicitly higher stability, enzyme-substrate kinetics, catalytic activity and antitumor efficacy as compared to free ASP. The nanobiocarrier exhibited excellent in vivo safety and biocompatibility and can be employed for the treatment of several other malignancies [299].

Whitener et al. developed a unique DNA derivatized gold nanoparticles that can bind to $\sim 1100$ daunomycin molecules. The drug was held by the mutating nucleic acid strands of the bio-nanocarrier. The length and sequence of the doublestranded DNA of bio-nanocarrier can be modulated to enhance payload. Moreover, diverse array of aptamers can be used for facilitating binding of the nanocarrier to diverse targets. The highly specific, programmable bio-nanocarrier presents a highly specific, avidity driven nanosystem with high drug loading ability and biocompatibility administrable by intratracheal or intravenous route. The drug release rates and quantity can be modulated by mutating the base pairs of the drugbinding region and changing the sequence. The SCLC-specific aptamer-based bio-nanocarrier needs to be evaluated for in vivo efficacy in orthotopic nude mice model for ensuring safety and efficacy [300].

Bio-nanocarriers may also facilitate alteration in the route of administration (preferably inhalational, oral [301] over the conventional i.v / intratumoral or parenteral). This may increase patient compliance while avoiding the need for hospitalization
[302-306]. Although not much explored until now, the concept may be extrapolated for the nano-biocarriers as well.

A few select examples from each of the therapeutic categories have been discussed in the respective sections.

\subsubsection{Nano-biocarriers in Chemotherapy}

Bacterial-derived minicells represent a breakthrough example of nano-biohybrids to have reached the clinical trial phase of approval. These 400-nm bio-nanocarriers have been claimed to offer targeted chemotherapy to many types of cancers including lung cancer. For facilitating tumor targeting, these minicells may be surface-functionalized using bispecific antibodies that bind specifically to both; the lipopolysaccharide component bacterial O-antigen as well as to the EGFR receptor. The versatile drug delivery carrier may be loaded with chemotherapeutics having different physicochemical properties (solubility, charge, and hydrophobicity) at therapeutic concentrations. The minicells were reported to incorporate vinblastine, cisplatin, and irinotecan that represent amphiphilic, hydrophobic, and hydrophilic prototypic cargo. The in vitro and in vivo evaluations in the A549 xenograft model provide compelling proof of the safety and efficacy of this drug delivery platform. Besides having an excellent antitumor activity (greater than 11 other antitumor treatments), these minicells are highly suitable for facilitating combination chemotherapy [307].

A novel nano-biohybrid drug delivery system, 'nanofibrin' was recently reported by Vedakumari et al. for the targeted delivery of erlotinib. The erlotinib-encapsulated nanofibrin was developed through the wet co-precipitation method and was subsequently conjugated to bevacizumab (anti-VEGF antibody) by employing the EDC/NHS method of conjugation. The bio-nanocarriers had a spherical shape with a surface positive charge and a hydrodynamic diameter of $\sim 79 \mathrm{~nm}$. The in vitro evaluations in the A549 lung cancer cell line proved the strategy to exhibit enhanced anticancer activity. Effective cell inhibition accompanied by an increase in the sub-G0/G1 phase with a subtle decrease in the G0/G1 phase was observed from the in vitro cytotoxicity assessment [168].

In another instance, Chen et al. developed hyaluronic acid (HA) and nitroimidazole (NZ) co-decorated polymeric (PNPs) and lipo-polymeric (LPNs) bio-nanocarriers for targeted delivery of cisplatin. While HA provided targeting to 
the CD 44 and CD 33 receptors that are overexpressed in lung cancer, NZ facilitated drug delivery to deeper hypoxic regions through bio-reductive prodrug designing and provided an amphiphilic drug delivery platform. The hydrodynamic particle size of LPNs and PNPs was observed to be $185.6 \pm 4.7 \mathrm{~nm}$ and $136.7 \pm 3.5 \mathrm{~nm}$, respectively. In vitro cell uptake of the LPNs in the drug-resistant A549/DDP cell line was significantly greater than the PNPs, indicating the fusogenic property of the lipids to cell membranes. The LPNs and PNPs were observed to have remarkably higher antitumor activity as compared to the pure drug in drugresistant human lung cancer A549/DDP cells. The in vivo survival rates in LNP-treated animal groups was higher (90\%) as compared to the groups treated with PNPs (80\%) vs the cisplatin-treated groups (30\%) [308].

Novel biomimetic bio-nanocarriers composed of platelet cell membrane-derived were developed by Chi et al. for the targeted delivery of Docetaxel to the lung cancer cells. For the construction of these novel bio-nanocarriers, poly (lactide-coglycolide) (PLGA) nanoparticles, encapsulating DTX, were enveloped using the platelet membrane. The developed nano-biohybrid exhibited high drug loading capacity, sustained drug release, excellent stability, and tumor-targeting ability. The results of in vivo studies on A549 xenograft showed increased tumor regression accompanied by reduced adverse effects and toxicity [309]. Some other relevant examples are summarized in Table 2.

\subsubsection{Nano-biocarriers in Phototherapy}

Wang et al. have developed a novel nano-biohybrid for enhanced phototherapy of lung cancer. The research group developed a biomimetic nanoreactor with synergistic cascade starvation property and imaging ability at $980 \mathrm{~nm}$ radiation. The nanoreactor composed of polyacrylic acidn-octylamine (PAAO) micelles-encapsulating NaYF4: Yb, Tm upconversion nanoparticles (UCNPs)-surface-modified using cancer cell membranes, i.e., (PAAO-UCNPs- $\mathrm{GO}_{\mathrm{x}}$ ), was employed for homotypic cancer cell targeting. Cancer starvation was initiated through glucose oxidase (GO) catalysis that causes glucose breakdown, while the anticancer activity was promoted by the photolysis of hydrogen peroxide to hydroxyl radical. The PAAO-UCNPs- $\mathrm{GO}_{\mathrm{x}}$ were observed to emit photons of $470 \mathrm{~nm}$ on being irradiated by $980 \mathrm{~nm}$ laser, which facilitated deep tissue photothermal therapy in the hypoxic tumor milieu. Furthermore, the fluorescent emission of $800 \mathrm{~nm}$ generated by the nanoreactor facilitated image-guided therapeutic monitoring. The in vitro and in vivo anticancer efficiency of this formulation was validated employing a 4T1 cell-induced metastatic lung cancer model (Fig. 5). The research findings affirm the developed biomimetic nanoreactor to be an efficient, smart, and simple approach for multimodal oncotherapy [310].

Yet another instance of the application of nano-biohybrid in phototherapy was available in the research work of Ouyang et al. They developed a nano-biohybrid composed of mesenchymal stem cell (MSCs) encapsulating the Chlorin e6 (Ce6)-conjugated polydopamine nanoparticles (PD-Ce6) for photodynamic (PD) and photothermal therapy (PT) of lung metastatic melanoma. The MSC-mediated phototherapy was facilitated by the 'Trojan-horse' like transit between the cancer cells and the MSCs, characterized by an interplay of endocytosis-exocytosis and re-endocytosis in addition to high tumor penetration and high tumor homing capability. The bio-nanocarriers exhibit no overt toxicity to the MSCs while being highly cytotoxic to the cancer cells. The highly selective cytotoxicity can be achieved after being triggered by NIR for inducing the PD/PT mechanisms. About $60 \%$ release of the phototherapeutic agents was observed after $72 \mathrm{~h}$ of MSC-PD-Ce6 bio-nanocarriers administration. In vivo evaluations in B16-F10 melanoma, cell-induced metastatic mice model displayed excellent anticancer activity, as apparent from the reduced number of metastatic colonies and survival rates in the animals treated with MSC-PD-Ce6 bio-nanocarriers as compared to the simple PDS-C6-based therapy [311].

Cao et al. developed a novel nano-biohybrid composed of the mesenchymal stem cells (MSCs) encapsulating the Ce6conjugated manganese dioxide $\left(\mathrm{MnO}_{2}\right)$ nanoparticles. $\mathrm{MnO}_{2}$ is an excellent oxygen-producing substrate, employed in the design of antitumoral nanomedicine to respond to hypoxic and acidic $\mathrm{pH}$-stimuli. The $\mathrm{MnO}_{2}-\mathrm{Ce} 6$ were formed by physical adsorption of the $\mathrm{Ce} 6$ moiety to the $\mathrm{MnO}_{2}$ nanoparticles to increase the systemic circulation. The MSCs bound to the $\mathrm{MnO}_{2}-\mathrm{Ce} 6$ increased the cell uptake significantly while reducing the non-target toxicity. $\mathrm{MnO}_{2}$ released from the $\mathrm{MnO}_{2}-\mathrm{Ce} 6$ nano-biohybrid catalyzed the reactions that consume the abnormal cancer cell metabolic products like protons $\left(\mathrm{H}^{+}\right)$and hydrogen peroxide $\left(\mathrm{H}_{2} \mathrm{O}_{2}\right)$. Consequent formation of $\mathrm{O}_{2}$ resourced the formation of ${ }^{1} \mathrm{O}_{2}$ upon being irradiated by $633 \mathrm{~nm}$ laser light, thereby incapacitating 
(i)
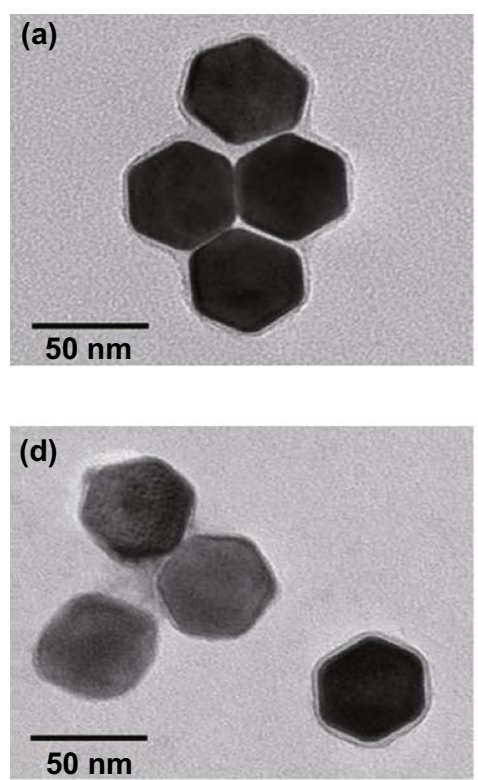

(b)

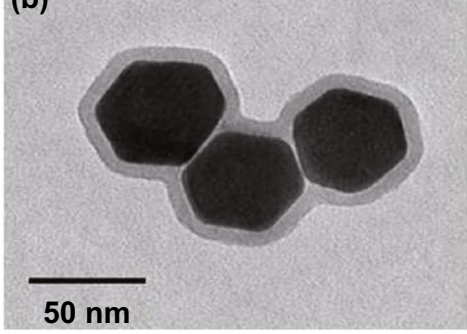

(c)

(e)

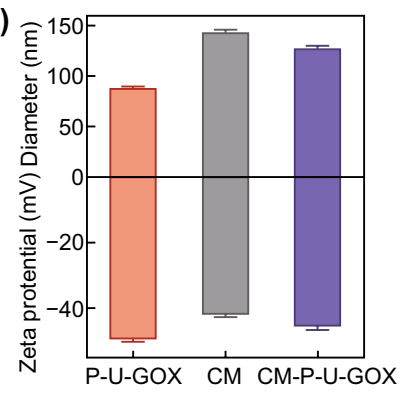

(ii)
RBC-P-U-GOX
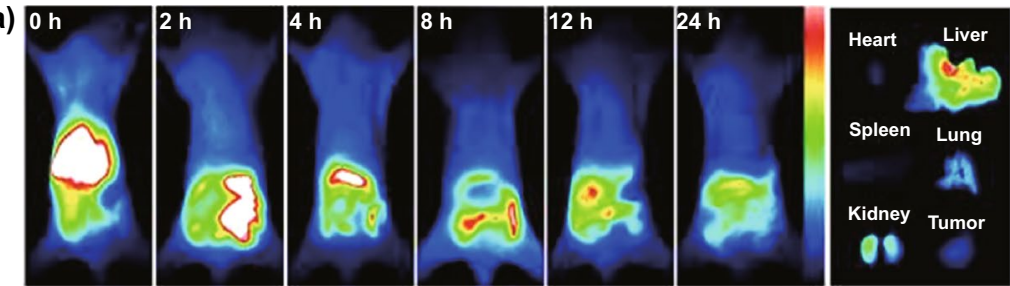

CM-P-U-GOX
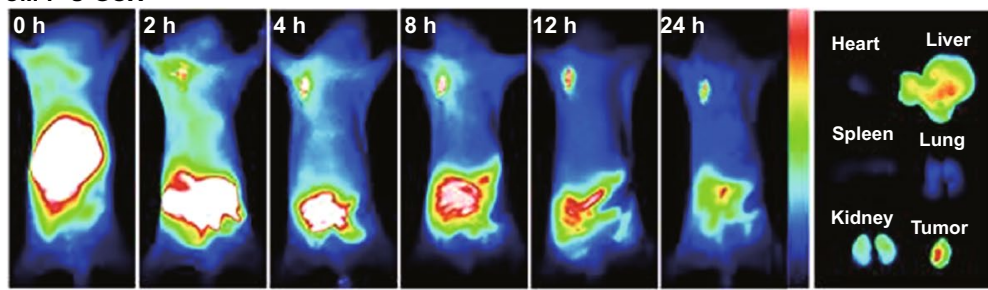

(c)
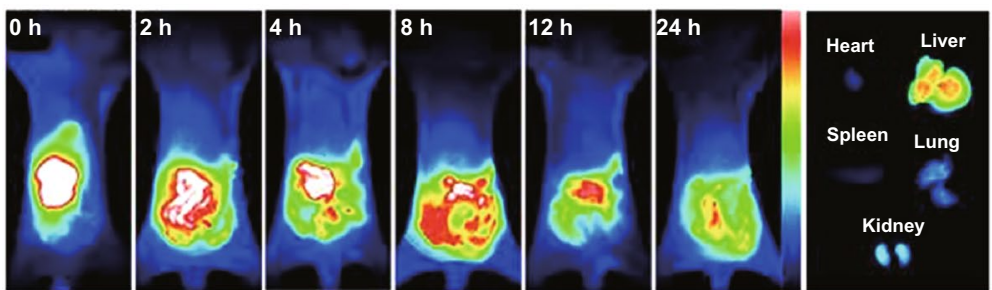

CM-P-U-GOX
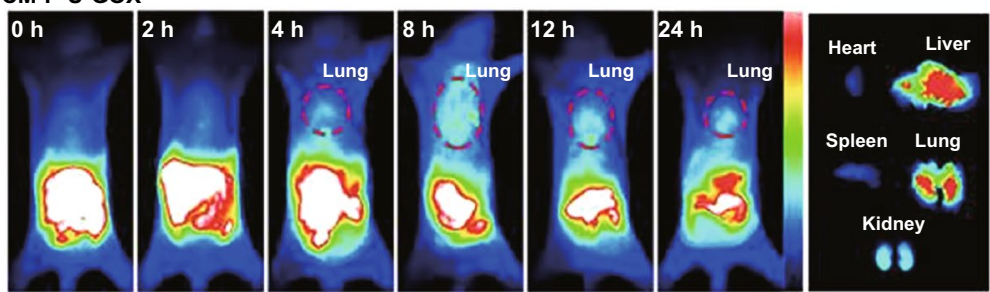
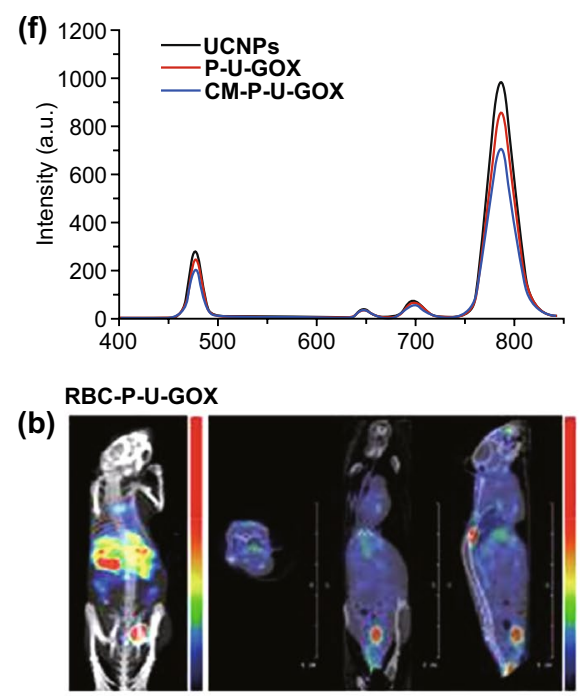

CM-P-U-GOX

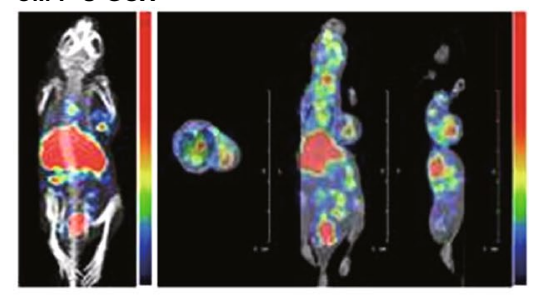

RBC-P-U-GOX

(d)

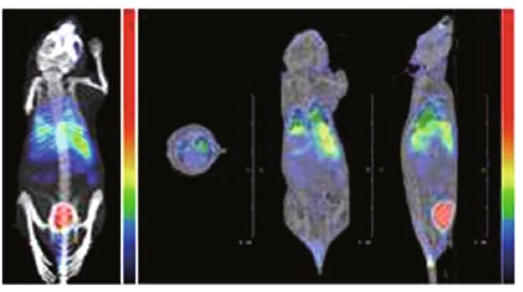

CM-P-U-GOX

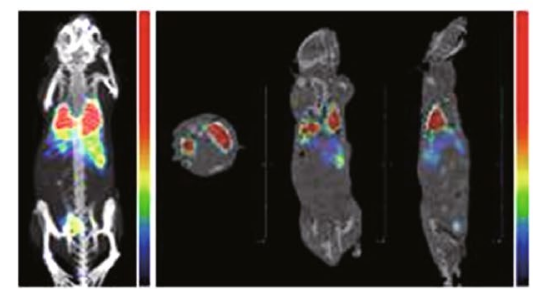


\Fig. 5 (i) TEM microphotographs of a PAAO-UCNPs-GOx, b CMPAAO-UCNPs-2 GOx, c CM-PAAO3-UCNPs-GOx+ pH6.5 buffer solution for $30 \mathrm{~min}$, d CM-PAAO-UCNPs-GOx + pH6.5 buffer solution for $2 \mathrm{~h}$, e hydrodynamic particle sizes and electrokinetic potentials of PAAO-UCNPs-GOx, cell membrane, and CM-PAAOUCNPs-GOx, $\mathbf{f}$ emission spectra of UCNPs, PAAO-UCNPs-GOx and CM-PAAO-UCNPs-GOx upon $980 \mathrm{~nm}$ irradiation. (ii) In vivo homotypic tumor targeting 4T1 tumor bearing mice after being administered ${ }^{125}$ I-CM-PAAO, UCNPs-GOx and ${ }^{125}$ I-RBC-PAAO-UCNPsGOx. a fluorescence images, $\mathbf{b}$ nuclide images, $\mathbf{c}$ fluorescence images of 4T1-lung metastasis, and $\mathbf{d}$ nuclide images of 4T1-lung metastasis mice. Adapted from Ref. [310] with permission from Elsevier, Copyright 2020

the hypoxic constraint of photodynamic therapy (PDT) for effective antitumor therapy. $\mathrm{MnO}_{2}$ decomposition to $\mathrm{Mn}^{2+}$ representing high $\mathrm{T} 1$ relaxivity in the MRI region, followed by its hepatic metabolism and renal excretion. The $\mathrm{Mn}^{2+}$ may greatly facilitate the direct MRI imaging of MSCs and tumor microenvironment (TME), providing a theranostic advantage. The in vivo evaluation in a xenograft mice model of LLC revealed higher survival rates, apoptosis, and tumor cell death in the animals receiving phototherapy with MSCs- $\mathrm{MnO}_{2}-\mathrm{Ce} 6$ as compared to the phototherapy with $\mathrm{MnO}_{2}-\mathrm{Ce} 6$ groups, indicating high anticancer activity. The MSCs- $\mathrm{MnO}_{2}-\mathrm{Ce} 6$ besides being highly biocompatible and biodegradable had no significant systemic toxicity. Some other relevant examples from this category of anticancer activity are discussed in Table 3 [312].

\subsubsection{Nano-biocarriers in Immunotherapy}

Chiang et al. formulated a fucoidan-based magnetic nanobiohybrid for tumor-targeted immunotherapy of checkpoint inhibitors. Despite the remarkable clinical success, anti-PD1 inhibitors are ineffective in a subset of patients with compromised immunity and have immunotoxicity constraints. Novel bio-nanocarriers composed of magnetic nanoparticles and fucoidan-dextran (IO- FuDex3) conjugated to T-cell activators (anti-CD28 and anti-CD3) or checkpoint inhibitors (anti-PD-L1) were developed and evaluated for their efficacy in lung cancer. The IOFuDex3-nano-biohybrid had an immuno-restorative effect in the immunocompromised patients, mediated by tumorinfiltrating lymphocytes, and tumor targeting was achieved using the external magnetic drive. The nano-biohybridbased immunotherapy (at dose $<1 \%$ ) was observed to extend the median survival of animals from 32 to 63 days, with low systemic toxicity in a 4T1-metastatic model of lung carcinoma [313].

Granzyme B is a natural serine protease, secreted by the natural killer cells and cytotoxic T cells. Despite being a highly effective anticancer agent, such peptides lack biostability and have low cellular permeability, which desists their therapeutic effectiveness. Yang et al. developed reduction-responsive polymerosomes loaded with Granzyme B for immunotherapy of lung cancer. The polymerosomes were surface-functionalized with cell-penetrating peptides to facilitate targeted intracellular delivery of the enzyme. The polymerosomes were reported to have a particle size of 82-90 $\mathrm{nm}$, reduction-sensitive drug release property, high cellular internalization, and cytoplasm-specific protein release in the A549 cells. The FITC-labeled cytochrome C-mediated model protein analysis of the developed polymerosomes depicted protein loading of $\sim 17.2 \% \mathrm{w} / \mathrm{w}$. The cell line studies of the polymerosomes on A549 cells demonstrated high anticancer activity (IC50 of $20.7 \mathrm{nM}$ ) and high cell-penetrating ability. In vivo evaluation in orthotopic A549-Luc pulmonary tumor-bearing nude murine model demonstrated tumor inhibition in the treatment groups receiving granzyme $\mathrm{B}$-polymerosomes at a dose equivalent to $2.88 \mathrm{nmol} \mathrm{kg}^{-1} \mathrm{GrB}$. This was accompanied by significantly increase survival rates over the non-targeted and untreated disease control groups, suggesting this approach to be an effective immunotherapeutic modality.

Immuno-liposomes are a well-known class of nano-biohybrid with multiple oncological applications. Repic et al. developed immunoliposomes, with antibody fragment (Fab) targeted to lung cancer-specific antigen. While covalent coupling is used for the conventional conjugation method of antibody fragments, these novel immunoliposomes were formulated employing a novel formulation strategy that obviated the use of cross-linking agents. For precise conversion of the MAbs to recombinant antibody fragments, P. pastoris. P. pastoris were employed as hosts. The C-terminal of the recombinant $\mathrm{Fab}$ antibody fragment was fused to a peptide derived from pulmonary surfactant protein $\mathrm{D}$ and incorporated into the liposomal bilayer to fabricate the immunoliposome. The immunoliposomes containing the CD59 and CD48 FAbs were thus observed to have dual specificity. The Fab-labelled immunoliposomes were demonstrated to target the antigen-positive cells with great affinity and specificity [314]. The multimodal platform can be employed for the targeted delivery of several therapeutic and imaging agents 
to the cells overexpressing the receptors for these antibodies, like lung cancer [315]. Some other examples of nanobiohybrid-based immunotherapeutics that have been applied in lung cancer are discussed in Table 3.

\subsubsection{Nano-biocarriers in Gene/Epigenetic Therapy}

Numerous bio-nanocarriers have been researched extensively for facilitating gene delivery. It has been well established that the replenishment of the downregulated miR-660 gene has the potential to inhibit the proliferation of lung cancer cells through the restoration of the MDM2-P53 axis. However, the administration of the miRNA has been a challenging task owing to the poor in vivo bioavailability issues. Moro et al. formulated bio-nanocarriers composed of cationic lipid 1, 2-biology-1-3- tri-methylammonium propane (DOTAP) to facilitate targeted delivery of miR-660 gene to lung cancer cells while increasing its bioavailability. In vivo experiments, tumorigenesis was induced in the SCID mice using P53 wild-type patient-derived xenografts (PdX). Upon biweekly administration at a dose of $\left(1.5 \mathrm{mg} \mathrm{kg}^{-1}\right)$ for four weeks, a significant reduction in tumor growth was observed amongst the SCID mice expressing two different P53 with no systemic toxicity. Significant inhibition of the MDM2 and restoration of the P53-downstream signaling pathway were observed in the animal groups receiving the cationic liposomal formulation, suggesting potential anticancer activity. Moreover, the metastatic potential of the $\mathrm{H}-460$ cell was reported to be greatly disrupted by stable bioexpression of the miRNA cells [316].

The inhalational route of administration has gained incredible attention from the researchers to facilitate the localized treatment of numerous morbidities including lung cancer. However, due to the challenges associated with the inhalational delivery of the genes, the search for novel vectors that can effectively and safely deliver the genetic cargo has not ended [317]. Also, targeted delivery to the lung is a challenging task owing to the high perfusion rate, which disfavors the localization of the nanoparticles therein. To address these issues, Yunfeng Yan developed polyester bio-nanocarriers for aerosolized delivery of siRNA to lung tumors. Out of 540 members scrutinized from the functionalized polyester library, PE4K-A13-0.33C6 and PE4K-A13$0.33 \mathrm{C} 10$ were found suitable for the delivery of siLUC-targeted siRNA to the lungs, through the formation of stable nano-biohybrid, 'polyplexes'. The serum stability of these polyplexes was improved by employing Pluronic F-127 or PEG 2000 DMG to reduce their surface charge. The polyplexes were reported to be endocytosed by the A549-Luc cells within $4 \mathrm{~h}$ of administration. Upon aerosolized delivery in mice with orthotopic lung tumors, the polyplexes were observed to undergo selective biodistribution and targeting, resulting in effective gene silencing in the tumor cells [318].

Elwakil et al. developed bio-nanocarriers with GALApeptide-functionalized nanoparticles composed of $\mathrm{pH}$-sensitive lipids for delivering siRNA that prevents metastatic dissemination of lung cancer. Besides serving as a lipid matrix, the $\mathrm{pH}$-sensitive lipid (YSK05) also effectively caused gene silencing, and GALA (a peptide with 31 amino acids) facilitated the endosomal escape. The developed nano-biocarrier was found to be 40 -fold more efficient in inducing gene silencing and higher anti-metastatic potential than the formerly developed membrane-based nanodevice. Effective gene silencing was observed at $0.01 \mathrm{mg}$ siRNA $/ \mathrm{kg}$ dose, with no reports of other non-targeted toxicity [319].

The research work by Merckx et al. exemplifies how the endogenous surfactant protein $b$ may augment the inhalational delivery of siRNA-encapsulated proteolipid-layered nanogels. Led by the promising results obtained with bionanocarriers composed of the Curosurf $\AA$, the researchers identified major constitutional components contributing to an improvement in the particle biostability and facilitating in vitro and in vivo siRNA delivery. Wherein, surfactant protein B (SPB) reconstituted in proteolipid-coated nanocomposite/nanogels was identified to be one of the most potent delivery aid (Fig. 6). An effective anticancer activity with no systemic cytotoxicity was observed on their in vitro and in vivo evaluations. Cancer-associated macrophages can also be targeted by employing this novel nano-biohybrid, presenting a novel and extremely useful tool for effective targeting to lung cancer via the inhalational route of administration [320].

\subsubsection{Nano-biocarriers in Radiotherapy}

Radiation therapy is one of the most important oncology modalities. In patients with radio-resistant oncological cell populations, various nanoparticle-mediated radiosensitization strategies have materialized to be a useful therapeutic aid [321]. 
While PLK1 inhibition has been well established to sensitize the cancer cells to radiation via mitotic regulation, EGFR is reported to be an arbitrator of DNA repair and is upregulated in $\sim 50 \%$ of pulmonary carcinoma patients. Based on these facts, Reda et al. developed a novel nanobiohybrid for radiosensitization of the non-small cell lung cancer cells (NSCLC). For optimizing the synergy of radiotherapy and targeted delivery, the research group devised cetuximab-conjugated nanoparticles, encapsulating siRNAdirected against polo-like kinase 1 (PLK1). Thus, formulated bio-nanocarriers (C@siPLK1-NH) were reported to effectively target the EFGR-positive A549 cells, causing apoptosis by G2/M cell cycle arrest. The C@siPLK1-NH were observed to have excellent translational potential in an orthotopic murine model of lung cancer, which manifested as reduced tumor proliferation and prolonged survival rates (Fig. 7). Similar anticancer synergy with radiation therapy was observed in breast cancer and colorectal cancer also [322].

In another instance, Travis et al. developed a nano-biohybrid of gold nanoparticles, surface-modified with cilengitide (a linear/cyclic RGDfV pentapeptide sequence targeted to $\alpha v \beta 3$ integrin receptor) to cause radiation sensitization. The radiosensitization capacity of developed nanoparticles and the $137 \mathrm{Cs}$ irradiation was evaluated by clonogenic assay on $\alpha v \beta 3$-overexpressing tumor cells like H460, HUVEC, and MCF7. The developed nano-biohybrid was observed to induce the dose enhancement factors (DFs) significantly, which was insignificant in the treatment groups receiving radiation therapy alone and the groups treated with radiation and unconjugated gold nanoparticles. Moreover, it was concluded from the observations of the DFs that cyclized RGDfV pentapeptides had higher radiosensitization capability as compared to its linear counterpart and the radiosensitization efficacy bio-nanocarriers was almost equivalent to the radiation therapy with cilengitide [323].

\subsubsection{Nano-biocarriers in Combination Therapy}

Combination oncotherapy has recently emerged as one of the most feasible therapeutic approaches to tackle complex diseases like cancer. A combination of different therapeutic modalities has led to a paradigm shift in oncology [292].

A unique therapeutic approach, combining the targeting ability of natural cancer cell membrane with the photothermal property of plasmonic gold nanorods and cytotoxic effect of $\beta$-Lapachone $(\beta-\mathrm{LN})$, was adopted by Marangoni et al. for the treatment of lung cancer. $\beta$-LN is a pro-drug like an anticancer agent that is activated by $\mathrm{NADP}(\mathrm{H})$ : quinine oxidoreductase enzyme, that is intrinsically produced by the cancer cells of solid tumors like lung cancer. Plasmonic nanorods have been established to exhibit excellent photothermal activity upon IR irradiation. This research was undertaken to assemble the advantages of both these therapeutic modalities by fabrication of a multifunctional nano-biohybrid, composed of lung cancer cell (A549)-derived membrane co-loaded with PEGylated plasmonic gold nanorods and $\beta$-LN. The system exhibited NIR-triggered release of both the payloads from the cancer cell membrane vesicle. The developed nano-biohybrid demonstrated high in vitro cytotoxicity. In vivo histopathological examination of tumors in cancer-induced animals treated with the nanohybrid revealed excellent antineoplastic potential as compared to the groups receiving only radiation therapy [324].

Bio-nanocarriers combining chemotherapy and gene therapy were developed by $\mathrm{Li}$ et al. to combine the anti-angiogenic activity of vascular endothelial growth factor (VEGF)siRNA with anticancer activity of etoposide (ET) for the treatment of metastatic and malignant forms of lung cancer. The nano-biohybrid constructs are designed using the cationic liposomes co-loaded with (VEGF)-siRNA and ET, enveloped with PEGylated histidine-grafted chitosan-lipoic acid polymer. The developed nano-biohybrid exhibited an excellent tumor penetration and high cellular endocytosis in addition to the $\mathrm{pH}$-triggered release of the siVEGF and ET in an orthotopic mice model of NSCLC. The anticancer and antimetastatic potential of the nano-biohybrid is clear from the in vivo data that supports its high tumor growth suppression and antimetastatic potential [325].

Song et al. have developed bio-nanocarriers to facilitate combination therapy (photodynamic therapy and immunotherapy) for the effective treatment of metastatic lung cancer. Photosensitizer protoporphyrin IX (PIX) was conjugated to a chimeric peptide C16-K(PpIX)-PEG8-KDEVD-1MT (MT) (immune checkpoint inhibitor) via caspase-responsive peptide Asp-Glu-Val-Asp for developing nanoparticles by self-assembling upon dispersion in PBS. The nano-biohybrid thus developed had a high EPR effect and potent antitumor activity. The antitumor activity was mediated by 
(i)
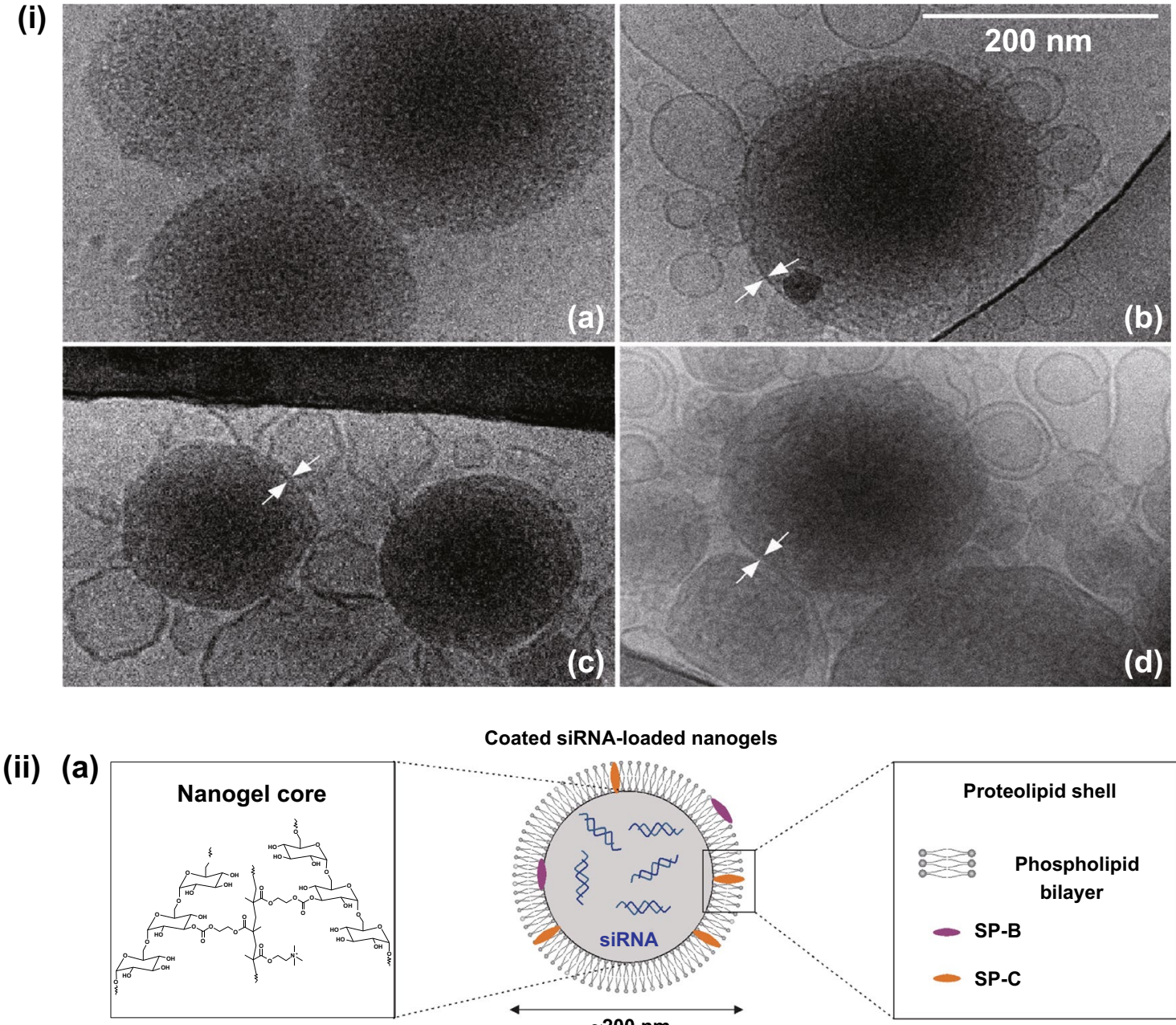

Coated siRNA-loaded nanogels
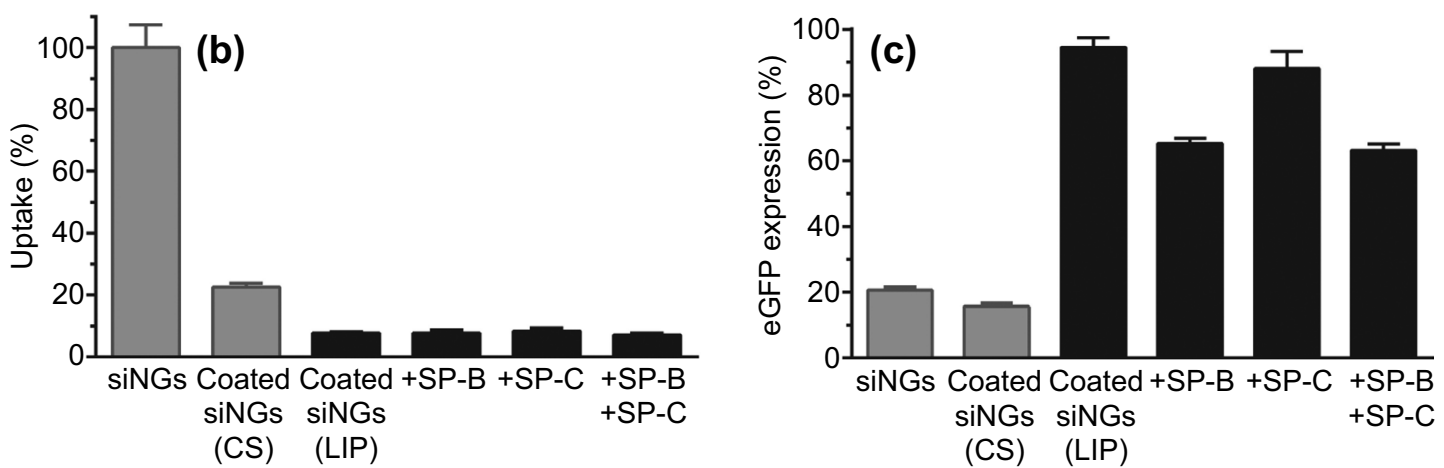

Fig. 6 (i) Cryo-TEM microimages of different nanoformulations: a uncoated, b Curosurf® coated. c DPPC:eggPG:SP-B-coated, and d DOPC:eggPG:SP-B-coated siRNA-loaded nanogels (siNGs). (ii) Proteolipid shell over the siNG core is depicted by white arrows. a Illustration of (proteo)lipid-coated siRNA-loaded nanogels (siNGs), b comparative cell uptake, and c gene silencing capacity of (siNGs) in H1299_eGFP cells determined employing flow cytometry. The siNGs were layered using DPPC:POPC:eggPG (50:35:15 wt\%; the coated siNGs (LIP) and Curosurf® (coated siNGs (CS)) or in this LIP outer layer, SP-B (0.4 wt\%) and/or SP-C (0.7 wt\%) was incorporated. For cell uptake studies, the siRNA (siCy5) was tagged with fluorescent dye and their formulations wherein significant eGFP-targeting siRNA (siEGFP) normalization was observed as compared to EGF expression in animals treated with control siRNA (siCTRL). Adapted with permission from Ref. [320] with permission from Elsevier, Copyright 2018 
(a)

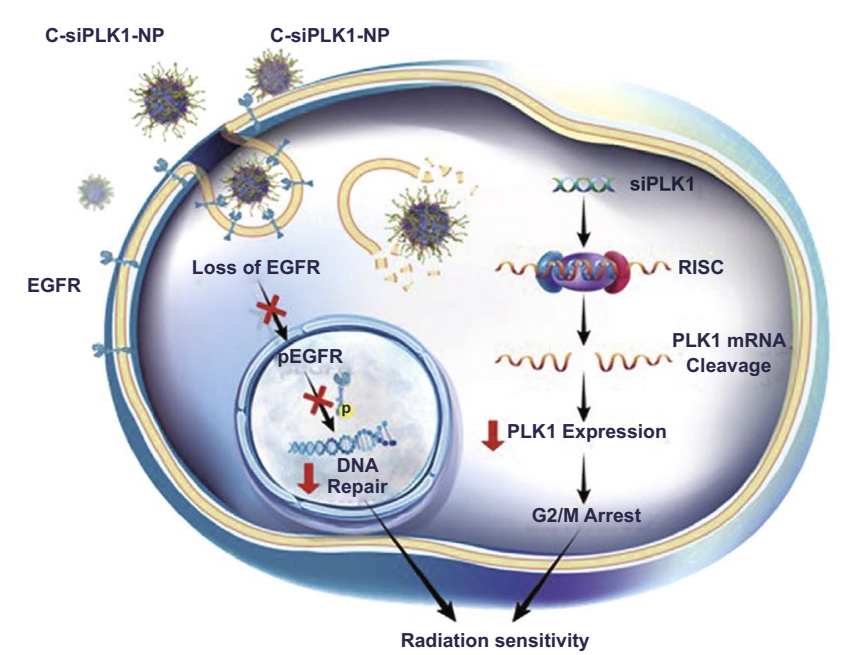

(b)

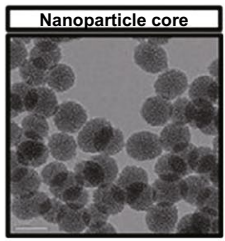

(c)

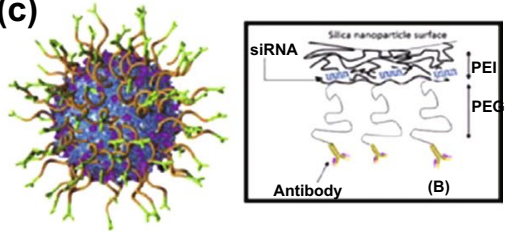

(d) 20 Size Distribution by Intensity

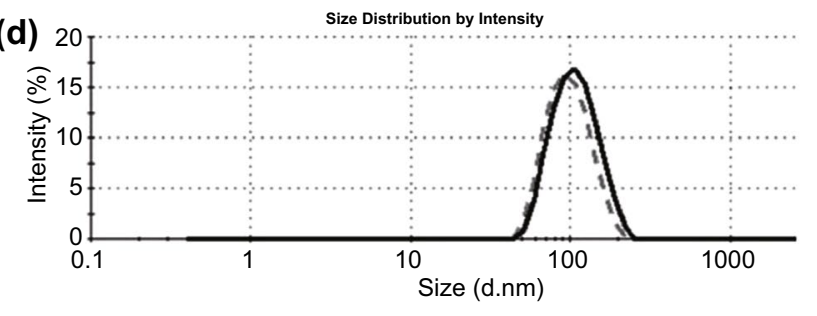

(e)

\begin{tabular}{|c|c|c|c|c|c|c|c|}
\hline \multirow{2}{*}{$\begin{array}{l}\text { MSNP size } \\
\quad(\mathrm{nm})\end{array}$} & \multicolumn{2}{|c|}{$\begin{array}{l}\text { Hydrodynamic size with } \\
\text { modifications }\end{array}$} & \multirow{2}{*}{$\begin{array}{c}\text { Zeta } \\
\text { potential } \\
(\mathrm{mV})\end{array}$} & \multicolumn{2}{|c|}{ TGA } & \multirow{2}{*}{$\begin{array}{c}\text { BCA } \\
\text { \%antibody/ } \\
\text { MSNP }\end{array}$} & \multirow{2}{*}{$\begin{array}{l}\text { complete siRNA } \\
\text { loading }\end{array}$} \\
\hline & Size (nm) & PDI & & \%PEI & \%PEG & & \\
\hline $61.7 \pm 2.0$ & $115.8 \pm 6.9$ & $0.23 \pm 0.04$ & $13.4 \pm 0.7$ & $15 \%$ & $10 \%$ & 2.7 & 2-4 wt.\% \\
\hline
\end{tabular}
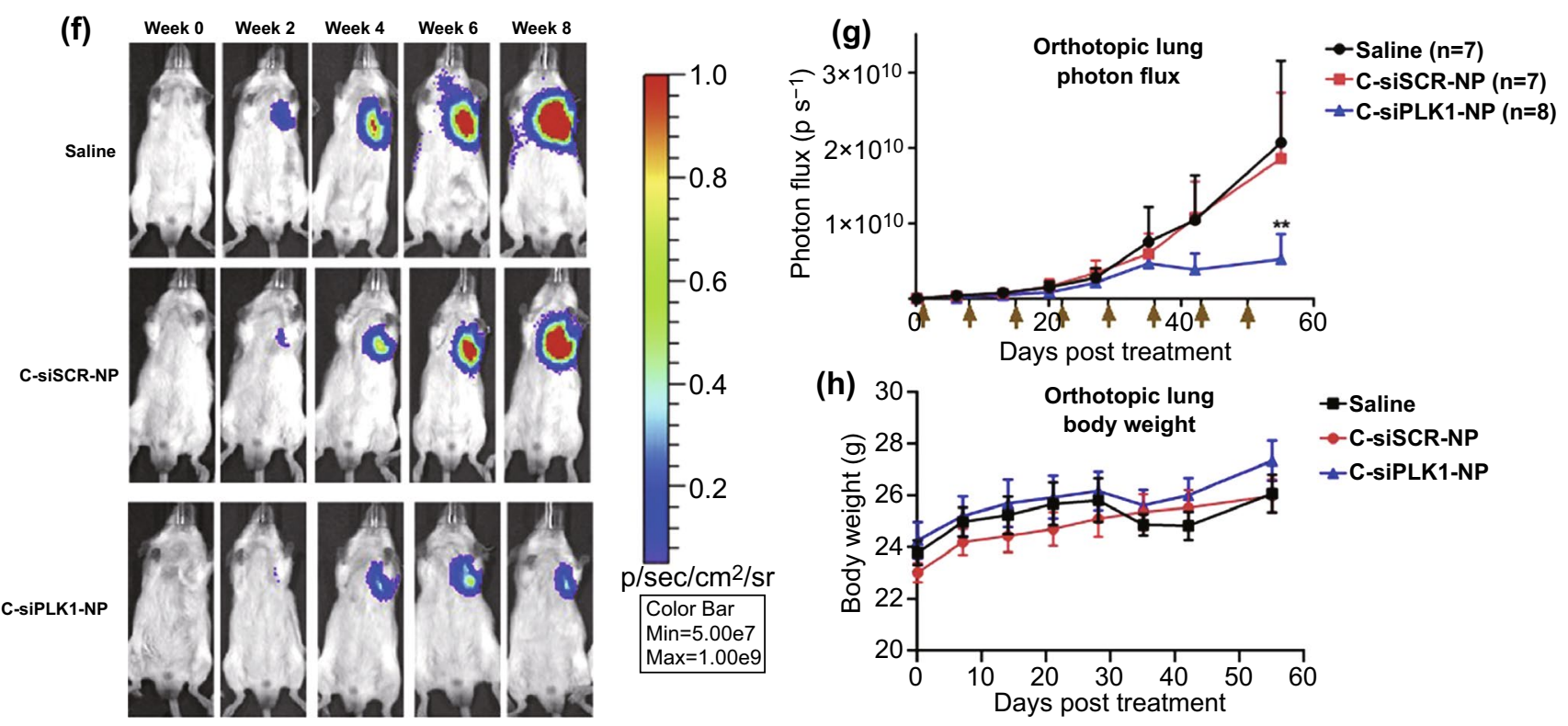

Fig. 7 Cetuximab-conjugated mesoporous silica nanoparticles (MNP) loaded with PLK1 siRNA (siPLK1) or C-siPLK1 for EGFR-targeted delivery. a radiosensitization strategy with combined EGFR antibody and siPLK1-nanoparticles. The C-siPLK1-NPs bind to EGFR receptors and are endocytosed to result in loss of EGFR and phosphorylated EGFR to initiate DNA repair, while reducing DNA damage due to radiation and releasing the siPLK1 to cytosol. The siPLK1 reduces the PLK1 protein expression and arrests cell arrest at G2/M, thereby sensitizing the cells to radiation damage. b TEM microscopic images of 50-nm MNPs. c Layer-by-layer surface-conjugated nanoparticles. d Hydrodynamic diameter of C-NP (solid lines) and without siRNA(dotted lines). e Particle size, zeta potential and other characteristics like drug loading and antibody conjugation of C-siRNA-NPs expressed as mean \pm SD. $\mathbf{f}$ IVIS imaging in orthotopic lung tumor-induced mice after being treated with C-siPLK1-NP, C-siSCR-NP, or saline. $\mathbf{g}$ Tumor growth determined using photon flux in prone and supine position of the treated mice $(n=7-8)$. Arrows indicating days of treatment. $(\mathrm{H})$ Body weight of mice post-therapy. Adapted from Ref. [322] with permission from Elsevier, Copyright 2019 
ROS production at $630 \mathrm{~nm}$ on NIR irradiation and caspase3-mediated intratumoral release of MT, thereby evoking an intense CD8+ T cell-induced immune response in lung cancer cells. The strategy was reported to inhibit growth as well as metastasis of lung cancer cells and can be foreseen as a potential clinical-oncotherapy candidate [326].

\subsubsection{Novel Nano-biocarrier-Based Anticancer Therapy}

Some recent and noteworthy examples of bio-nanocarriers, used for targeted delivery of novel categories of anticancer agents to lung cancer, have been discussed in this section. Liu et al. developed graphene oxide (GNO) nanocomposites functionalized with polysaccharide for targeted delivery of a novel anticancer agent SNX-2112 (Hsp90 inhibitor) to lung tumors. The unique physicochemical characteristics of the GNO make them an attractive material for constructing nanocarriers. Surface modification of the GNO-based nanocomposites with polysaccharides like chitosan $(\mathrm{CH})$ and hyaluronic acid (HA) greatly improves its biocompatibility, while targeting the payload to the CD44 positive tumor cells (GNO@CH-HA). SNX-2112 was thereafter loaded in the GNO@CH-HA. SNX-2112 was released at a higher amount and release rate in acidic tumor conditions, conferring an additional TME-targeted property. While being highly cytotoxic to A549 cells, the SNX-2112-loaded GNO@CH-HA nanocomposites showed no cytotoxicity on erythrocytes or normal human bronchial epithelial cells. In vivo toxicity evaluation in Sprague-Dawley rats showed a short-term inflammatory response, but no long-term injury was witnessed. The novel nanocomposite was concluded to be a safe and effective means of targeted onco-therapy [327].

In another instance, Yokoyama et al. developed a nanobiohybrid targeted to EGFR for synergistic anticancer activity through induction of apoptosis and autophagy. To develop a highly targeted formulation, plasmonic magnetic nanoparticles (PMNs) were surface-functionalized with anti-EGFR antibody (Clone 225) that target the NSCLC cells with great selectivity (Fig. 8). Thus, developed C225-PMNs were observed to inhibit the EGFR-transduction pathway and high cytotoxicity in the EGFR-positive cells, while not affecting EGFR-negative cells [328]. Other few examples that can be considered under this category are discussed in Table 3.

Despite promising preclinical results, the clinical transformation of these formulations remains questionable due to the challenges associated with their active targeting ability. Due to large hydrodynamic sizes, multi-functionality, non-specific immune interactions, 'on target but off the site' response, low bio-stability and difficult nanoparticle conjugation, the efficacy of antibodies and proteins for functionalization is dubious. While the antibody fragments and peptides reduce the size to facilitate their conjugation to the surface of the nanoparticles, their efficacy is challenged by nonspecific biological interactions and peptide geometry. Aptamers have low circulation stability and are prone to degradation by nucleases that are non-specifically attached over the surface of nanoparticles. Small molecules, despite being effective, have a high cost for personalization and targeting. Receptor-negative cell population, genetic mutations, and high inter- and intra-patient diversity play an important role in determining their effectiveness. Moreover, most of the above-stated approaches may be unfeasible to be devised with precision at a large scale [101]. Employing bionanotechnology-based approaches to devise natural and semisynthetic bioinspired/bioderived bio-nanocarriers may help overcome the majority of these challenges while reinforcing their targeting ability [15]. However, the novel approach is still under reappraisal and demands extensive efforts to bring the concept to reality.

\subsection{Nanobiotheranostics in Lung Cancer}

The term 'nanobiotheranostics' refers to a unified diagnostic and therapeutic application of a single agent. Theranostics not only facilitates concurrent diagnostic and therapeutic aspects but also facilitates image-guided drug delivery and therapeutic drug monitoring. While nanotechnology has significantly contributed to advance this field, bionanotechnology-derived tools are being explored to overcome the limitations of the former. The majority of the nano-biotheranostics that have been employed till now include the inorganic nanoparticles, nanocages, nanoshells, nanoclusters, and metallo-organic frameworks composed of gold, silver, iron nanoparticles, silica, liposomes, dendrimers, micelles, and other bio-polymers conjugated to the bio-molecular ligands. However, with advancing bionanotechnology, several bioinspired bio-nanocarriers such as nanobots and cellderived nano-biocarriers have emerged [4]. Several virusbased, protein-based, and apoferritin nano-biocarriers that have been explored for their theranostic applications in lung 
(a)

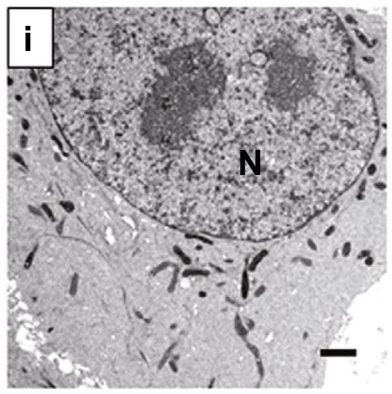

Cont. $(\times 5000)$

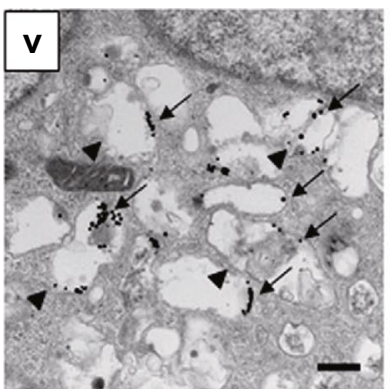

C225-NP $(\times 25000)$

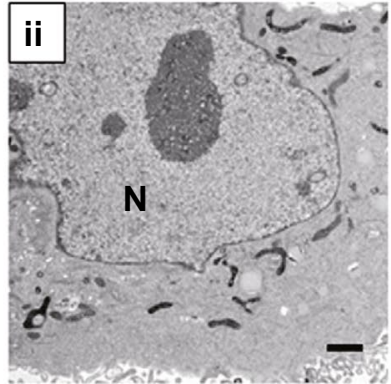

$\mathrm{C} 225 \mathrm{Ab}(\times 5000)$

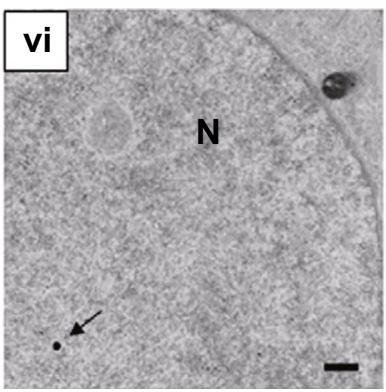

C225-NP $(\times 25000)$

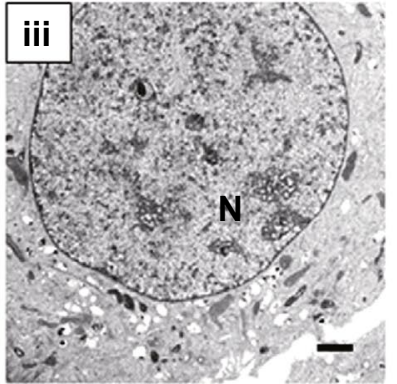

IgG-NP $(\times 5000)$

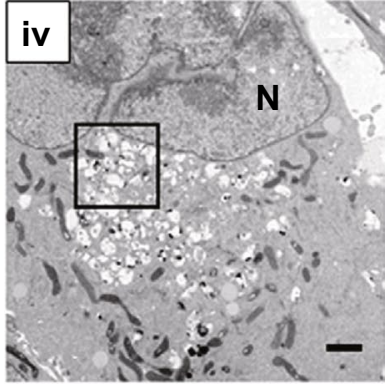

C225-NP $(\times 5000)$

vii

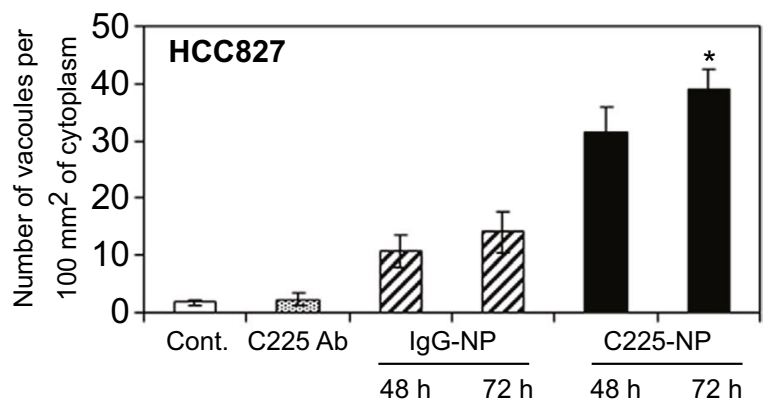

(b)
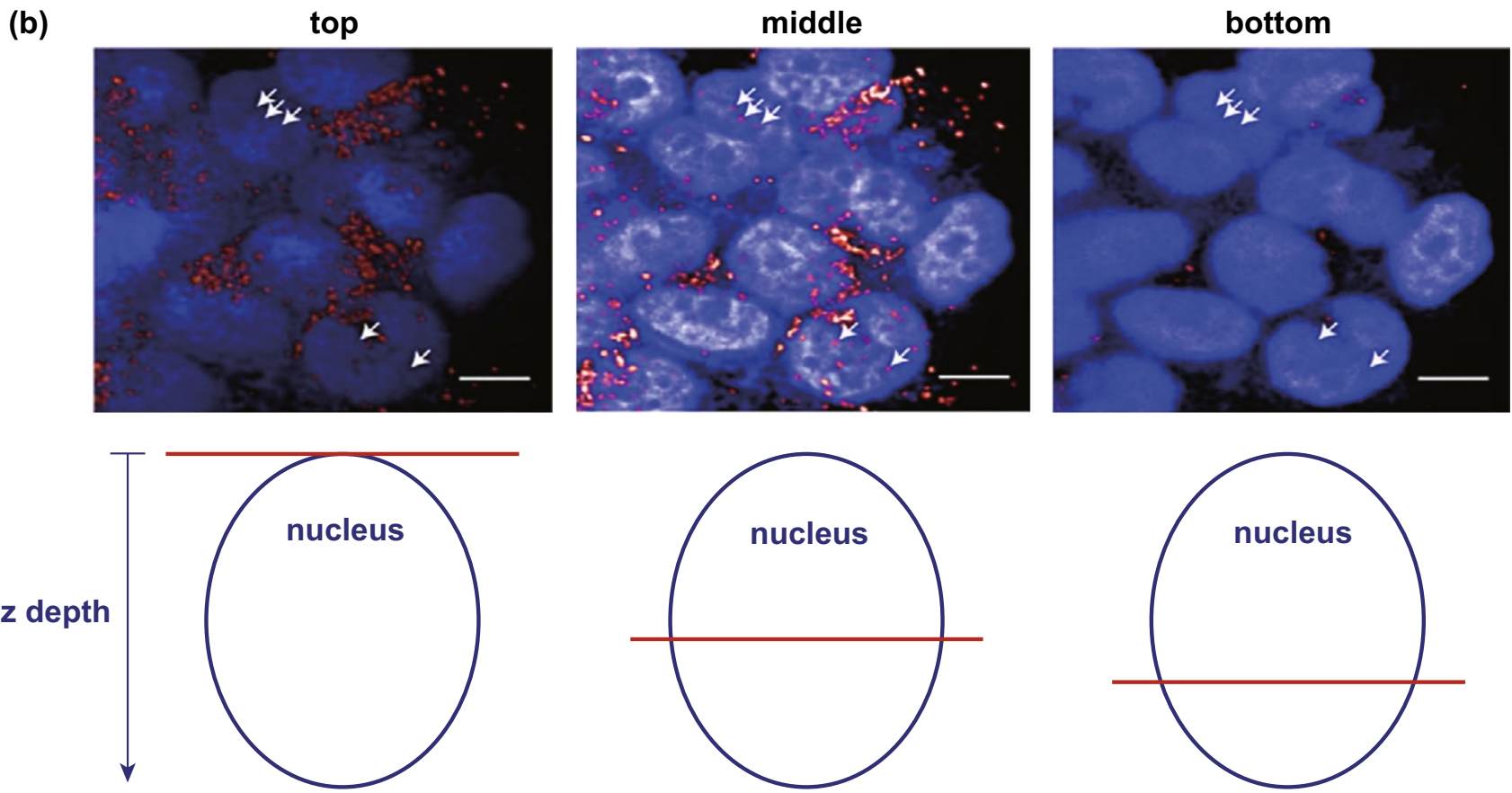

Fig. 8 a In situ localization of C225-NP in the NSCLC cells. Electron micrographs presenting the ultrastructure of a cell, including the nucleus (n), of HCC827 cells treated with $0.065 \mathrm{mg} / \mathrm{ml}$ of C225 antibody, IgG-NP, or 0.661010 particles of C225-NP for $72 \mathrm{~h}$. (i) Non-treated cells, (ii) C225 antibody-treated cells, (iii) IgG-NP-treated cells, (iv) C225-NP-treated cells, (v) a magnified view of the area boxed in (iv). The arrow indicates C225-NP, and the arrowhead indicates autophagosomes of including residual material and NP in the cytosol and C225-NP inside the nucleus. Arrow indicates NP in the nucleus. Scale bar $=1 \mathrm{~mm}$. (vii) number of vacuoles per $\mu \mathrm{m}^{3}$ of cytoplasm after 48 and $72 \mathrm{~h} * P$ value, 0.05 vs control, C225 antibody and IgG-NP. b Confocal microscopy images of C225-NPs localized in the nucleus (top panel), where nuclei have been stained with DAPI dye and C225-NP localization can be marked in red. A specific area of $x y$ plane of the nucleus at locations above or below the nucleus is denoted by the arrows indicating middle, top and bottom, respectively, whereas the Z-position of image within the nucleus is indicated by the sketch in the lower panel, wherein the red horizontal line represents the depth within nucleus from where the cross sectioning was made, Scale bar $=10 \mu \mathrm{m}$. Adapted from Ref. [328] under the terms of Creative Commons Attribution License as permitted by PLoS One, Copyright 2011 
cancer have been discussed elsewhere [348]. Some of the recently explored approaches that have an immense potential to bring breakthrough in lung cancer theranostics have been discussed here.

The research work by Shevtsov et al. is a unique theranostic approach that combines the immunotherapeutic ability of Granzyme B ( $\mathrm{Gn} \mathrm{B}$ ) with the diagnostic ability of superparamagnetic iron oxide nanoparticles (SPIONs) to target many types of cancers including lung cancer. The surfacemodified SPIONs target a membrane-bound protein, Hsp 70, that is selectively overexpressed over the tumor cells but is absent over the normal cells. Gn B is a serine protease that is produced by the immune cells like the NK and T cells, that selectively targets the HsP70 receptors. The GnB-functionalized SPIONs (GnB-SPIONs) were reported to undergo selective endocytosis into the tumor cells and provide significantly higher MRI contrast and apoptosis-inducing ability. The therapeutic efficiency of GnB-SPIONs was observed to increase still further by employing a regimen combining magnetic targeting and stereotactic radiotherapy [349].

Yet another theranostic approach was employed by Duman et al. to facilitate tumor targeting to EGFR-positive cancer cells like lung cancer cells. For facilitating tumor targeting, the research group developed cetuximab-conjugated $\mathrm{Ag}_{2} \mathrm{~S}$ quantum dots entrapping 5-fluorouracil (5-FU). The theranostic quantum dots were observed to overcome the issues of drug resistance and pro-survival mechanisms in A549 cells while facilitating targeted NIR imaging. The novel nanohybrid was observed to induce significant apoptosis in EGFR-positive lung cancer cells by suppression of autophagic mechanisms [350].

Cheng et al. developed a nano-biohybrid composed of $\mathrm{Ag}_{2} \mathrm{~S}$ quantum dots (QD), entrapped in the erythrocyte membrane for combining the benefits of non-invasive sonodynamic therapy with imaging ability. The novel approach employs $\mathrm{Ag}_{2} \mathrm{~S}$ quantum dots for sonosensitization while utilizing the endogenous erythrocytic catalase-mediated $\mathrm{O}_{2}$ as sonodynamic therapeutic. This is the first instance of employing sonodynamic therapy as an oncological modality, which is difficult to be employed otherwise due to hypoxic tumor conditions. To overcome challenges associated with spatial tumor characteristics, the research groups utilized a novel theranostic formulation that had an intrinsic source for $\mathrm{O}_{2}$ production. To increase the sensitivity of sonodynamic therapy through increased intracellular $\mathrm{O}_{2}$ production, phenethyl isothiocyanate (PEITC) was administered orally. The theranostic agent can be image-guided to the tumor tissue by employing fluorescence-NIR II-aided imaging technique and subsequently subjected to ultrasound to evoke reactive oxygen species (ROS) generation and cause subsequent cell death. The in vivo evaluation of the nanobiohybrid demonstrated long systemic circulation, exceptional biocompatibility accompanied by high anticancer efficacy in a xenograft mice model [351].

c-MET (hepatocyte growth factor receptor) aberrations have been well reported in many forms of cancers including lung cancer and metastatic malignancies. Lu et al. have developed a novel nano-biohybrid employing anti-c-Met human single-chain variable fragment ( $\mathrm{scFv}$ ) antibody as a vector. The anti-c-Met scFv fragment was attached over the surface of PEGylated liposomes encapsulating doxorubicin. The nano-biohybrid offered excellent targetability while facilitating in vivo fluorescent imaging and tumoral cell uptake as apparent from the tumor to normal ratio. Thus, devised immunoliposomes demonstrated high antitumor activity in the $\mathrm{H} 460$ xenograft mice model, suggesting its potential as a theranostic agent [179].

An innovative approach for theranostic relegation of progression and metastasis of lung adenocarcinoma has been reported by Chan et al. The authors of this research work have developed novel nanomaterial by employing silica shell-based nanocarrier, which serves as near infraredpersistent luminescence nanoparticles (NIR PNs). The NIR PNs were optimized for their physicochemical properties to attain a prolonged NIR luminescence. For an additional therapeutic effect, afatinib (AT) was conjugated to the PNs, and was subsequently functionalized with MAGE-A3 (Map) to obtain C). MAGE-A3 is a DNA aptamer, targeted against tumor-specific melanoma-associated peptide antigen (MAGE-A3111-125), that is overexpressed in lung cancer and many metastatic forms of cancer. Due to the advantages like highly modifiable structure and specific/targeted tumor targeting, this nano-biohybrid may be envisioned as a future of image-guided theranostics [352].

\section{Contemporary Erudition and Outlook}

With several positive outcomes, the application of doctrines of nano-bioscience and bio-nanotechnology has presented an immense potential to redefine the current oncological scenario. An entire armada of different forms of bio-modified 
nanocarriers is being researched to subjugate various hurdles in the way of oncotargeting. Nanobiomedicines, by the virtue of their three-dimensional, multicomponent array exhibit certain distinct colloidal characteristics that bear an immense potential to transfigure the current state of oncotherapy. These future 'nano' tools have been supposed to cast their idealism upon the forthcoming preventive, diagnostic, therapeutic as well as theranostic aspects of several forms of neoplasms including lung cancer. Various novel nanosystems have been extensively explored to solve various issues confronted by conventional therapies like poor tumor bioavailability, nonspecific drug targeting, drug resistance, off-target side effects as well as detection of cancer cell progression and metastasis. However, the prognostic significance of nanotechnology and biotechnology in the oncological context is constrained and demands remarkable improvement.

An entirely different perspective on oncology awaits unanimous efforts in the field of nano-biosciences and bionanotechnology. Bio-nanotechnology tools may help envision and discover several novel oncological aspects by providing kaleidoscopic vision through molecular diagnosis and advanced bioimaging techniques. Several novel targets may be identified and novel therapeutic strategies be devised for reinforcement of oncotherapy. Revisiting the principles of nano-biosciences may help leverage the oncological sciences to a considerable extent by devising novel strategies that smoothen the trajectory to target the tumors. Nano-biocarriers may be explicitly designed to assist the delivery of various types of cargoes to the tumor tissue while overcoming various physicochemical and biological barriers. Additionally, the nano-biocarriers are a useful means for addressing tumor heterogeneity through personalized and tailored-drug delivery. The concept of combination therapy for targeting as well as theranostic purpose may also be facilitated using several forms of nano-biocarriers. Bionanotechnologyderived theranostic and other multi-functional arsenal has an immense potential to empower the oncology and expand the horizon toward optimistic outcomes.

However, the factual translation of nanomedicine may be made possible only by overpowering the challenges associated with them. The major challenges faced by bionanotechnology-based approaches are related to the lack of comprehensive interdisciplinary understanding amongst researchers of different scientific disciplines. Some of the other challenges associated with the use of nanomedicines relate to their biological repercussions, pharmacoeconomic impact, scale-up, immunological and toxicological concerns due to inter-patient bio-variance and modulated pharmacokinetics and biodistribution. Subtle alterations in the pharmacokinetic behavior of nanoparticles may often impede the in vivo biodistribution and alter the tumor bioavailability of the drug, thereby reflecting their impact on its pharmacodynamics. Bio-phenomenon like nano-biointeractions, bio-molecular corona formation, RBC hitchhiking, hepatic sequestration of nanomedicine for prevention of metastasis, etc., that have been less explored also needs to be extensively researched to deduce the complete therapeutic serendipity of the nano-biocarriers [353]. Björnmalm et al. have provided a concise overview of several approaches employed for bridging the bio-nanosciences and cancer nanomedicines in their review [353].

Streamlined efforts of the researchers from mathematical, engineering, chemistry, physics, and biology disciplines may help devise models for predictive analysis of the raw research data and findings gathered through bionanotechnology. Besides this, regulatory guidelines on the validation, functionalization, processing, safety, and toxicity assessments of nano-biocarriers and nano-biodevices also need to be devised. While there is a long way to safeguard the clinical applicability of bionanotechnology-derived tools, pacing up data integration and facilitating applications of validated predictive analytical and biomodeling tools may significantly pace up the process of their regulatory approval. With compelling shreds of evidence from current advances in the bionanotechnology-derived tools, their application in oncology proclaims a promising futuristic scenario.

Acknowledgements The authors are grateful to Nirma University, Ahmedabad, India, for providing financial assistance in form of a Major Research Project (NU/Ph.D./Major Res Pro/IP/16-17/669) and for providing the necessary facilities to carry out the research work. The authors are also thankful to the Department of Science and Technology (DST), Fund for Improvement of S\&T Infrastructure (FIST) (Grant No.: SR/FST/LSI-607/2014), Government of India for providing the necessary funding to establish equipment facility. Ms. Shruti Rawal is also grateful to Nirma University for providing the Junior Research Fellowship and Senior Research Fellowship.

Open Access This article is licensed under a Creative Commons Attribution 4.0 International License, which permits use, sharing, adaptation, distribution and reproduction in any medium or format, as long as you give appropriate credit to the original author(s) and the source, provide a link to the Creative Commons licence, and 
indicate if changes were made. The images or other third party material in this article are included in the article's Creative Commons licence, unless indicated otherwise in a credit line to the material. If material is not included in the article's Creative Commons licence and your intended use is not permitted by statutory regulation or exceeds the permitted use, you will need to obtain permission directly from the copyright holder. To view a copy of this licence, visit http://creativecommons.org/licenses/by/4.0/.

\section{References}

1. F. Bray, J. Ferlay, I. Soerjomataram, Global cancer statistics 2018: GLOBOCAN estimates of incidence and mortality worldwide for 36 cancers in 185 countries. CA A Cancer J. Clin. (2018). https://doi.org/10.3322/caac.21492

2. American Cancer Society, Cancer Facts \& Figures 2018, 1-71 (2018)

3. A.M. Cryer, A.J. Thorley, Nanotechnology in the diagnosis and treatment of lung cancer. Pharmacol. Ther. 198, 189-205 (2019). https://doi.org/10.1016/j.pharmthera.2019.02.010

4. G. Holdridge, E. Kousvelari, S.-S. Lim, M. Roco, J. Scholss, NNI workshop report on nanobiotechnology (2003)

5. K. Willow, J.A. Holland, Lung cancer: types, survival rates, and more. https://www.healthline.com/health/lung-cancerstages-survival-rates. Accessed 4 Mar 2020

6. U. Koli, A. Dey, P. Nagendra, P.V. Devarajan, R. Jain, P. Dandekar, Lung cancer receptors and targeting strategies, in Targeted Intracellular Drug Delivery by Receptor Mediated Endocytosis (Springer, Cham, 2019), pp. 229-268

7. USFDA, NovoTTF ${ }^{\mathrm{TM}}$-100L System - H180002, https:// www.fda.gov/medical-devices/recently-approved-devices/ novottftm-1001-system-h180002. Accessed 4 Mar 2020

8. R. van der Meel, L.J.C. Vehmeijer, R.J. Kok, G. Storm, E.V.B. van Gaal, Ligand-targeted particulate nanomedicines undergoing clinical evaluation: current status. Adv. Drug Deliv. Rev. 65, 1284-1298 (2013). https://doi.org/10. 1016/j.addr.2013.08.012

9. J.A. MacDiarmid, H. Brahmbhatt, Minicells: versatile vectors for targeted drug or si/shRNA cancer therapy. Curr. Opin. Biotechnol. 22, 909-916 (2011). https://doi.org/10. 1016/j.copbio.2011.04.008

10. J.A. Macdiarmid, N.B. Amaro-mugridge, J. Madrid-weiss, I. Sedliarou, S. Wetzel et al., Sequential treatment of drugresistant tumors with targeted minicells containing siRNA or a cytotoxic drug. Nat. Biotechnol. 27(7), 643-651 (2009). https://doi.org/10.1038/nbt.1547

11. V. Gujrati, S. Kim, S.H. Kim, J.J. Min, H.E. Choy et al., Bioengineered bacterial outer membrane vesicles as cellspecific drug-delivery vehicles for cancer therapy. ACS Nano 8, 1525-1537 (2014). https://doi.org/10.1021/nn405 $724 \mathrm{x}$

12. Y. Zhang, W. Ji, L. He, Y. Chen, X. Ding et al., E. coli Nissle 1917-derived minicells for targeted delivery of chemotherapeutic drug to hypoxic regions for cancer therapy. Theranostics 8, 1690-1705 (2018). https://doi. org/10.7150/thno. 21575

13. E. Galanis, S.K. Carlson, N.R. Foster, V. Lowe, F. Quevedo et al., Phase I trial of a pathotropic retroviral vector expressing a cytocidal cyclin G1 construct (Rexin-G) in patients with advanced pancreatic cancer. Mol. Ther. 16, 979-984 (2008). https://doi.org/10.1038/mt.2008.29

14. M. Huo, L. Wang, Y. Chen, J. Shi, Nanomaterials/microorganism-integrated microbiotic nanomedicine. Nano Today 32, 100854 (2020). https://doi.org/10.1016/j.nantod.2020. 100854

15. C. Constantin, M. Neagu, Bio-inspired nanomaterials: a better option for nanomedicine. Trends Toxicol. Relat. Sci. 1(1), 3-20 (2017)

16. M.G. Kramer, M. Masner, F.A. Ferreira, R.M. Hoffman, Bacterial therapy of cancer: promises, limitations, and insights for future directions. Front. Microbiol. 9, 9-16 (2018). https://doi.org/10.3389/fmicb.2018.00016

17. M.T. Duong, Y. Qin, S. You, J. Min, Bacteria-cancer interactions: bacteria-based cancer therapy. Exp. Mol. Med. 51(12), 1-5 (2019). https://doi.org/10.1038/s12276-019-0297-0

18. N. Forbes, Engineering the perfect (bacterial) cancer therapy. Nat. Rev. Cancer 10, 785-794 (2010). https://doi.org/10. 1038/nrc2934

19. F. Farjadian, M. Moghoofei, S. Mirkiani, A. Ghasemi, N. Rabiee et al., Bacterial components as naturally inspired nano-carriers for drug/gene delivery and immunization: set the bugs to work? Biotechnol. Adv. 36, 968-985 (2018). https://doi.org/10.1016/j.biotechadv.2018.02.016

20. American Association for Cancer Research, "Minicells" safely deliver targeted drugs. Cancer Discov. 3(1), 5 (2013). https://doi.org/10.1158/2159-8290.CD-NB2012-134

21. H.N. Nguyen, S. Romero Jovel, T.H.K. Nguyen, Nanosized minicells generated by lactic acid bacteria for drug delivery. J. Nanomater. (2017). https://doi.org/10.1155/2017/6847297

22. C. Mader, S. Ku, U.B. Sleytr, M. Sa, S-layer-coated liposomes as a versatile system for entrapping and binding target molecules. Biochem. Biophys. Acta 1463, 142-150 (2000). https:// doi.org/10.1016/S0005-2736(99)00190-X

23. M.H. Ucisik, S. Küpcü, B. Schuster, U.B. Sleytr, Characterization of CurcuEmulsomes: nanoformulation for enhanced solubility and delivery of curcumin. J. Nanobiotechnol. 11, 1-13 (2013). https://doi.org/10.1186/1477-3155-11-37

24. M. Wu, X. Liu, H. Bai, L. Lai, Q. Chen et al., Surface-layer protein-enhanced immunotherapy based on cell membranecoated nanoparticles for the effective inhibition of tumor growth and metastasis. ACS Appl. Mater. Interfaces 11, 9850-9859 (2019). https://doi.org/10.1021/acsami.9b00294

25. M. Lakatos, S. Matys, J. Raff, W. Pompe, M. Lakatos et al., Colorimetric as (V) detection based on S-layer functionalized gold nanoparticles. Talanta 144, 241-246 (2015). https://doi. org/10.1016/j.talanta.2015.05.082

26. C. Jogler, D. Sch, Genomics, genetics, and cell biology of magnetosome formation. Annu. Rev. Microbiol. 63, 501-521 
(2009). https://doi.org/10.1146/annurev.micro.62.081307. 162908

27. Y. Lu, L. Dong, L. Zhang, Y. Su, S. Yu, Biogenic and biomimetic magnetic nanosized assemblies. Nano Today $\mathbf{7}$, 297-315 (2012). https://doi.org/10.1016/j.nantod.2012.06. 011

28. M. Boucher, F. Geffroy, S. Prévéral, L. Bellanger, E. Selingue et al., Genetically tailored magnetosomes used as MRI probe for molecular imaging of brain tumor. Biomaterials 121, 167178 (2017). https://doi.org/10.1016/j.biomaterials.2016.12. 013

29. Q. Dai, R. Long, S. Wang, R.K. Kankala, J. Wang et al., Bacterial magnetosomes as an efficient gene delivery platform for cancer theranostics. Microb. Cell Fact. 16, 1-9 (2017). https://doi.org/10.1186/s12934-017-0830-6

30. A.M. Dunn, O.S. Hofmann, B. Waters, E. Witchel, Cloaking malware with the trusted platform module, in Proceedings of the 20th USENIX Security Symposium (2011), pp. 395-410

31. X. Guan, B. Yang, M. Xie, D.K. Ban, X. Zhao et al., MRI reporter gene MagA suppresses transferrin receptor and maps $\mathrm{Fe}^{2+}$ dependent lung cancer. Nanomed. Nanotechnol. Biol. Med. 21, 102064 (2019). https://doi.org/10.1016/j.nano.2019. 102064

32. K. Maruyama, H. Takeyama, T. Mori, K. Ohshima, Detection of epidermal growth factor receptor (EGFR) mutations in non-small cell lung cancer (NSCLC) using a fully automated system with a nano-scale engineered biomagnetite. Biosens. Bioelectron. 22, 2282-2288 (2007). https://doi.org/10.1016/j. bios.2006.11.018

33. J. Wang, Y. Geng, Y. Zhang, X. Wang, J. Liu et al., Bacterial magnetosomes loaded with doxorubicin and transferrin improve targeted therapy of hepatocellular carcinoma. Nanotheranostics 3(3), 284 (2019). https://doi.org/10.7150/ntno. 34601

34. Y. Maeda, T. Yoshino, T. Matsunaga, Novel nanocomposites consisting of in vivo -biotinylated bacterial magnetic particles and quantum dots for magnetic separation and fluorescent labeling of cancer cells. J. Mater. Chem. 19, 6361-6366 (2009). https://doi.org/10.1039/b900693a

35. Z.V. Novakova, I. Gasparova, L. Krajciova, M. Molcan, I. Varga et al., Effect of magnetosomes on cell proliferation, apoptosis induction and expression of Bcl-2 in the human lung cancer cell line A549. Biologia 72(5), 554-560 (2017). https://doi.org/10.1515/biolog-2017-0059

36. J.A. Kraśko, K. Źilionyte, A. Darinskas, M. Strioga, S.R. Jabceva et al., Bacterial ghosts as adjuvants in syngeneic tumour cell lysate-based anticancer vaccination in a murine lung carcinoma model. Oncol. Rep. 37, 171-178 (2017). https://doi. org/10.3892/or.2016.5252

37. T. Langemann, V.J. Koller, A. Muhammad, P. Kudela, U.B. Mayr et al., The bacterial ghost platform system: production and applications. Bioeng. Bugs 1, 326-336 (2010). https:// doi.org/10.4161/bbug.1.5.12540

38. I.A. Hajam, P.A. Dar, G. Won, J.H. Lee, Bacterial ghosts as adjuvants: mechanisms and potential. Vet. Res. 48, 1-13 (2017). https://doi.org/10.1186/s13567-017-0442-5
39. R. Acevedo, S. Fernández, C. Zayas, A. Acosta, M.E. Sarmiento et al., Bacterial outer membrane vesicles and vaccine applications. Front. Immunol. 5, 1-6 (2014). https://doi.org/ 10.3389/fimmu.2014.00121

40. A. Gholami, M. Milad, R.-A. Sara, Y. Ghasemi, Industrial production of polyhydroxyalkanoates by bacteria: opportunities and challenges. Minerva Biotechnol. 28, 59-74 (2016). https://doi.org/10.13140/RG.2.1.5129.4169

41. O.Y. Kim, H.T. Park, N.T.H. Dinh, S.J. Choi, J. Lee et al., Bacterial outer membrane vesicles suppress tumor by interferon- $\boldsymbol{\gamma}$-mediated antitumor response. Nat. Commun. 8(1), 1-9 (2017). https://doi.org/10.1038/ s41467-017-00729-8

42. C. Irene, L. Fantappiè, E. Caproni, F. Zerbini, A. Anesi et al., Bacterial outer membrane vesicles engineered with lipidated antigens as a platform for Staphylococcus aureus vaccine. Proc. Natl. Acad. Sci. USA 116, 21780-21788 (2019). https://doi.org/10.1073/pnas.1905112116

43. S. Jain, J. Pillai, Bacterial membrane vesicles as novel nanosystems for drug delivery. Int. J. Nanomed. 12, 6329-6341 (2017). https://doi.org/10.2147/IJN.S137368

44. V. Gujrati, J. Prakash, J. Malekzadeh-najafabadi, A. Stiel, U. Klemm et al., Heaters for optoacoustic imaging. Nat. Commun. 10, 1-10 (2019). https://doi.org/10.1038/ s41467-019-09034-y

45. N.P. Katuwavila, A.D.L.C. Perera, S.R. Samarakoon, P. Soysa, V. Karunaratne et al., Chitosan-alginate nanoparticle system efficiently delivers doxorubicin to MCF-7 Cells. J. Nanomater. (2016). https://doi.org/10.1155/2016/3178904

46. L. Li, R. Tao, M. Song, Y. Zhang, K. Chen et al., Fabrication of self-assembled folate-biotin-quaternized starch nanoparticles as co-carrier of doxorubicin and siRNA. J. Biomater. Appl. 32, 587-597 (2017). https://doi.org/10.1177/08853 28217737187

47. M. Sreeranganathan, S. Uthaman, B. Sarmento, C.G. Mohan, I.K. Park et al., In vivo evaluation of cetuximab-conjugated $\operatorname{poly}(\gamma$-glutamic acid)-docetaxel nanomedicines in EGFRoverexpressing gastric cancer xenografts. Int. J. Nanomed. 12, 7167-7182 (2017). https://doi.org/10.2147/IJN.S143529

48. M. Li, W. Song, Z. Tang, S. Lv, L. Lin et al., Nanoscaled poly(l-glutamic acid)/doxorubicin-amphiphile complex as pH-responsive drug delivery system for effective treatment of nonsmall cell lung cancer. ACS Appl. Mater. Interfaces 5, 1781-1792 (2013). https://doi.org/10.1021/am303073u

49. Y. Luo, X. Cai, H. Li, Y. Lin, D. Du, Hyaluronic Acid-modified multifunctional Q-graphene for targeted killing of drugresistant lung cancer cells. ACS Appl. Mater. Interfaces 8, 4048-4055 (2016). https://doi.org/10.1021/acsami.5b11471

50. V. Le Joncour, P. Laakkonen, Seek \& Destroy, use of targeting peptides for cancer detection and drug delivery. Bioorg. Med. Chem. 26, 2797-2806 (2018). https://doi.org/10.1016/j.bmc. 2017.08.052

51. J. Zou, S. Su, Z. Chen, F. Liang, Y. Zeng et al., Hyaluronic acid-modified selenium nanoparticles for enhancing the therapeutic efficacy of paclitaxel in lung cancer therap. Artif. 
Cells Nanomed. Biotechnol. 47, 3456-3464 (2019). https:// doi.org/10.1080/21691401.2019.1626863

52. I.I. Lungu, A.M. Grumezescu, A. Volceanov, E. Andronescu, Nanobiomaterials used in cancer therapy: an up-to-date overview. Molecules 24, 1-21 (2019). https://doi.org/10.3390/ molecules 24193547

53. K. Lundstrom, Latest trends in cancer therapy applying viral vectors. Future Med. 12(11), 667-684 (2017). https://doi.org/ 10.2217/fvl-2017-0070

54. E.W. Kovacs, J.M. Hooker, D.W. Romanini, P.G. Holder, K.E. Berry et al., Dual-surface-modified bacteriophage $\mathrm{MS}_{2}$ as an ideal scaffold for a viral capsid-based drug delivery system. Bioconjug. Chem. 18, 1140-1147 (2007). https://doi.org/10. 1021/bc070006e

55. T.L. Schlick, Z. Ding, E.W. Kovacs, M.B. Francis, Dual-surface modification of the tobacco mosaic virus. J. Am. Chem. Soc. 127, 3718-3723 (2005). https://doi.org/10.1021/ja046 $239 \mathrm{n}$

56. S.K. Dixit, N.L. Goicochea, M. Daniel, A. Murali, L. Bronstein et al., Quantum dot encapsulation in viral capsids. Nano Lett. 6, 1993-1998 (2006). https://doi.org/10.1021/n1061 $165 \mathrm{u}$

57. Y.M. Huh, E.S. Lee, J.H. Lee, Y. WJun, P. Kim, et al., Hybrid nanoparticles for magnetic resonance imaging of targetspecific viral gene delivery. Adv. Mater. 19(20), 3109-3112 (2007). https://doi.org/10.1002/adma.200701952

58. K.T. Nam, D.W. Kim, P.J. Yoo, C.Y. Chiang, N. Meethong et al., Virus-enabled synthesis and assembly of nanowires for lithium ion battery electrodes. Science 312, 885-888 (2006). https://doi.org/10.1126/science.1122716

59. R.J. Tseng, C. Tsai, L. Ma, J. Ouyang, C.S. Ozkan et al., Digital memory device based on tobacco mosaic virus conjugated with nanoparticles. Nat. Nanotechnol. 1(1), 72-77 (2006). https://doi.org/10.1038/nnano.2006.55

60. D. Ghosh, Y. Lee, S. Thomas, A.G. Kohli, D.S. Yun et al., M13-templated magnetic nanoparticles for targeted in vivo imaging of prostate cancer. Nat. Nanotechnol. 7, 677-682 (2012). https://doi.org/10.1038/nnano.2012.146

61. A. Kornienko, A. Evidente, M. Vurro, V. Mathieu, A. Cimmino et al., Toward a cancer drug of fungal origin. Med. Res. Rev. 35, 937-967 (2015). https://doi.org/10.1002/med.21348

62. C. Sabu, P. Mufeedha, K. Pramod, Yeast-inspired drug delivery: biotechnology meets bioengineering and synthetic biology. Expert Opin. Drug Del. 16(1), 27-41 (2019). https://doi. org/10.1080/17425247.2019.1551874

63. A. Geller, R. Shrestha, J. Yan, Yeast-derived $\beta$-glucan in cancer: novel uses of a traditional therapeutic. Int. J. Mol. Sci. 20, 1-20 (2019). https://doi.org/10.3390/ijms20153618

64. R. Roudi, S.R. Mohammadi, M. Roudbary, M. Mohsenzadegan, Lung cancer and $\beta$-glucans: review of potential therapeutic applications. Invest. New Drugs 35, 509-517 (2017). https://doi.org/10.1007/s10637-017-0449-9

65. S.H. Albeituni, C. Ding, M. Liu, X. Hu, F. Luo et al., Yeastderived particulate $\beta$-glucan treatment subverts the suppression of myeloid-derived suppressor cells (MDSC) by inducing polymorphonuclear MDSC apoptosis and monocytic MDSC differentiation to APC in cancer. J. Immunol. 196(5), 2167-2180 (2016). https://doi.org/10.4049/jimmunol. 1600346

66. S. Majeed, M.S. Bin Abdullah, G.K. Dash, M.T. Ansari, A. Nanda, Biochemical synthesis of silver nanoprticles using filamentous fungi Penicillium decumbens (MTCC-2494) and its efficacy against A-549 lung cancer cell line. Chin. J. Nat. Med. 14, 615-620 (2016). https://doi.org/10.1016/S18755364(16)30072-3

67. X. Hu, K. Saravanakumar, T. Jin, M.H. Wang, Mycosynthesis, characterization, anticancer and antibacterial activity of silver nanoparticles from endophytic fungus Talaromyces purpureogenus. Int. J. Nanomed. 14, 3427-3438 (2019). https://doi.org/10.2147/IJN.S200817

68. K. Saravanakumar, E. Jeevithan, X. Hu, R. Chelliah, D.H. Oh et al., Enhanced anti-lung carcinoma and anti-biofilm activity of fungal molecules mediated biogenic zinc oxide nanoparticles conjugated with $\beta$-D-glucan from barley. J. Photochem. Photobiol. B Biol. 203, 111728 (2020). https://doi.org/10. 1016/j.jphotobiol.2019.111728

69. V. Gujrati, M. Lee, Y.J. Ko, S. Lee, D. Kim et al., Bioengineered yeast-derived vacuoles with enhanced tissue-penetrating ability for targeted cancer therapy. Proc. Natl. Acad. Sci. USA 113, 710-715 (2016). https://doi.org/10.1073/pnas. 1509371113

70. X. Zhou, K. Ling, M. Liu, X. Zhang, J. Ding et al., Targeted delivery of cisplatin-derived nanoprecursors via a biomimetic yeast microcapsule for tumor therapy by the oral route. Theranostics 9, 6568-6586 (2019). https://doi.org/10.7150/thno. 35353

71. E.R. Soto, G.R. Ostroff, Characterization of multilayered nanoparticles encapsulated in yeast cell wall particles for DNA. Bioconjug. Chem. 19, 840-848 (2008). https://doi. org/10.1021/bc700329p

72. G. Baskar, K. Lalitha, R. Aiswarya, R. Naveenkumar, Synthesis, characterization and synergistic activity of ceriumselenium nanobiocomposite of fungal L-asparaginase against lung cancer. Mater. Sci. Eng. C 93, 809-815 (2018). https:// doi.org/10.1016/j.msec.2018.08.051

73. Q. Xia, Y. Zhang, Z. Li, X. Hou, N. Feng, Red blood cell membrane-camouflaged nanoparticles: a novel drug delivery system for antitumor application. Acta Pharm. Sin. B 9, 675-689 (2019). https://doi.org/10.1016/j.apsb.2019.01.011

74. M. Gagliardi, Biomimetic and bioinspired nanoparticles for targeted drug delivery. Ther. Deliv. 8, 289-299 (2017). https://doi.org/10.4155/tde-2017-0013

75. M. Gagliardi, A. Bertero, A. Bifone, Molecularly imprinted biodegradable nanoparticles. Sci. Rep. 7, 1-9 (2017). https:// doi.org/10.1038/srep40046

76. A. Sahari, M.A. Traore, B.E. Scharf, B. Behkam, Directed transport of bacteria-based drug delivery vehicles: bacterial chemotaxis dominates particle shape. Biomed. Microdevices 16, 717-725 (2014). https://doi.org/10.1007/ s10544-014-9876-y 
77. S. Tan, T. Wu, D. Zhang, Z. Zhang, Cell or cell membranebased drug delivery systems. Theranostics 5, 863-881 (2015). https://doi.org/10.7150/thno.11852

78. S.O. Choi, Y.C. Kim, J.H. Park, J. Hutcheson, H.S. Gill et al., An electrically active microneedle array for electroporation. Biomed. Microdevices 12, 263-273 (2010). https://doi.org/ 10.1007/s10544-009-9381-x

79. A.L. Lynch, R. Chen, N.K.H. Slater, PH-responsive polymers for trehalose loading and desiccation protection of human red blood cells. Biomaterials 32, 4443-4449 (2011). https://doi. org/10.1016/j.biomaterials.2011.02.062

80. C. Gutiérrez Millán, A.Z. Castañeda, M.L. Sayalero Marinero, J.M. Lanao, Factors associated with the performance of carrier erythrocytes obtained by hypotonic dialysis. Blood Cells Mol. Dis. 33, 132-140 (2004). https://doi.org/10.1016/j. bcmd.2004.06.004

81. J. Bird, R. Best, D.A. Lewis, The encapsulation of insulin in erythrocytes. J. Pharm. Pharmacol. 35, 246-247 (1983). https://doi.org/10.1111/j.2042-7158.1983.tb02921.x

82. M. Seth, A. Ramachandran, L.G. Leal, Dilution technique to determine the hydrodynamic volume fraction of a vesicle suspension. Langmuir 26, 15169-15176 (2010). https://doi. org/10.1021/la1023086

83. Y. Sato, H. Yamakose, Y. Suzuki, Mechanism of hypotonic hemolysis of human erythrocytes. Biol. Pharm. Bull. 16, 506-512 (1993)

84. Z. Zhao, A. Ukidve, Y. Gao, J. Kim, S. Mitragotri, Erythrocyte leveraged chemotherapy (ELeCt): nanoparticle assembly on erythrocyte surface to combat lung metastasis. Sci. Adv. 5, 1-13 (2019). https://doi.org/10.1126/sciadv.aax9250

85. M. Gao, C. Liang, X. Song, Q. Chen, Q. Jin et al., Erythrocyte-membrane-enveloped perfluorocarbon as nanoscale artificial red blood cells to relieve tumor hypoxia and enhance cancer radiotherapy. Adv. Mater. 170, 1429 (2017). https:// doi.org/10.1002/adma.201701429

86. I.V. Zelepukin, A.V. Yaremenko, V.O. Shipunova, Nanoparticle-based drug delivery via RBC- hitchhiking for the inhibition of lung metastases. Nanoscale 11, 1636-1646 (2019). https://doi.org/10.1039/c8nr07730d

87. D.M. Zhu, W. Xie, Y.S. Xiao, M. Suo, Z. Ming-Hui et al., Erythrocyte membrane-coated Gold nanocages for targeted photothermal and chemical therapy. Nanotechnology 29(8), 084002 (2017). https://doi.org/10.1088/1361-6528/aa9ca1

88. Y. Huang, X. Gao, J. Chen, Leukocyte-derived biomimetic nanoparticulate drug delivery systems for cancer therapy. Acta Pharm. Sin. B 8, 4-13 (2018). https://doi.org/10.1016/j. apsb.2017.12.001

89. B. Qian, J. Li, H. Zhang, T. Kitamura, J. Zhang et al., CCL2 recruits inflammatory monocytes to facilitate breast tumor metastasis. Nature 475, 222-225 (2007). https://doi.org/10. 1038/nature10138

90. F. Pierigè, S. Serafini, L. Rossi, M. Magnani, Cell-based drug delivery. Adv. Drug Deliv. Rev. 60, 286-295 (2008). https:// doi.org/10.1016/j.addr.2007.08.029
91. L.E. Paulis, S. Mandal, M. Kreutz, C.G. Figdor, Dendritic cell-based nanovaccines for cancer immunotherapy. Curr. Opin. Immunol. 25, 389-395 (2013). https://doi.org/10. 1016/j.coi.2013.03.001

92. X. Dong, D. Chu, Z. Wang, Leukocyte-mediated delivery of nanotherapeutics in inflammatory and tumor sites. Theranostics 7, 751-763 (2017). https://doi.org/10.7150/thno.18069

93. S.B. Coffelt, M.D. Wellenstein, K.E. De Visser, Neutrophils in cancer: neutral no more. Nat. Rev. Cancer 16, 431-446 (2016). https://doi.org/10.1038/nrc.2016.52

94. A.D. Fesnak, C.H. June, B.L. Levine, Engineered T cells: the promise and challenges of cancer immunotherapy. Nat. Rev. Cancer 16, 566-581 (2016). https://doi.org/10.1038/nrc.2016. 97

95. S.R. Hyslop, E.C. Josefsson, Undercover agents: targeting tumours with modified platelets. Trends Cancer 3, 235-246 (2017). https://doi.org/10.1016/j.trecan.2017.01.006

96. H. Wang, J. Wu, G.R. Williams, Q. Fan, S. Niu et al., Plateletmembrane-biomimetic nanoparticles for targeted antitumor drug delivery. J. Nanobiotechnol. 17, 1-16 (2019). https:// doi.org/10.1186/s12951-019-0494-y

97. C.J. Hu, R.H. Fang, K. Wang, B.T. Luk, S. Thamphiwatana et al., Nanoparticle biointerfacing by platelet membrane cloaking. Nat. Lett. 526(7571), 118-121 (2015). https://doi. org/10.1038/nature 15373

98. S. Zou, B. Wang, C. Wang, Q. Wang, L. Zhang, Cell membrane-coated nanoparticles: research advances. Nanomedicine 15, 13 (2020). https://doi.org/10.2217/nnm-2019-0388

99. T. Squillaro, G. Peluso, U. Galderisi, Clinical trials with mesenchymal stem cells: an update. Cell Transplant. 25, 829-848 (2016). https://doi.org/10.3727/096368915X689622

100. S. Ma, N. Xie, W. Li, B. Yuan, Y. Shi et al., Immunobiology of mesenchymal stem cells. Cell Death Differ. 21, 216-225 (2014). https://doi.org/10.1038/cdd.2013.158

101. M.Y. Thanuja, C. Anupama, S.H. Ranganath, Bioengineered cellular and cell membrane-derived vehicles for actively targeted drug delivery: so near and yet so far. Adv. Drug Deliv. Rev. 132, 57-80 (2018). https://doi.org/10. 1016/j.addr.2018.06.012

102. V. Vijayan, S. Uthaman, I.K. Park, Cell membrane-camouflaged nanoparticles: a promising biomimetic strategy for cancer theragnostics. Polymers 10(9), 983 (2018). https:// doi.org/10.3390/polym10090983

103. R.H. Fang, A. Kroll, W. Gao, L. Zhang, Cell membrane coating nanotechnology. Adv. Mater. 30, 1-68 (2018). https://doi.org/10.1002/adma.201706759

104. R.H. Fang, C.J. Hu, B.T. Luk, W. Gao, J.A. Copp et al., Cancer cell membrane-coated nanoparticles for anticancer vaccination and drug delivery. Nano Lett. 14(4), 2181-2188 (2015). https://doi.org/10.1021/nl500618u

105. J.Y. Zhu, D.W. Zheng, M.K. Zhang, W.Y. Yu, W.X. Qiu et al., Preferential cancer cell self-recognition and tumor self-targeting by coating nanoparticles with homotypic cancer cell membranes. Nano Lett. 16, 5895-5901 (2016). https://doi.org/10.1021/acs.nanolett.6b02786 
106. J. Jin, B. Krishnamachary, J.D. Barnett, S. Chatterjee, D. Chang et al., Human cancer cell membrane-coated biomimetic nanoparticles reduce fibroblast-mediated invasion and metastasis and induce T-cells. ACS Appl. Mater. Interfaces 11, 7850-7861 (2019). https://doi.org/10.1021/ acsami.8b22309

107. H. Sun, J. Su, Q. Meng, Q. Yin, L. Chen et al., Cancer-cellbiomimetic nanoparticles for targeted therapy of homotypic tumors. Adv. Mater. 28, 9581-9588 (2016). https://doi.org/ 10.1002/adma.201602173

108. B. Luk, L. Zhang, Cell membrane-camouflaged nanoparticles for drug delivery. J. Control Release 28, 600-607 (2015). https://doi.org/10.1016/j.jconrel.2015.07.019

109. G. Raposo, W. Stoorvogel, Extracellular vesicles: exosomes, microvesicles, and friends. J. Cell Biol. 200, 373-383 (2013). https://doi.org/10.1083/jcb.201211138

110. G. Van Niel, G. D’Angelo, G. Raposo, Shedding light on the cell biology of extracellular vesicles. Nat. Rev. Mol. Cell Biol. 19, 213-228 (2018). https://doi.org/10.1038/nrm. 2017.125

111. C. Sheehan, C. D'Souza-Schorey, Tumor-derived extracellular vesicles: Molecular parcels that enable regulation of the immune response in cancer. J. Cell Sci. 132, 1-12 (2019). https://doi.org/10.1242/jcs.235085

112. V. Muralidharan-Chari, J.W. Clancy, A. Sedgwick, C. D'Souza-Schorey, Microvesicles: mediators of extracellular communication during cancer progression. J. Cell Sci. 123, 1603-1611 (2010). https://doi.org/10.1242/jcs.064386

113. R. Kalluri, The biology and function of exosomes in cancer. J. Clin. Invest. 126(4), 1208-1215 (2016). https://doi.org/ 10.1172/JCI81135

114. J. Cheng, T. Nonaka, D.T.W. Wong, Salivary exosomes as nanocarriers for cancer biomarker delivery. Materials 12, 1-18 (2019). https://doi.org/10.3390/ma12040654

115. J. Conde-Vancells, E. Rodriguez-Suarez, N. Embade, D. Gil et al., Characterization and comprehensive proteome profiling of exosomes secreted by hepatocytes. J. Proteome Res. 7, 5157-5166 (2008). https://doi.org/10.1021/pr8004887

116. A.C. Marques, P.J. Costa, S. Velho, M.H. Amaral, P.J. Costa et al., Functionalizing nanoparticles with cancer-targeting antibodies: a comparison of strategies. J. Control. Release 320, 180-200 (2020). https://doi.org/10.1016/j.jconrel. 2020.01 .035

117. J. Löfblom, J. Feldwisch, V. Tolmachev, J. Carlsson, S. Ståhl et al., Affibody molecules: engineered proteins for therapeutic, diagnostic and biotechnological applications. FEBS Lett. 584, 2670-2680 (2010). https://doi.org/10. 1016/j.febslet.2010.04.014

118. K.K. Ng, J.F. Lovell, G. Zheng, Lipoprotein-inspired nanoparticles for cancer theranostics. Acc. Chem. Res. 44, 1105-1113 (2011). https://doi.org/10.1021/ar200017e

119. J.Y. Oh, H.S. Kim, L. Palanikumar, E.M. Go, B. Jana et al., Cloaking nanoparticles with protein corona shield for targeted drug delivery. Nat. Commun. 9, 1-9 (2018). https:// doi.org/10.1038/s41467-018-06979-4
120. S.H. Van Rijt, D.A. Bölükbas, C. Argyo, K. Wipplinger, M. Naureen et al., Applicability of avidin protein coated mesoporous silica nanoparticles as drug carriers in the lung. Nanoscale 8, 8058-8069 (2016). https://doi.org/10. $1039 / \mathrm{c} 5 \mathrm{nr} 04119 \mathrm{~h}$

121. Y.J. Huang, S.H. Hsu, Trail-functionalized gold nanoparticles selectively trigger apoptosis in polarized macrophages. Nanotheranostics 1, 326-337 (2017). https://doi.org/10. 7150/ntno.20233

122. P. Kaur, T. Garg, G. Rath, R.S.R. Murthy, A.K. Goyal, Surfactant-based drug delivery systems for treating drug-resistant lung cancer. Drug Deliv. 7544, 1-12 (2014). https://doi. org/10.3109/10717544.2014.935530

123. F. Mousseau, C. Puisney, S. Mornet, R. Le Borgne, A. Vacher et al., Supported pulmonary surfactant bilayers on silica nanoparticles: formulation, stability and impact on lung epithelial cells-introduction. Nanoscale (2017). https://doi.org/10.1039/C7NR04574C

124. J.Y. Kasper, L. Feiden, M.I. Hermanns, C. Bantz, M. Maskos et al., Pulmonary surfactant augments cytotoxicity of silica nanoparticles: studies on an in vitro air-blood barrier model. Beilstein J. Nanotechnol. 6, 517-528 (2015). https://doi.org/10.3762/bjnano.6.54

125. L. De Backer, K. Braeckmans, M.C.A. Stuart, J. Demeester, S.C. De Smedt et al., Bio-inspired pulmonary surfactantmodified nanogels: a promising siRNA delivery system. J. Control. Release 206, 177-186 (2015). https://doi.org/10. 1016/j.jconrel.2015.03.015

126. N. Joshi, N. Shirsath, A. Singh, K.S. Joshi, R. Banerjee, Endogenous lung surfactant inspired $\mathrm{pH}$ responsive nanovesicle aerosols: pulmonary compatible and site-specific. Sci. Rep. 4, 1-11 (2014). https://doi.org/10.1038/srep07085

127. J. Yoo, C. Park, G. Yi, D. Lee, H. Koo, Active targeting strategies using biological ligands for nanoparticle drug delivery systems. Cancers 11, 1-13 (2019). https://doi.org/ 10.3390/cancers 11050640

128. H. Khatri, N. Chokshi, S. Rawal, B.M. Patel, M. Badanthadka et al., Fabrication and in vivo evaluation of ligand appended paclitaxel and artemether loaded lipid nanoparticulate systems for the treatment of NSCLC: a nanoparticle assisted combination oncotherapy. Int. J. Pharm. 583, 119386 (2020). https://doi.org/10.1016/j.ijpharm.2020.119386

129. S. Rawal, M. Patel, Lipid nanoparticulate systems: modern versatile drug carriers, in Lipid Nanocarriers Drug Target. ed. by A.M. Grumezescu (Elseveir, Oxford, 2018), pp. 49-138. https://doi.org/10.1016/B978-0-12-813687-4. 00002-5

130. H. Khatri, N. Chokshi, S. Rawal, M. Patel, Fabrication, charecterization and optimization of Artemether loaded PEGylated solid lipid nanoparticles for the treatment of lung cancer. Mater. Res. Express 6(4), 045014 (2019). https://doi. org/10.1088/2053-1591/aaf8a3

131. R.K. Tekade, T. Dutta, A. Tyagi, A.C. Bharti, B.C. Das et al., Surface-engineered dendrimers for dual drug delivery: a receptor up-regulation and enhanced cancer targeting 
strategy. J. Drug Target. 16(10), 758-772 (2008). https://doi. org/10.1080/10611860802473154

132. H. Kulhari, D. Pooja, S. Shrivastava, M. Kuncha, Trastuzumab-grafted PAMAM dendrimers for the selective delivery of anticancer drugs to HER2-positive breast cancer. Sci. Rep. 6(1), 1-3 (2016). https://doi.org/10.1038/srep23179

133. S. Parveen, R. Misra, S.K. Sahoo, Nanoparticles: A boon to drug delivery, therapeutics, diagnostics and imaging. Nanomed. Nanotechn. Biol. Med. 8, 147-166 (2012). https:// doi.org/10.1016/j.nano.2011.05.016

134. C. Clementi, K. Miller, A. Mero, R. Satchi-Fainaro, G. Pasut, Dendritic poly(ethylene glycol) bearing paclitaxel and alendronate for targeting bone neoplasms. Mol. Pharm. 8, 1063 1072 (2011). https://doi.org/10.1021/mp2001445

135. W. Xuan, Y. Xia, T. Li, L. Wang, Y. Liu et al., Molecular self-assembly of bioorthogonal aptamer-prodrug conjugate micelles for hydrogen peroxide and ph-independent cancer chemodynamic therapy. J. Am. Chem. Soc. 142, 937-944 (2020). https://doi.org/10.1021/jacs.9b10755

136. S.S. Desale, S.M. Cohen, Y. Zhao, A.V. Kabanov, T.K. Bronich, Biodegradable hybrid polymer micelles for combination drug therapy in ovarian cancer. J. Control. Release 171, 339348 (2013). https://doi.org/10.1016/j.jconrel.2013.04.026

137. C. Shi, Z. Zhang, J. Shi, F. Wang, Y. Luan, Co-delivery of docetaxel and chloroquine via PEO-PPO-PCL/TPGS micelles for overcoming multidrug resistance. Int. J. Pharm. 495, 932939 (2015). https://doi.org/10.1016/j.ijpharm.2015.10.009

138. C. Sarisozen, A.H. Abouzeid, V.P. Torchilin, The effect of co-delivery of paclitaxel and curcumin by transferrin-targeted PEG-PE-based mixed micelles on resistant ovarian cancer in 3-D spheroids and in vivo tumors. Eur. J. Pharm. Biopharm. 88, 539-550 (2014). https://doi.org/10.1016/j.ejpb.2014.07. 001

139. G. Salzano, G. Navarro, M.S. Trivedi, G. De Rosa, V.P. Torchilin, Multifunctional polymeric micelles co-loaded with anti-survivin siRNA and paclitaxel overcome drug resistance in an animal model of ovarian cancer. Mol. Cancer Ther. 14, 1075-1084 (2015). https://doi.org/10.1158/1535-7163. MCT-14-0556

140. C.L. Jun Zhao, C. Wu, J. Abbruzzese, R.F. Hwang, Cyclopamine-loaded core-crosslinked polymeric micelles enhance radiation response in pancreatic cancer and pancreatic stellate cells. Mol. Pharm. 12, 2093-2100 (2015). https://doi.org/10. 1021/mp500875f

141. H.E. Colley, V. Hearnden, M. Avila-olias, D. Cecchin, I. Canton et al., Polymersome-mediated delivery of combination anticancer therapy to head and neck cancer cells: 2D and 3D in vitro evaluation. Mol. Pharm. 11, 1176-1188 (2014). https://doi.org/10.1021/mp400610b

142. T.O. Pangburn, K. Georgiou, F.S. Bates, E. Kokkoli, Targeted polymersome delivery of siRNA induces cell death of breast cancer cells dependent upon orai3 protein expression. Langmuir 28, 12816-12830 (2012). https://doi.org/10.1021/la300 $874 \mathrm{z}$
143. L. Guan, L. Rizzello, G. Battaglia, Polymersomes and their applications in cancer delivery and therapy. Nanomedicine 10, 2757-2780 (2015). https://doi.org/10.2217/nnm.15.110

144. D. Vergara, C. Bellomo, X. Zhang, V. Vergaro, A. Tinelli et al., Lapatinib/paclitaxel polyelectrolyte nanocapsules for overcoming multidrug resistance in ovarian cancer. Nanomed. Nanotechnol. Biol. Med. 8, 891-899 (2012). https://doi.org/ 10.1016/j.nano.2011.10.014

145. Z. Xu, Z. Zhang, Y. Chen, L. Chen, L. Lin et al., The characteristics and performance of a multifunctional nanoassembly system for the co-delivery of docetaxel and iSur-pDNA in a mouse hepatocellular carcinoma model. Biomaterials 31, 916-922 (2010). https://doi.org/10.1016/j.biomaterials.2009. 09.103

146. B. Zhu, L. Yu, Q. Yue, Co-delivery of vincristine and quercetin by nanocarriers for lymphoma combination chemotherapy. Biomed. Pharmacother. 91, 287-294 (2017). https://doi.org/ 10.1016/j.biopha.2017.02.112

147. G. Hariri, A.D. Edwards, T.B. Merrill, J.M. Greenbaum, A.E. Van Der Ende et al., Sequential targeted delivery of paclitaxel and camptothecin using a cross-linked nanosponge. Netw. Lung Cancer Chemother. 11(1), 265-75 (2014). https://doi. org/10.1021/mp400432b

148. G. Tejashri, B. Amrita, J. Darshana, Cyclodextrin based nanosponges for pharmaceutical use: a review. Acta Pharm. 63, 335-358 (2013). https://doi.org/10.2478/acph-2013-0021

149. K. Li, Tumor-targeted polymeric nanostructured lipid carriers with precise ratiometric control over dual-drug loading for combination therapy in non-small-cell lung cancer. Int. J. Nanomed. 2(12), 1699-1715 (2017). https://doi.org/10.2147/ IJN.S121262

150. A. Ediriwickrema, J. Zhou, Y. Deng, W.M. Saltzman, Multilayered nanoparticles for combination gene and drug delivery to tumors. Biomaterials 35, 9343-9354 (2014). https://doi. org/10.1016/j.biomaterials.2014.07.043

151. W. Lohcharoenkal, L. Wang, Y.C. Chen, Y. Rojanasakul, Protein nanoparticles as drug delivery carriers for cancer therapy. Biomed. Res. Int. 2014, 180549 (2014). https://doi. org/10.1155/2014/180549

152. W. Yu, C. Liu, Y. Liu, N. Zhang, W. Xu, Mannan-modified solid lipid nanoparticles for targeted gene delivery to alveolar macrophages. Pharm. Res. 27(8), 1584-1596 (2010). https://doi.org/10.1007/s11095-010-0149-z

153. B. Posocco, E. Dreussi, J. De Santa, G. Toffoli, M. Abrami et al., Polysaccharides for the delivery of antitumor drugs. Materials 8(5), 2569-2615 (2015). https://doi.org/10.3390/ ma8052569

154. K. Liu, W. Zheng, C. Wang, Covalent linkage of nanodiamond-paclitaxel for drug delivery and cancer. Nanotechnology 21(31), 315106 (2010). https://doi.org/10.1088/0957$4484 / 21 / 31 / 315106$

155. J.M. Oh, S.J. Choi, G.E. Lee, S.H. Han, J.H. Choy, Inorganic drug-delivery nanovehicle conjugated with cancercell-specific ligand. Adv. Funct. Mater. 19, 1617-1624 (2009). https://doi.org/10.1002/adfm.200801127 
156. J.P. Oliveira, A.R. Prado, W.J. Keijok, P.W.P. Antunes, E.R. Yapuchura et al., Impact of conjugation strategies for targeting of antibodies in gold nanoparticles for ultrasensitive detection of 17 $\beta$-estradiol. Sci. Rep. 9, 1-8 (2019). https:// doi.org/10.1038/s41598-019-50424-5

157. K. Fan, X. Yan, Bioengineered Ferritin Nanoprobes for cancer Theranostics, in Handbook Nanomaterials for Cancer Theranostics. ed. by J. Conde (Elsevier, Amsterdam, 2018), pp. 143-175. https://doi.org/10.1016/B978-0-12-813339-2. 00006-2

158. V.R. Cherkasov, E.N. Mochalova, A.V. Babenyshev, J.M. Rozenberg, I.L. Sokolov et al., Antibody-directed metalorganic framework nanoparticles for targeted drug delivery. Acta Biomater. 103, 223-236 (2019). https://doi.org/ 10.1016/j.actbio.2019.12.012

159. K.S. Kim, W. Park, K. Na, Gadolinium-chelate nanoparticle entrapped human mesenchymal stem cell via photochemical internalization for cancer diagnosis. Biomaterials 36, 90-97 (2014). https://doi.org/10.1016/j.biomaterials.2014.09.014

160. Y. Cong, Z.-Y. Qiao, H. Wang, Molecular self-assembly constructed in physiological conditions for cancer diagnosis and therapy. Adv. Ther. 1, 1800067 (2018). https://doi.org/ 10.1002/adtp.201800067

161. S. Stupp, H. Zha, L. Palmer, H. Cui, R. Bitton, Self-assembly of biomolecular soft matter. Bone 166, 9-30 (2013). https://doi.org/10.1161/CIRCULATIONAHA.110.956839

162. D.J. Toft, T.J. Moyer, S.M. Standley, Y. Ruff, A. Ugolkov et al., Coassembled cytotoxic and pegylated peptide amphiphiles form filamentous nanostructures with potent antitumor activity in models of breast cancer. ACS Nano 6, 7956-7965 (2012). https://doi.org/10.1021/nn302503s

163. M. He, J. Zhu, N. Yu, H. Kong, X. Zeng et al., The superior antitumor effect of self-assembled paclitaxel nanofilaments for lung cancer cells. Curr. Drug Deliv. 16, 171-178 (2018). https://doi.org/10.2174/15672018156661810170 94003

164. N.P. Truong, M.R. Whittaker, C.W. Mak, T.P. Davis, The importance of nanoparticle shape in cancer drug delivery. Expert Opin. Drug Deliv. 12, 129-142 (2015). https://doi. org/10.1517/17425247.2014.950564

165. W. Hoffman, F.G. Lakkis, G. Chalasani, B cells, antibodies, and more. Clin. J. Am. Soc. Nephrol. 11, 137-154 (2016). https://doi.org/10.2215/CJN.09430915

166. J.M. Redman, E.M. Hill, D. AlDeghaither, L.M. Weiner, Mechanisms of action of therapeutic antibodies for cancer. Mol. Immunol. 67, 28-45 (2015). https://doi.org/10.1016/j. molimm.2015.04.002

167. M.J. Adler, D.S. Dimitrov, Therapeutic antibodies against cancer. Hematol. Oncol. Clin. N. Am. 26, 447-481 (2012). https://doi.org/10.1016/j.hoc.2012.02.013

168. S. Weslen, R. Senthil, S. Sekar, Enhancing anti-cancer activity of erlotinib by antibody conjugated nano fibrin: in vitro studies on lung adenocarcinoma cell lines. Mater. Chem. Phys. 224, 328-333 (2019). https://doi.org/10.1016/j.match emphys.2018.11.061
169. Z. Wang, N. Sun, H. Liu, C. Chen, P. Ding et al., High-efficiency isolation and rapid identification of heterogeneous circulating tumor cells ( CTCs ) using dual-antibody-modified fluorescent-magnetic nanoparticles. ACS Appl. Mater. Interfaces 11(43), 39586-39593 (2019). https://doi.org/10.1021/ acsami.9b14051

170. J. Wan, W. Wu, R. Zhang, S. Liu, Y. Huang, Anti-EGFR antibody conjugated silica nanoparticles as probes for lung cancer detection. Exp. Ther. Med. 14(4), 3407-3412 (2017). https://doi.org/10.3892/etm.2017.4988

171. C. Tseng, T. Wang, G. Dong, S.Y. Wu, T. Young et al., Development of gelatin nanoparticles with biotinylated EGF conjugation for lung cancer targeting. Biomaterials 28, 3996-4005 (2007). https://doi.org/10.1016/j.biomaterials.2007.05.006

172. L. Yang, H. Mao, Y.A. Wang, Z. Cao, X. Peng et al., Single chain epidermal growth factor receptor antibody conjugated nanoparticles for in vivo tumor targeting and imaging. Small 5(2), 235-243 (2009). https://doi.org/10.1002/smll.20080 0714

173. B. Zhang, Y. Hu, Z. Pang, Modulating the tumor microenvironment to enhance tumor nanomedicine delivery. Front. Pharmacol. 8, 1-16 (2017). https://doi.org/10.3389/fphar. 2017.00952

174. K.T. Xenaki, S. Oliveira, P.M.P. van Bergen en Henegouwen, Antibody or antibody fragments: Implications for molecular imaging and targeted therapy of solid tumors. Front. Immunol. 8, 1287 (2017). https://doi.org/10.3389/fimmu.2017. 01287

175. M.A.T. Groves, L. Amanuel, J.I. Campbell, D.G. Rees, S. Sridharan et al., Antibody VH and VL recombination using phage and ribosome display technologies reveals distinct structural routes to affinity improvements with VH-VL interface residues providing important structural diversity. MAbs 6, 236-245 (2014). https://doi.org/10.4161/mabs.27261

176. S. Awwad, U. Angkawinitwong, Overview of antibody drug delivery. Pharmaceutics 10, 1-24 (2018). https://doi.org/10. 3390/pharmaceutics 10030083

177. R. Adams, L. Griffin, J.E. Compson, M. Jairaj, T. Baker et al., Extending the half-life of a fab fragment through generation of a humanized anti-human serum albumin Fv domain: an investigation into the correlation between affinity and serum half-life. MAbs 8, 336-1346 (2016). https:// doi.org/10.1080/19420862.2016.1185581

178. X. Peng, Y. Wang, D. Huang, Y. Wang, H.J. Shin et al., Targeted delivery of cisplatin to lung cancer using ScFvEGFRheparin-cisplatin. ACS Nano 5, 9480-9493 (2011). https:// doi.org/10.1021/nn202410f

179. R.M. Lu, Y.L. Chang, M.S. Chen, H.C. Wu, Single chain anti-c-Met antibody conjugated nanoparticles for in vivo tumor-targeted imaging and drug delivery. Biomaterials 32, 3265-3274 (2011). https://doi.org/10.1016/j.biomaterials. 2010.12.061

180. J.K. Myers, T.G. Oas, Preorganized secondary structure as an important determinant of fast protein folding. Nat. Struct. Biol. 8, 552-558 (2001). https://doi.org/10.1038/ 88626 
181. F.Y. Frejd, K. Kim, Affibody molecules as engineered protein drugs. Exp. Mol. Med. 49, 1-8 (2017). https://doi.org/10. 1038/emm.2017.35

182. J. Chaudhary, J. Bower, I.R. Corbin, Lipoprotein drug delivery vehicles for cancer: rationale and reason. Int. J. Mol. Sci. 20(24), 6327 (2019). https://doi.org/10.3390/ijms20246327

183. H. Lu, A biocompatible reconstituted high-density lipoprotein nano-system as a probe for lung cancer detection. Int. Med. J. Exp. Clin. Res. 21, 2726-2733 (2015). https://doi.org/10. 12659/MSM.895255

184. X. Ma, Q. Song, X. Gao, Reconstituted high-density lipoproteins: novel biomimetic nanocarriers for drug delivery. Acta Pharm. Sin. B 8, 51-63 (2018). https://doi.org/10.1016/j. apsb.2017.11.006

185. S. Raut, L. Mooberry, N. Sabnis, A. Garud, A.S. Dossou et al., Reconstituted HDL: drug delivery platform for overcoming biological barriers to cancer therapy. Front. Pharmacol. 9, 1-12 (2018). https://doi.org/10.3389/fphar.2018.01154

186. M.A.A. Castro, F. Dal-Pizzol, S. Zdanov, M. Soares, C.B. Müller et al., CFL1 expression levels as a prognostic and drug resistance marker in nonsmall cell lung cancer. Cancer 116, 3645-3655 (2010). https://doi.org/10.1002/cncr.25125

187. F.C.G. de Aquino, T.M. Guedes, A. Pires, H.P. Souza, Serum biomarkers for lung cancer screening: improving early detection and diagnosis. Rev. Med. 98, 59-71 (2019)

188. M.J. Campa, M.Z. Wang, B. Howard, M.C. Fitzgerald, E.F. Patz, Protein expression profiling identifies macrophage migration inhibitory factor and cyclophilin A as potential molecular targets in non-small cell lung cancer. Cancer Res. 63, 1652-1656 (2003)

189. L. Wang, C. Dong, X. Li, W. Han, X. Su, Anticancer potential of bioactive peptides from animal sources (review). Oncol. Rep. 38, 637-651 (2017). https://doi.org/10.3892/or.2017. 5778

190. E.J. McConnell, B. Devapatla, K. Yaddanapudi, K.R. Davis, The soybean-derived peptide lunasin inhibits non-small cell lung cancer cell proliferation by suppressing phosphorylation of the retinoblastoma protein. Oncotarget 6, 4649-4662 (2015). https://doi.org/10.18632/oncotarget.3080

191. G.M. Suarez-Jimenez, A. Burgos-Hernandez, J.M. Ezquerra-Brauer, Bioactive peptides and depsipeptides with anticancer potential: sources from marine animals. Mar. Drugs 10, 963-986 (2012). https://doi.org/10.3390/ md10050963

192. J. Thundimadathil, Cancer treatment using peptides: current therapies and future prospects. J. Amino Acids (2012). https://doi.org/10.1155/2012/967347

193. L. Yang, T. Mashima, S. Sato, M. Mochizuki, H. Sakamoto et al., Predominant suppression of apoptosome by inhibitor of apoptosis protein in non-small cell lung cancer H460 cells: therapeutic effect of a novel polyarginine-conjugated Smac peptide. Cancer Res. 63, 831-837 (2003)

194. H. Hariu, Y. Hirohashi, T. Torigoe, H. Asanuma, M. Hariu et al., Aberrant expression and potency as a cancer immunotherapy target of inhibitor of apoptosis protein family, Livin/
ML-IAP in lung cancer. Clin. Cancer Res. 11, 1000-1009 (2005)

195. G.E. Holt, P. Daftarian, Non-small-cell lung cancer homing peptide-labeled dendrimers selectively transfect lung cancer cells. Immunotherapy 10, 1349-1360 (2018). https://doi.org/ 10.2217/imt-2018-0078

196. W. Jin Jeong, J. Bu, L.J. Kubiatowicz, S.S. Chen, Y.S. Kim et al., Peptide-nanoparticle conjugates: a next generation of diagnostic and therapeutic platforms? Nano Converg. 5, 1-18 (2018). https://doi.org/10.1186/s40580-018-0170-1

197. L.E. Scheeren, D.R. Nogueira-librelotto, L.B. Macedo, Transferrin-conjugated doxorubicin-loaded PLGA nanoparticles with $\mathrm{pH}$-responsive behavior: a synergistic approach for cancer therapy. J. Nanopart. Res. 22(3), 1-18 (2020). https://doi. org/10.1007/s11051-020-04798-7

198. P. Upadhyay, S. Sarker, A. Ghosh, P. Gupta, S. Das et al., Transferrin ornamented thymoquinone loaded PEG-PLGA nanoparticle furnishes anticarcinogenic effect in non-small cell lung carcinoma through modulation of miR-34a and miR16. Biomater. Sci. 7, 4325-4344 (2019). https://doi.org/10. 1039/C9BM00912D

199. H. Thuy, Z. Chi, K. Yeol, C. Dai, Biointerfaces transferrinconjugated $\mathrm{pH}$-sensitive platform for effective delivery of porous palladium nanoparticles and paclitaxel in cancer treatment. Colloids Surf. B Biointerfaces 176, 265-275 (2019). https://doi.org/10.1016/j.colsurfb.2019.01.010

200. S. Raha, T. Paunesku, G. Woloschak, Peptide mediated cancer targeting of nanoconjugates. Wiley Interdiscip. Rev. Nanomed. Nanobiotechnol. 3, 269-281 (2011). https://doi. org/10.1002/wnan.121

201. S. Hatakeyama, K. Sugihara, T.K. Shibata, J. Nakayama, T.O. Akama et al., Targeted drug delivery to tumor vasculature by a carbohydrate mimetic peptide. Proc. Natl. Acad. Sci. USA 108(49), 19587-19592 (2011). https://doi.org/10.1073/pnas. 1105057108

202. F. Chen, G. Huang, Sugar ligand-mediated drug delivery. Future Med. Chem. 12, 161-171 (2019). https://doi.org/10. 4155/fmc-2019-0114

203. B. Jang, M.S. Moorthy, P. Manivasagan, L. Xu, Fucoidancoated $\mathrm{CuS}$ nanoparticles for chemo-and photothermal therapy against cancer. Oncotarget 9, 12649-12661 (2018). https://doi.org/10.18632/oncotarget.23898

204. A.D. Keefe, S. Pai, A. Ellington, Aptamers as therapeutics. Nat. Rev. Drug Discov. 9, 537-550 (2010). https://doi.org/ $10.1038 / \mathrm{nrd} 3141$

205. E. Zavyalova, A. Kopylov, DNA aptamer-based molecular nanoconstructions and nanodevices for diagnostics and therapy, in Nanostructures Engineering of Cells Tissues Organs. ed. by A.M. Grumezescu (Elsevier, Amsterdam, 2018), pp. 249-290. https://doi.org/10.1016/B978-0-12813665-2.00007-7

206. Y.U. Zhang, J. Zhao, J. Sun, L.U. Huang, Q. Li, Targeting lung cancer initiating cells by all-trans retinoic acidloaded lipid-PLGA nanoparticles with CD133 aptamers. Exp. Ther. Med. 16(6), 4639-4649 (2018). https://doi.org/ 10.3892/etm.2018.6762 
207. H. Wang, X. Zhao, C. Guo, D. Ren, Y. Zhao, Aptamerdendrimer bioconjugates for targeted delivery of miR-34a expressing plasmid and antitumor effects in non-small cell lung cancer cells. PLoS ONE 10(9), e0139136 (2015). https://doi.org/10.1371/journal.pone.0139136

208. F. Guo, Y. Hu, L. Yu, X. Deng, J. Meng et al., Enhancement of thermal damage to adenocarcinoma cells by iron nanoparticles modified with MUC1 aptamer. J. Nanosci. Nanotechnol. 16(3), 2246-2253 (2016). https://doi.org/10. 1166/jnn.2016.10941

209. W. Ping, Y. Gao, Y. Lu, H. Zhang, C. Cai, High specific detection and near-infrared photothermal therapy of lung cancer cells with high SERS active aptamer-silver-gold shell-core nanostructures. Analyst 138, 6501-6510 (2013). https://doi.org/10.1039/c3an01375h

210. X. Huang, J. Huang, D. Leng, S. Yang, Q. Yao et al., Gefitinib-loaded DSPE-PEG2000 nanomicelles with CD133 aptamers target lung cancer stem cells. World J. Surg. Oncol. 15, 1-10 (2017). https://doi.org/10.1186/ s12957-017-1230-4

211. M. Alibolandi, M. Ramezani, K. Abnous, F. Hadizadeh, AS1411 aptamer-decorated biodegradable polyethylene glycol e poly (lactic-co-glycolic acid) nanopolymersomes for the targeted delivery of gemcitabine to nonsmall cell lung cancer in vitro. J. Pharm. Sci. 105(5), 1741-1750 (2016). https://doi. org/10.1016/j.xphs.2016.02.021

212. J.K. Herr, J.E. Smith, C.D. Medley, D. Shangguan, W. Tan, Aptamer-conjugated nanoparticles for selective collection and detection of cancer cells. Anal. Chem. 78, 2918-2924 (2006). https://doi.org/10.1021/ac052015r

213. C.D. Medley, S. Bamrungsap, W. Tan, J.E. Smith, Aptamerconjugated nanoparticles for cancer cell detection. Anal. Chem. 83, 727-734 (2011). https://doi.org/10.1021/ac102 $263 \mathrm{v}$

214. S.A. Rooney, Lung surfactant. Environ. Health Perspect. 55, 205-226 (1984). https://doi.org/10.2307/3429704

215. R.K. Harishchandra, M. Saleem, H.J. Galla, Nanoparticle interaction with model lung surfactant monolayers. J. R. Soc. Interface 7, S15-26 (2010). https://doi.org/10.1098/rsif.2009. 0329.focus

216. W. Huang, Y. Lang, A. Hakeem, Y. Lei, L. Gan et al., Surfactin-based nanoparticles loaded with doxorubicin to overcome multidrug resistance in cancers. Int. J. Nanomed. 13, 1723-1736 (2018). https://doi.org/10.2147/IJN.S157368

217. A. Bakur, Y. Niu, H. Kuang, Q. Chen, Synthesis of gold nanoparticles derived from mannosylerythritol lipid and evaluation of their bioactivities. AMB Express 9, 62 (2019). https:// doi.org/10.1186/s13568-019-0785-6

218. J. Zhang, W. Tao, Y. Chen, D. Chang, T. Wang, Doxorubicin-loaded star-shaped copolymer PLGA-vitamin E TPGS nanoparticles for lung cancer therapy. J. Mater. Sci. Mater. Med. 26(4), 165 (2015). https://doi.org/10.1007/ s10856-015-5498-Z

219. M. Cheng, D. Ma, K. Zhi, B. Liu, W. Zhu, Synthesis of biotin-modified galactosylated chitosan nanoparticles and their characteristics in vitro and in vivo. Cell Physiol. Biochem. 50, 569-584 (2018). https://doi.org/10.1159/000494169

220. P.T. Wong, K. Sinniah, S.K. Choi, Riboflavin-conjugated multivalent dendrimer platform for cancer-targeted drug and gene delivery. Bioact. Eng. Nanopart. (2017). https://doi.org/ 10.1007/978-981-10-5864-6

221. S. Singh, N.K. Mehra, N.K. Jain, Development and characterization of the paclitaxel loaded riboflavin and thiamine conjugated carbon nanotubes for cancer treatment. Pharm. Res. 33, 1769-1781 (2016). https://doi.org/10.1007/ s11095-016-1916-2

222. S.Y. Kim, S.H. Cho, Y.M. Lee, L.Y. Chu, Biotin-conjugated block copolymeric nanoparticles as tumor-targeted drug delivery systems. Macromol. Res. 15, 646-655 (2007). https://doi.org/10.1007/BF03218945

223. N.C. Fan, F.Y. Cheng, J.A.A. Ho, C.S. Yeh, Photocontrolled targeted drug delivery: photocaged biologically active folic acid as a light-responsive tumor-targeting molecule. Angew. Chem. Int. Ed. 51, 8806-8810 (2012). https://doi.org/10. 1002/anie.201203339

224. C.Y. Wu, Y.C. Chen, Riboflavin immobilized $\mathrm{Fe}_{3} \mathrm{O}_{4}$ magnetic nanoparticles carried with n-butylidenephthalide as targetingbased anticancer agents. Artif. Cells Nanomed. Biotechnol. 47, 210-220 (2019). https://doi.org/10.1080/21691401.2018. 1548473

225. P. Parashar, C.B. Tripathi, M. Arya, J. Kanoujia, M. Singh et al., Biotinylated naringenin intensified anticancer effect of gefitinib in urethane-induced lung cancer in rats: favourable modulation of apoptotic regulators and serum metabolomics. Artif. Cells Nanomed. Biotechnol. 46, S598-S610 (2018). https://doi.org/10.1080/21691401.2018.1505738

226. E.V. Khaydukov, K.E. Mironova, V.A. Semchishen, A.N. Generalova, Riboflavin photoactivation by upconversion nanoparticles for cancer treatment. Sci. Rep. 12(6), 35103 (2016). https://doi.org/10.1038/srep35103

227. Y. Dai, H. Xing, F. Song, Y. Yang, Z. Qiu et al., Biotin-conjugated multilayer poly [D, L-lactide-co-glycolide]-lecithinpolyethylene glycol nanoparticles for targeted delivery of doxorubicin. J. Pharm. Sci. 105, 2949-2958 (2016). https:// doi.org/10.1016/j.xphs.2016.03.038

228. M.A. Quadir, S.W. Morton, L.B. Mensah, K. Shopsowitz, J. Dobbelaar et al., Ligand-decorated click polypeptide derived nanoparticles for targeted drug delivery applications. Nanotechnol. Biol. Med. 13, 1797-1808 (2017). https://doi.org/10. 1016/j.nano.2017.02.010

229. N.K. Garg, P. Dwivedi, C. Campbell, R.K. Tyagi, Site specific/targeted delivery of gemcitabine through anisamide anchored chitosan/poly ethylene glycol nanoparticles: an improved understanding of lung cancer therapeutic intervention. Eur. J. Pharm. Sci. 47, 1006-1014 (2012). https://doi. org/10.1016/j.ejps.2012.09.012

230. L. Wang, J. Pei, Z. Cong, Y. Zou, T. Sun et al., Development of anisamide-targeted PEGegylated gold nanorods to deliver epirubicin for chemo-photothermal therapy in tumor-bearing mice. Int. J. Nanomed. 14, 1817-1833 (2019). https://doi.org/ 10.2147/IJN.S192520 
231. X. Wang, H. Tang, C. Wang, J. Zhang, W. Wu et al., Phenylboronic acid-mediated tumor targeting of chitosan nanoparticles. Theranostics 6, 1378-1392 (2016). https://doi.org/ 10.7150/thno. 15156

232. J. Lee, J. Kim, Y.M. Lee, D. Park, S. Im et al., Self-assembled nanocomplex between polymerized phenylboronic acid and doxorubicin for efficient tumor-targeted chemotherapy. Acta Pharmacol. Sin. 38, 848-858 (2017). https://doi.org/10.1038/ aps.2017.16

233. Y. Baba, NanoBiodevices for cancer diagnosis, cancer therapy, and ips cell based regenerative medicine. (Japan Symposium 2015), https://www.gdch.de/fileadmin/downloads/ Veranstaltungen/Tagungen/2014_Tagungen/analytica/abstr acts/baba.pdf. Accessed 25 Oct 2020.

234. S. Kurbanoglu, B. Uslu, S.A. Ozkan, Nanobiodevices for Electrochemical Biosensing of Pharmaceuticals (Elsevier, Amsterdam, 2018). https://doi.org/10.1016/B978-0-12813665-2.00008-9

235. Y. Kashimura, A. Oshima, K. Sumitomo, Fabrication of nanobiodevices that utilize the function of membrane proteins. NTT Tech. Rev. 1-14 (2016)

236. S. Li, Q. Jiang, S. Liu, Y. Zhang, Y. Tian et al., A DNA nanorobot functions as a cancer therapeutic in response to a molecular trigger in vivo. Nat. Biotechnol. 36(7), 258-264 (2018). https://doi.org/10.1038/nbt.4071

237. A.C. Hortelão, T. Patiño, A. Perez-Jiménez, À. Blanco, S. Sánchez, Enzyme-powered nanobots enhance anticancer drug delivery. Adv. Funct. Mater. 28, 1-10 (2018). https://doi.org/ 10.1002/adfm. 201705086

238. T. Patino, R. Mestre, S. Sánchez, Miniaturized soft bio-hybrid robotics: a step forward into healthcare applications. Lab Chip 16, 3626-3630 (2016). https://doi.org/10.1039/c6lc9 $0088 \mathrm{~g}$

239. T. Yasui, N. Kaji, Y. Baba, Nanobiodevices for biomolecule analysis and imaging. Annu. Rev. Anal. Chem. 6, 83-96 (2013). https://doi.org/10.1146/annur ev-anchem-062012-092619

240. A. Gao, X. Yang, J. Tong, L. Zhou, Y. Wang et al., Biosensors and bioelectronics multiplexed detection of lung cancer biomarkers in patients serum with CMOS-compatible silicon nanowire arrays. Biosens. Bioelectron. 91, 482-488 (2017). https://doi.org/10.1016/j.bios.2016.12.072

241. K.K. Jain, The role of nanobiotechnology in drug discover. Drug Discovery Today. 10(21), 1435-1442 (2005). https:// doi.org/10.1016/S1359-6446(05)03573-7

242. R.L. Keith, Lung cancer chemoprevention. Proc. Am. Thorac. Soc. 9(2), 52-56 (2012). https://doi.org/10.1513/ pats.201107-038MS

243. J. Soria, E.S. Kim, J. Fayette, S. Lantuejoul, E. Deutsch, W.K. Hong, Chemoprevention of lung cancer. Lancet Oncol. 4(11), 659-669 (2003). https://doi.org/10.1016/ S1470-2045(03)01244-0

244. H. Oliveres, C. Caglevic, F. Passiglia, S. Taverna, E. Smits et al., Vaccine and immune cell therapy in non-small cell lung cancer. J. Thorac. Dis. 10, S1602-S1614 (2018). https://doi.org/10.21037/jtd.2018.05.134
245. U.K. Kar, M.K. Srivastava, A. Andersson, F. Baratelli, M. Huang et al., Novel CCL21-vault nanocapsule intratumoral delivery inhibits lung cancer growth. PLoS ONE 6(5), e18758 (2011). https://doi.org/10.1371/journal.pone. 0018758

246. C. Butts, M.A. Socinski, P.L. Mitchell, N. Thatcher, L. Havel et al., Tecemotide ( L-BLP25) versus placebo after chemoradiotherapy for stage III non-small-cell lung cancer ( START ): a randomised, double-blind, phase 3 trial. Lancet Oncol. 15(1), 59-68 (2014). https://doi.org/10.1016/ S1470-2045(13)70510-2

247. R. Wen, A.C. Umeano, Y. Kou, J. Xu, A.A. Farooqi, Nanoparticle systems for cancer vaccine. Nanomedicine 14(5), 627-648 (2019). https://doi.org/10.2217/nnm-2018-0147

248. C. Butts, N. Murray, A. Maksymiuk, G. Goss, E. Marshall et al., Randomized phase IIB trial of BLP25 liposome vaccine in stage IIIB and IV non-small-cell lung cancer. J. Clin. Oncol. 23(27), 6674-6681 (2020). https://doi.org/10. 1200/JCO.2005.13.011

249. A.J. Grippin, E.J. Sayour, D.A. Mitchell, Translational nanoparticle engineering for cancer vaccines. Oncoimmunology 6(10), e1290036 (2017). https://doi.org/10.1080/ 2162402X.2017.1290036

250. M. Fusciello, F. Fontana, S. Tähtinen, C. Capasso, S. Feola et al., Artificially cloaked viral nanovaccine for cancer immunotherapy. Nat. Commun. 10, 1-13 (2019). https:// doi.org/10.1038/s41467-019-13744-8

251. T. Storni, C. Ruedl, K. Schwarz, R.A. Schwendener, W.A. Renner et al., Nonmethylated CG motifs packaged into virus-like particles induce protective cytotoxic $\mathrm{T}$ cell responses in the absence of systemic side effects. J. Immunol. 172, 1777-1785 (2004). https://doi.org/10.4049/jimmu nol.172.3.1777

252. K. Wilson, Y.K. Tam, Lipid-based delivery of CpG oligodeoxynucleotides for cancer immunotherapy. Expert Rev. 2, 181-193 (2009). https://doi.org/10.1586/17512433.2.2.181

253. S. Song, Y. Wang, Y. Zhang, F. Wang, Y. He et al., Augmented induction of $\mathrm{CD} 8+$ cytotoxic $\mathrm{T}$-cell response and antitumor effect by DCs pulsed with virus-like particles packaging with CpG. Cancer Lett. 256, 90-100 (2007). https://doi. org/10.1016/j.canlet.2007.06.004

254. Z. Xu, S. Ramishetti, Y. Tseng, S. Guo, Y. Wang et al., Multifunctional nanoparticles co-delivering Trp2 peptide and $\mathrm{CpG}$ adjuvant induce potent cytotoxic T-lymphocyte response against melanoma and its lung metastasis. J. Control. Release 172, 259-265 (2013). https://doi.org/10.1016/j.jconrel.2013. 08.021

255. Q. Chen, H. Bai, W. Wu, G. Huang, Y. Li, Bioengineering bacterial vesicle-coated polymeric nanomedicine for enhanced cancer immunotherapy and metastasis prevention. Nano Lett. 20(11), 11-21 (2019). https://doi.org/10.1021/acs. nanolett.9b02182

256. K. Chen, X. Cao, M. Li, Y. Su, H. Li et al., A TRAILdelivered lipoprotein-bioinspired nanovector engineering stem cell-based platform for inhibition of lung metastasis of 
melanoma. Theranostics 9, 2984-2998 (2019). https://doi. org/10.7150/thno.31157

257. N. Dobrovolskienè, V. Pašukonienè, A. Darinskas, J.A. Kraśko, K. Žilionytė et al., Tumor lysate-loaded Bacterial Ghosts as a tool for optimized production of therapeutic dendritic cell-based cancer vaccines. Vaccine 36, 4171-4180 (2018). https://doi.org/10.1016/j.vaccine.2018.06.016

258. G. Sozzi, D. Conte, M. Leon, R. Cirincione, L. Roz et al., Quantification of free circulating DNA As a diagnostic marker in lung cancer. J. Clin. Oncol. 21, 3902-3908 (2003). https://doi.org/10.1200/JCO.2003.02.006

259. R. Valenti, V. Huber, P. Filipazzi, L. Pilla, G. Sovena et al., Human tumor-released microvesicles promote the differentiation of myeloid cells with transforming growth factorB-mediated suppressive activity on T lymphocytes. Cancer Res. 66(18), 9290-9298 (2006). https://doi.org/10.1158/ 0008-5472.CAN-06-1819

260. F. Andre, N.E.C. Schartz, M. Movassagh, C. Flament, P. Pautier et al., Malignant effusions and immunogenic tumourderived exosomes. Lancet 360, 295-305 (2002). https://doi. org/10.1016/S0140-6736(02)09552-1

261. G. Rabinowits, C. Gerçel-Taylor, J.M. Day, D.D. Taylor, G.H. Kloecker, Exosomal microRNA: A diagnostic marker for lung cancer. Clin. Lung Cancer 10, 42-46 (2009). https:// doi.org/10.3816/CLC.2009.n.006

262. M. Mitas, L. Hoover, G. Silvestri, C. Reed, M. Green et al., Lunx is a superior molecular marker for detection of nonsmall lung cell cancer in peripheral blood. J. Mol. Diagn. 5, 237-242 (2003). https://doi.org/10.1016/S15251578(10) 60480-1

263. T.N. Zamay, G.S. Zamay, O.S. Kolovskaya, R.A. Zukov, M.M. Petrova et al., Current and prospective protein biomarkers of lung cancer. Cancers 9(11), 155 (2017). https://doi.org/ 10.3390/cancers9110155

264. J. Beane, J.D. Campbell, J. Lel, J. Vick, A. Spira, Genomic approaches to accelerate cancer interception. Lancet Oncol. 18(8), e494-e502 (2017). https://doi.org/10.1016/S14702045(17)30373-X

265. N. Hasan, R. Kumar, M.S. Kavuru, Lung cancer screening beyond low-dose computed tomography: the role of novel biomarkers. Lung 192, 639-648 (2014). https://doi.org/10. 1007/s00408-014-9636-z

266. S. Nagrath, L.V. Sequist, S. Maheswaran, D.W. Bell, D. Irimia et al., Isolation of rare circulating tumour cells in cancer patients by microchip technology. Nature 450, 1235-1239 (2007). https://doi.org/10.1038/nature06385

267. A. Montazeri, C.R. Gillis, J. McEwen, Quality of life in patients with lung cancer: a review of literature from 1970 to 1995. Chest 113, 467-481 (1998). https://doi.org/10.1378/ chest.113.2.467

268. J. Bar, M. Damianovich, G. Hout Siloni, E. Dar, Y. Cohen et al., Genetic mutation screen in early non-small-cell lung cancer (NSCLC) specimens. Clin. Lung Cancer 15, 159-165 (2014). https://doi.org/10.1016/j.cllc.2013.11.005
269. R. Salgia, Diagnostic challenges in non-small-cell lung cancer: an integrated medicine approach. Future Oncol. 11, 489-500 (2015). https://doi.org/10.2217/fon.14.275

270. L.V. Sequist, R.S. Heist, A.T. Shaw, P. Fidias, R. Rosovsky et al., Implementing multiplexed genotyping of non-smallcell lung cancers into routine clinical practice. Ann. Oncol. 22, 2616-2624 (2011). https://doi.org/10.1093/annonc/ mdr489

271. I.S. Hagemann, S. Devarakonda, C.M. Lockwood, D.H. Spencer, Clinical next-generation sequencing in patients with non-small cell lung cancer. Cancer (2015). https://doi.org/10. 1002/cncr.29089

272. F. Montani, M.J. Marzi, F. Dezi, E. Dama, R.M. Carletti et al., miR-Test: a blood test for lung cancer early detection. J. Natl. Cancer Inst. 107, 6 (2015). https://doi.org/10.1158/ 1538-7445.AM2015-1573

273. S.K. Sahoo, V. Labhasetwar, Nanotech approaches to drug delivery and imaging. Drug Discov. Today 8, 1112-1120 (2003). https://doi.org/10.1016/S1359-6446(03)02903-9

274. J. Zhang, Y. Cao, Aptasensrs, Nano-Inspired Biosensors for Protein Assay with Clinical Applications ( Elsevier, Amsterdam, 2019), pp. 139-166. https://doi.org/10.1016/b978-0-12815053-5.00006-4

275. J. Xu, S. Zhang, W. Zhang, E. Xie, M. Gu et al., SP70targeted imaging for the early detection of lung adenocarcinoma. Sci. Rep. 10, 1-8 (2020). https://doi.org/10.1038/ s41598-020-59439-9

276. P. Cai, D. Su, W. Yang, Z. He, C. Zhang et al., Inherently $\mathrm{PET} / \mathrm{CT}$ dual modality imaging lipid nanocapsules for early detection of orthotopic lung tumors. ACS Appl. Bio-Mater. 3, 611-621 (2020). https://doi.org/10.1021/acsabm.9b00993

277. S.H. Yoon, J.M. Goo, S.M. Lee, C.M. Park, H.J. Seo et al., Positron emission tomography/magnetic resonance imaging evaluation of lung cancer. J. Thorac. Imaging 29, 4-16 (2014). https://doi.org/10.1097/rti.0000000000000062

278. L. Xia, X. Guo, T. Liu, X. Xu, J. Jiang et al., Multimodality imaging of naturally active melanin nanoparticles targeting somatostatin receptor subtype 2 in human small-cell lung cancer. Nanoscale 11(30), 14400-14409 (2019). https://doi. org/10.1039/c9nr04371c

279. B.C. Chen, Y.S. Munot, S.B. Salunke, Y. Wang, R. Lin et al., A triantennary dendritic galactoside-capped nanohybrid with a $\mathrm{ZnS} / \mathrm{CdSe}$ nanoparticle core as a hydrophilic, fluorescent, multivalent probe for metastatic lung cancer cells. Adv. Funct. Mater. 18(4), 527-540 (2008). https://doi.org/10.1002/ adfm.200700449

280. Y. Yang, M. Lyu, J.H. Li, D.M. Zhu, Y.F. Yuan et al., Ultrasmall bimetallic iron-palladium (FePd) nanoparticle loaded macrophages for targeted tumor photothermal therapy in NIR-II biowindows and magnetic resonance imaging. RSC Adv. 9, 33378-33387 (2019). https://doi.org/10.1039/c9ra0 $5649 \mathrm{a}$

281. Y. Li, J. Xuan, Y. Song, W. Qi, B. He et al., Nanoporous glass integrated in volumetric bar-chart chip for point-of-care diagnostics of non-small cell lung cancer. ACS Nano 10(1), 1640-1647 (2016). https://doi.org/10.1021/acsnano.5b07357 
282. Y. Huang, Y. Li, Cancer nanobiotechnolgy. Acta Pharmacol. Sin. 38(6), 735-737 (2017). https://doi.org/10.1038/aps.2017. 48

283. D.M. Valcourt, J. Harris, R.S. Riley, M. Dang, J. Wang, E.S. Day, Advances in targeted nanotherapeutics: from bioconjugation to biomimicry. Nano Res. 11, 4999-5016 (2018). https://doi.org/10.1007/s12274-018-2083-Z

284. A. Parodi, R. Molinaro, M. Sushnitha, M. Evangelopoulos, J.O. Martinez et al., Biomaterials bio-inspired engineering of cell- and virus-like nanoparticles for drug delivery. Biomaterials 147, 155-168 (2017). https://doi.org/10.1016/j.bioma terials.2017.09.020

285. A. Pasto, F. Giordano, M. Evangelopoulos, A. Amadori, E. Tasciotti, Cell membrane protein functionalization of nanoparticles as a new tumor-targeting strategy. Clin. Transl. Med. 8(1), 1-9 (2019). https://doi.org/10.1186/s40169019-0224-y

286. J. Du, L.A. Lane, S. Nie, Stimuli-responsive nanoparticles for targeting the tumor microenvironment. J. Control. Release 219, 205-214 (2015). https://doi.org/10.1016/j.jconrel.2015. 08.050

287. B. Chen, W. Dai, B. He, H. Zhang, X. Wang et al., Current multistage drug delivery systems based on the tumor microenvironment. Theranostics 7, 538-558 (2017). https://doi.org/ $10.7150 /$ thno. 16684

288. X. Sun, J. Li, C. Guo, H. Xing, J. Xu et al., Pharmacokinetic effects of curcumin on docetaxel mediated by OATP1B1, OATP1B3 and CYP450s. Drug Metab. Pharmacokinet. 31, 269-275 (2016). https://doi.org/10.1016/j.dmpk.2016.02.005

289. Y.W. Kong, E.C. Dreaden, P.T. Hammond, M.B. Yaffe, Exploiting Nanocarriers for Combination Cancer Therapy. Intracecuular Delivery (Springer, Cham, 2016), pp. 375-402. https://doi.org/10.1007/978-3-319-43525-1

290. Z. Binkhathlan, A. Lavasanifar, P-glycoprotein inhibition as a therapeutic approach for overcoming multidrug resistance in cancer: current status and future perspectives. Curr. Cancer Drug Targets 12, 326-346 (2013). https://doi.org/10.2174/ 15680096113139990076

291. J. He, C. Gong, J. Qin, M. Li, S. Huang, Cancer cell membrane decorated silica nanoparticle loaded with miR495 and doxorubicin to overcome drug resistance for effective lung cancer therapy. Nanoscale Res. Lett. 14(1), 339 (2019)

292. S. Rawal, M.M. Patel, Threatening cancer with nanoparticle aided combination oncotherapy. J. Control. Release 301, 76-109 (2019). https://doi.org/10.1016/j.jconrel.2019.03.015

293. H. Wu, Y. Xin, J. Zhao, D. Sun, W. Li et al., Metronomic docetaxel chemotherapy inhibits angiogenesis and tumor growth in a gastric cancer model. Cancer Chemother. Pharmacol. 68, 879-887 (2011). https://doi.org/10.1007/s00280-011-1563-6

294. X. Liu, D. Wang, P. Zhang, Y. Li, Recent advances in nanosized drug delivery systems for overcoming the barriers to anti-PD immunotherapy of cancer. Nano Today 29, 100801 (2019). https://doi.org/10.1016/j.nantod.2019.100801

295. S. Burgio, L. Noori, A. Marino Gammazza, C. Campanella, M. Logozzi et al., Extracellular vesicles-based drug delivery systems: a new challenge and the exemplum of malignant pleural mesothelioma. Int. J. Mol. Sci. 15, 5432 (2020). https://doi.org/10.3390/ijms21155432

296. K. Sakura, C. Lee, Y. Kaneda, T. Nakano, S. Atagi et al., Hemagglutinating virus of japan envelope (HVJ-E: inactivated viral nanoparticles) against chemotherapy-resistant pleural mesothelioma. J. Thorac. Oncol. 13, S606-S607 (2018). https://doi.org/10.1016/j.jtho.2018.08.921

297. Y. Sakurai, A. Kato, Y. Hida, J. Hamada, N. Maishi et al., Synergistic enhancement of cellular uptake with CD44expressing malignant pleural mesothelioma by combining cationic liposome and hyaluronic acid-lipid conjugate. J. Pharm. Sci. 108, 3218-3224 (2019). https://doi.org/10. 1016/j.xphs.2019.06.012

298. A. Singh, P. Majumder, J. Schneider, C.D. Hoang, Presented at Proceedings of the Annual Meeting of the American Association for Cancer Research. A novel peptide based microRNA nanoparticle hydrogel composite attenuates mesothelioma growth, Philadelphia (PA) (April and Jun, 2020)

299. Y. Huang, J. Gu, Z. Yan, X. Hu, D. He et al., Cytomembranemimicking nanocarriers with a scaffold consisting of a CD44targeted endogenous component for effective asparaginase supramolecule delivery. Nanoscale 12, 12083-12097 (2020). https://doi.org/10.1039/D0NR02588G

300. R.J. Whitener, J. Wower, M. Byrne, Avidity-driven targeting of a novel biohybrid nanoscale carrier engineered for high therapeutic payload and extended release of anticancer drugs to treat small cell lung cancer, in Food, Pharmaceutical and Bioengineering Division 2014-Core Programming Area at the 2014 AIChE Annual Meeting, 2014 Jan 1. AIChE (2014)

301. P. Mathur, S. Sharma, S. Rawal, B. Patel, M.M. Patel, Fabrication, optimization and invitro evaluation of long chain lipid based PEGylated NLCs for oral delivery of docetaxel in lung cancer. J. Liposome Res. 30(2), 182-196 (2020). https://doi. org/10.1080/08982104.2019.1614055

302. P. Lv, W. Wei, H. Yue, T. Yang, L. Wang, Porous quaternized chitosan nanoparticles containing paclitaxel nanocrystals improved therapeutic efficacy in non-small-cell lung cancer after oral administration. Biomacromolecules 12(12), 42304239 (2011). https://doi.org/10.1021/bm2010774

303. I. Kim, H. Jun, T. Hyung, E. Seong, K. Taek et al., Biomaterials doxorubicin-loaded porous PLGA microparticles with surface attached TRAIL for the inhalation treatment of metastatic lung cancer. Biomaterials 34, 6444-6453 (2013). https://doi.org/10.1016/j.biomaterials.2013.05.018

304. A. Garg, N.K. Sahu, A.K. Yadav, Usnic acid-loaded bioinspired heparin modified-cellulose acetate phthalate nanoparticle (s) as an efficient carrier for site-specific delivery in lung cancer cells. Int. J. Pharm. Investig. 8(2), 53-62 (2018). https://doi.org/10.4103/jphi.JPHI

305. E.J. Kwon, J.H. Lo, S.N. Bhatia, Smart nanosystems: bioinspired technologies that interact with the host environment. Proc. Natl. Acad. Sci. USA 112(47), 14460-14466 (2015). https://doi.org/10.1073/pnas.1508522112

306. R. Rosiere, M. Van Woensel, M. Gelbcke, V. Mathieu, J. Hecq et al., A new folate-grafted chitosan derivative to improve the delivery of paclitaxel-loaded solid lipid nanoparticles for lung 
tumour therapy by inhalation. Mol. Pharm. 15(3), 899-910 (2018). https://doi.org/10.1021/acs.molpharmaceut.7b00846

307. J.A. MacDiarmid, N.B. Mugridge, J.C. Weiss, L. Phillips, A.L. Burn et al., Bacterially derived $400 \mathrm{~nm}$ particles for encapsulation and cancer cell targeting of chemotherapeutics. Cancer Cell 11, 431-445 (2007). https://doi.org/10.1016/j. ccr.2007.03.012

308. G. Chen, Y. Zhang, H. Deng, Z. Tang, J. Mao, L. Wang, Pursuing for the better lung cancer therapy effect: comparison of two different kinds of hyaluronic acid and nitroimidazole co-decorated nanomedicines. Biomed. Pharmacother. 125, 1-11 (2020). https://doi.org/10.1016/j.biopha.2020.109988

309. C. Chi, F. Li, H. Liu, S. Feng, Docetaxel-loaded biomimetic nanoparticles for targeted lung cancer therapy in vivo. J. Nanopart. Res. 21, 1-10 (2019). https://doi.org/10.1007/ s11051-019-4580-8

310. H. Wang, Z. Wang, Y. Tu, Y. Li, T. Xu et al., Homotypic targeting upconversion nano-reactor for cascade cancer starvation and deep-tissue phototherapy. Biomaterials 235, 119765 (2020). https://doi.org/10.1016/j.biomaterials.2020.119765

311. X. Ouyang, X. Wang, H. Kraatz, S. Ahmadi, J. Gao et al., A Trojan horse biomimetic delivery strategy using mesenchymal stem cells for PDT/PTT therapy against lung melanoma metastasis. Biomater. Sci. 8(4), 1160-1170 (2020). https:// doi.org/10.1039/c9bm01401b

312. W. Cao, B. Liu, F. Xia, M. Duan, Y. Hong et al., $\mathrm{MnO}_{2} @$ Ce6-loaded mesenchymal stem cells as an "oxygen-laden guided-missile" for the enhanced photodynamic therapy on lung cancer. Nanoscale 12, 3090-3102 (2020). https://doi. org/10.1039/C9NR07947E

313. C. Chiang, Y. Lin, R. Lee, Y. Lai, H. Cheng et al., Combination of fucoidan-based magentic nanoparticles and immunomodulators enhances tumor-localized immunotherapy. Nat. Nanotechnol. 13, 764-754 (2018). https://doi.org/10.1038/ s41565-018-0146-7

314. A. Ohradanova-Repic, E. Nogueira, I. Hartl, A.C. Gomes, A. Preto et al., Fab antibody fragment-functionalized liposomes for specific targeting of antigen-positive cells. Nanomed. Nanotechnol. Biol. Med. 14, 123-130 (2018). https://doi. org/10.1016/j.nano.2017.09.003

315. B. Li, H.U.I. Lin, J. Fan, J. Lan, Y. Zhong et al., CD59 is overexpressed in human lung cancer and regulates apoptosis of human lung cancer cells. Int. J. Oncol. 43(3), 850-858 (2013). https://doi.org/10.3892/ijo.2013.2007

316. M. Moro, D. Di Paolo, M. Milione, G. Centonze, V. Bornaghi et al., Coated cationic lipid-nanoparticles entrapping miR660 inhibit tumor growth in patient-derived xenografts lung cancer models. J. Control. Release 308, 44-56 (2019). https:// doi.org/10.1016/j.jconrel.2019.07.006

317. P. Zarogouldis, N.K. Karamanos, K. Porpodis, K. Domvri, H. Huang et al., Vectors for inhaled gene therapy in lung cancer. Application for Nano oncology and safety of bio nanotechnology. Int. J. Mol. Sci. 13, 10828-10862 (2012). https://doi.org/10.3390/ijms130910828

318. Y. Yan, L. Liu, H. Xiong, J.B. Miller, K. Zhou et al., Functional polyesters enable selective siRNA delivery to lung cancer over matched normal cells. Proc. Natl. Acad. Sci. USA 113, E5702-E5710 (2016). https://doi.org/10.1073/ pnas. 1606886113

319. M.M.A. Elwakil, I.A. Khalil, Y.H.A. Elewa, K. Kusumoto, Lung-endothelium-targeted nanoparticles based on a $\mathrm{pH}$ sensitive lipid and the GALA peptide enable robust gene silencing and the regression of metastatic lung cancer. Adv. Funct. Mater. 1807677, 1-13 (2019). https://doi.org/10. 1002/adfm.201807677

320. P. Merckx, L. De Backer, L. Van Hoecke, R. Guagliardo, M. Echaide et al., Surfactant protein B (SP-B) enhances the cellular siRNA delivery of proteolipid coated nanogels for inhalation therapy. Acta Biomater. 78, 236-246 (2018). https://doi.org/10.1016/j.actbio.2018.08.012

321. C. Lian, J. Zhang, B. Ruan, K. Ying, Near infrared lightactuated PEG wrapping carbon nanodots loaded cisplatin for targeted therapy of lung cancer therapy. J. Clust. Sci. (2020). https://doi.org/10.1007/s10876-020-01769-9

322. M. Reda, W. Ngamcherdtrakul, S. Gu, D.S. Bejan, N. Siriwon et al., PLK1 and EGFR targeted nanoparticle as a radiation sensitizer for non-small cell lung cancer. Cancer Lett. 467, 9-18 (2019). https://doi.org/10.1016/j.canlet.2019.09. 014

323. A.R. Travis, V.A. Liau, A.C. Agrawal, D.E. Cliffel, Small gold nanoparticles presenting linear and looped Cilengitide analogues as radiosensitizers of cells expressing $\alpha \vee \beta 3$ integrin. J. Nanopart. Res. 19, 361 (2017)

324. V.S. Marangoni, J.C. Bernardi, I.B. Reis, W.J. Fa, Photothermia and activated drug release of natural cell membrane coated plasmonic gold nanorods and $\beta$-lapachone. ACS Appl. Biomater. 2, 728-736 (2019). https://doi.org/ 10.1021/acsabm.8b00603

325. F. Li, Y. Wang, W. Chen, D. Wang, Y. Zhou et al., Co-delivery of VEGF siRNA and etoposide for enhanced anti-angiogenesis and anti-proliferation effect via multi-functional nanoparticles for orthotopic non-small cell lung cancer treatment. Theranostics 9, 5886-5898 (2019). https://doi. org/10.7150/thno.32416

326. W. Song, J. Kuang, C. Li, M. Zhang, Enhanced immunotherapy based on photodynamic therapy for both primary and lung metastasis tumor eradication enhanced immunotherapy based on photodynamic therapy for both primary and lung metastasis tumor eradication. ACS Nano 12(2), 1978-1989 (2018). https://doi.org/10.1021/acsnano.7b09112

327. X. Liu, X. Cheng, F. Wang, L. Feng, Y. Wang et al., Targeted delivery of SNX-2112 by polysaccharide-modified graphene oxide nanocomposites for treatment of lung cancer. Carbohydr. Polym. 185, 85-95 (2018). https://doi.org/ 10.1016/j.carbpol.2018.01.014

328. T. Yokoyama, J. Tam, S. Kuroda, A.W. Scott, J. Aaron et al., EGFR-targeted hybrid plasmonic magnetic nanoparticles synergistically induce autophagy and apoptosis in non-small cell lung cancer cells. PLoS ONE 6, e25507 (2011). https://doi.org/10.1371/journal.pone.0025507

329. K.L. Robertson, C.M. Soto, M.J. Archer, O. Odoemene, J.L. Liu, Engineered T4 viral nanoparticles for cellular imaging 
and flow cytometry. Bioconjug. Chem. 22, 595-604 (2011). https://doi.org/10.1021/bc100365j

330. S.-D. Lii, L. Huang, Surface-modified LPD nanoparticles for tumor targeting. Ann. N. Y. Acad. Sci. 8, 1-8 (2006). https://doi.org/10.1196/annals.1348.001

331. S.A. Meenach, K.W. Anderson, J.Z. Hilt, R.C. McGarry, H.M. Mansour, High-performing dry powder inhalers of paclitaxel DPPC/DPPG lung surfactant-mimic multifunctional particles in lung cancer: physicochemical characterization, in vitro aerosol dispersion, and cellular studies. AAPS PharmSciTech 15, 1574-1587 (2014). https://doi. org/10.1208/s12249-014-0182-z

332. L. Cheng, F.Z. Huang, L.F. Cheng, Y.Q. Zhu, Q. Hu et al., GEII-modified liposomes for non-small cell lung cancer targeting: preparation, ex vitro and in vivo evaluation. Int. J. Nanomed. 9, 921-935 (2014). https://doi.org/10.2147/ IJN.S53310

333. C. Lin, X. Zhang, H. Chen, Z. Bian, G. Zhang et al., Dualligand modified liposomes provide effective local targeted delivery of lung-cancer drug by antibody and tumor lineage-homing cell-penetrating peptide. Drug Deliv. 25, 256-266 (2018). https://doi.org/10.1080/10717544.2018. 1425777

334. H. Ujiie, L. Ding, R. Fan, Porphyrin-high-density lipoprotein: a novel photosensitizing nanoparticle for lung cancer therapy. Ann. Thorac. Surg. 107, 369-377 (2019). https:// doi.org/10.1016/j.athoracsur.2018.08.053

335. W. Liu, M. Ruan, Y. Wang, R. Song, X. Ji et al., Lighttriggered biomimetic nanoerythrocyte for tumor-targeted lung metastatic combination therapy of malignant melanoma. Small (Nano Micro) 1801754, 1-15 (2018). https:// doi.org/10.1002/smll.201801754

336. K. Ding, C. Zheng, L. Sun, X. Liu, Y. Yin et al., NIR lightinduced tumor phototherapy using ICG delivery system based on platelet-membrane-camouflaged hollow bismuth selenide nanoparticles. Chin. Chem. Lett. 31(5), 1168-1172 (2019). https://doi.org/10.1016/j.cclet.2019.10.040

337. R. Meir, K. Shamalov, O. Betzer, M. Motiei, M. Horovitz et al., Nanomedicine for cancer immunotherapy: tracking cancer- specific T-cells in vivo with gold nanoparticles and CT imaging nanomedicine for cancer immunotherapy: tracking cancer-specific T-cells in vivo with gold nanoparticles and CT imaging. ACS Nano (2015). https://doi.org/ 10.1021/acsnano.5b01939

338. J. Conde, C. Bao, Y. Tan, D. Cui, E.R. Edelman et al., Dual targeted immunotherapy via in vivo delivery of biohybrid RNAi-peptide nanoparticles to tumor-associated macrophages and cancer cells. Adv. Funct. Meter. 25, 41834194 (2015). https://doi.org/10.1002/adfm.201501283

339. N.N. Parayath, A. Parikh, M.M. Amiji, Repolarization of tumor-associated macrophages in a genetically engineered nonsmall cell lung cancer model by intraperitoneal administration of hyaluronic acid-based nanoparticles encapsulating MicroRNA-125b. Nano Lett. 18, 3571-3579 (2018). https:// doi.org/10.1021/acs.nanolett.8b00689
340. A. Mukherjee, J. Bhattacharyya, M.V. Sagar, A. Chaudhuri, Liposomally encapsulated CDC20 siRNA inhibits both solid melanoma tumor growth and spontaneous growth of intravenously injected melanoma cells on mouse lung. Drug Deliv. Transl. Res. 3, 224-234 (2013). https://doi.org/10.1007/ s13346-013-0141-3

341. S. Ganesh, A.K. Iyer, D.V. Morrissey, M.M. Amiji, Hyaluronic acid based self-assembling nanosystems for CD44 target mediated siRNA delivery to solid tumors. Biomaterials 34, 3489-3502 (2013). https://doi.org/10.1016/j.biomateria 1s.2013.01.077

342. X. Zhang, Q. Wang, L. Qin, H. Fu, Y. Fang et al., EGF-modified mPEG-PLGA-PLL nanoparticle for delivering doxorubicin combined with Bcl-2 siRNA as a potential treatment strategy for lung cancer EGF-modified mPEG-PLGA-PLL nanoparticle for delivering doxorubicin combined with Bcl-2 siRNA as a potential treatment. Drug Deliv. (2016). https:// doi.org/10.3109/10717544.2015.1126769

343. S. Shi, M. Zhou, X. Li, M. Hu, C. Li et al., Synergistic active targeting of dually integrin $\alpha v \beta 3 / \mathrm{CD} 44$-targeted nanoparticles to B16F10 tumors located at different sites of mouse bodies. J. Control. Release 235, 1-13 (2016). https://doi.org/ 10.1016/j.jconrel.2016.05.050

344. T. Tan, H. Hu, H. Wang, J. Li, Z. Wang et al., Bioinspired lipoproteins-mediated photothermia remodels tumro stroma to improve cancer cell accessibility of second nanoparticles. Nat. Commun. 10, 1-17 (2019). https://doi.org/10.1038/ s41467-019-11235-4

345. Q. Chen, L. Xu, C. Liang, C. Wang, R. Peng et al., Photothermal therapy with immune adjuvant nanoparticles together with checkpoint blockade for effective cancer immunotherapy. Nat. Commun. 7, 1-13 (2016). https://doi.org/10.1038/ ncomms 13193

346. Y.F. Wu, H.C. Wu, C.H. Kuan, C.J. Lin, L.W. Wang et al., Multi-functionalized carbon dots as theranostic nanoagent for gene delivery in lung cancer therapy. Sci. Rep. 6, 1-12 (2016). https://doi.org/10.1038/srep21170

347. X.L. Song, R.J. Ju, Y. Xiao, X. Wang, S. Liu et al., Application of multifunctional targeting epirubicin liposomes in the treatment of non-small-cell lung cancer. Int. J. Nanomed. 12, 7433-7451 (2017). https://doi.org/10.2147/IJN.S141787

348. A. Mukherjee, M. Paul, S. Mukherjee, Recent progress in the theranostics application of nanomedicine in lung Cancer. Cancers 11, 1-18 (2019). https://doi.org/10.3390/cancers110 50597

349. M. Shevtsov, S. Stangl, B. Nikolaev, L. Yakovleva, Y. Marchenko et al., Granzyme B functionalized nanoparticles targeting membrane Hsp70-positive tumors for multimodal cancer theranostics. Small 15(13), 1-14 (2019). https://doi.org/10. 1002/smll.201900205

350. F.D. Duman, Y. Akkoc, G. Demirci, N. Bavili, Bypassing prosurvival and resistance mechanisms of autophagy in EGFRpositive lung cancer cells by targeted delivery of 5FU using theranostic $\mathrm{Ag}_{2} \mathrm{~S}$ quantum dots. J. Mater. Chem. B 7(46), 7363-7376 (2019). https://doi.org/10.1039/c9tb01602c 
351. C. Li, X. Yang, J. An, K. Cheng, X. Hou et al., Red blood cell membrane-enveloped $\mathrm{O}_{2}$ self-supplementing biomimetic nanoparticles for tumor imaging-guided enhanced sonodynamic therapy. Theranostics 10, 867-879 (2020). https://doi. org/10.7150/thno.37930

352. M.H. Chan, W.T. Huang, J. Wang, R.S. Liu, M. Hsiao, Next-generation cancer-specific hybrid theranostic nanomaterials: MAGE-A3 NIR persistent luminescence nanoparticles conjugated to afatinib for in situ suppression of lung adenocarcinoma growth and metastasis. Adv. Sci. (2020). https://doi.org/10.1002/advs.201903741

353. M. Bjo, K.J. Thurecht, M. Michael, A.M. Scott, F. Caruso, Bridging bio-nano science and cancer nanomedicine. ACS Nano 11, 9594-9613 (2017). https://doi.org/10.1021/acsna no. $7 \mathrm{~b} 0485$ 